University of Louisville

ThinkIR: The University of Louisville's Institutional Repository

Electronic Theses and Dissertations

$5-2007$

\title{
Investigation of head and neck injury risk associated with short- distance falls in 12 month old children.
}

Angela J. Knight

University of Louisville

Follow this and additional works at: https://ir.library.louisville.edu/etd

\section{Recommended Citation}

Knight, Angela J., "Investigation of head and neck injury risk associated with short-distance falls in 12 month old children." (2007). Electronic Theses and Dissertations. Paper 766.

https://doi.org/10.18297/etd/766

This Master's Thesis is brought to you for free and open access by ThinkIR: The University of Louisville's Institutional Repository. It has been accepted for inclusion in Electronic Theses and Dissertations by an authorized administrator of ThinkIR: The University of Louisville's Institutional Repository. This title appears here courtesy of the author, who has retained all other copyrights. For more information, please contact thinkir@louisville.edu. 


\title{
INVESTIGATION OF HEAD AND NECK INJURY RISK ASSOCIATED WITH SHORT-DISTANCE FALLS IN 12 MONTH OLD CHILDREN
}

\author{
By \\ Angela J. Knight \\ B.S., University of Louisville, 2005

\begin{abstract}
A Thesis
Submitted to the Faculty of the

University of Louisville
\end{abstract} \\ J. B. Speed School of Engineering \\ in Partial Fulfillment of the Requirements \\ for the Professional Degree \\ MASTER OF ENGINEERING \\ Department of Mechanical Engineering
}

May 2007 



\title{
INVESTIGATION OF HEAD AND NECK INJURY RISK ASSOCIATED WITH
} SHORT-DISTANCE FALLS IN 12 MONTH OLD CHILDREN

\author{
Submitted by:
}

Angela J. Knight

A Thesis Approved On

\section{(Date)}

By the Following Reading and Examination Committee:

\author{
Gina Bertocci, Thesis Director
}

Peter Quesada

Naira Campbell-Kyureghyan

Mary Clyde Pierce 


\section{ACKNOWLEDGEMENTS}

This research was funded by the Kosair's Children's Hospital, the Grosscurth Endowment in Biomechanics, and the CDC Center for Injury Research and Control at the University of Pittsburgh. The anthropomorphic test device used in this study was purchased with funds provided by the Children's Hospital of Pittsburgh.

I would especially like to thank my advisor, Dr. Gina Bertocci, who not only guided me through this process and taught me so much, but made this an enjoyable experience as well. With her help, I have grown both professionally and personally. I would also like to thank Dr. Mary Clyde Pierce for her insight into the clinical problem that inspired this project and for helping me see the importance of this research and its outcomes. I would like to thank Dr. Naira Campbell-Kyureghyan and Dr. Peter Quesada for serving on my thesis committee and for their guidance and input. In addition to my committee, I am thankful for my family and friends who have supported me along the way. 


\begin{abstract}
The purpose of this study was to determine the risk of severe head and neck injury in short distance falls for a 12-month-old child. A series of free falls and falls from standing were experimentally simulated using an instrumented anthropomorphic test device (ATD) representing a 12-month-old child. Three different falls heights, five different impact surfaces, and two levels of joint stiffness were tested to determine their effect on injury risk. Linear head accelerations were measured and angular head accelerations were calculated using the base of the neck as the pivot point. Head Injury Criteria (HIC) values and impact durations were also determined for each fall. Neck loads were measured and used to compute $\mathrm{N}_{\mathrm{ij}}$ values to be compared with injury thresholds.
\end{abstract}

The falls from standing generally were associated with a greater head injury risk than the free falls. In the free falls, ground-based falls were associated with a greater head injury risk than the higher fall heights tested. However, for the falls from standing, greater falls heights were associated with a greater head injury risk. Head injury risk also increased with stiffer surfaces and was greater for tightened joints than for joints adjusted to normal specifications. Neck injury risk also tended to increase with greater fall heights, stiffer surfaces, and increasing joint stiffness. However, the risk of severe head or neck injury was low for all fall scenarios evaluated using a 12-month-old ATD. The results of this study may aid clinicians in distinguishing between accidental and inflicted injuries (for which falls are a common excuse) by predicting the likelihood of a particular injury occurring in a certain type of fall. 


\section{TABLE OF CONTENTS}

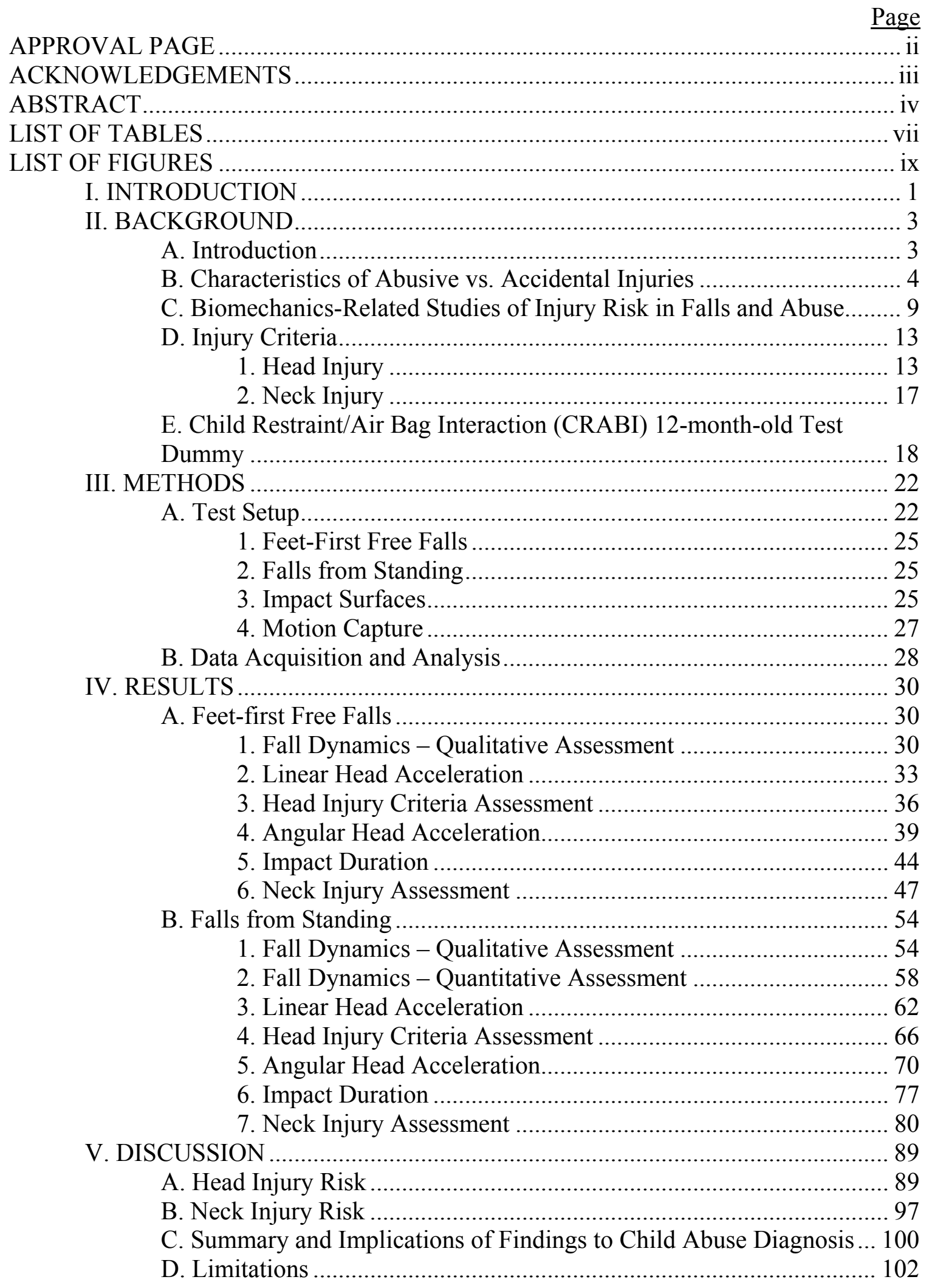


E. Recommendations for Future Work ............................................ 104

VI. CONCLUSIONS ................................................................................. 106

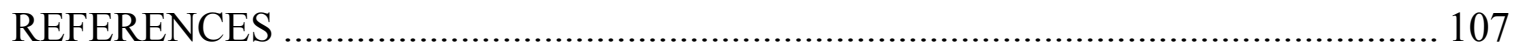

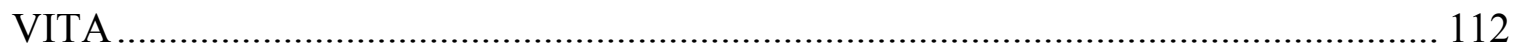




\section{LIST OF TABLES}

Table I. Suggested $\mathrm{HIC}_{15}$ limits for various dummy sizes

Table II. Proposed critical intercept values for $\mathrm{N}_{\mathrm{ij}}$ calculation

Table III. Weight specifications for the CRABI 12-month-old ATD

Table IV. External Dimensions for CRABI 12-month-old dummy

Table V. Fall scenarios evaluated

Table VI. Coefficients of friction and restitution for each impact surface

Table VII. Significant differences in peak resultant linear head accelerations for various heights in feet-first free falls

Table VIII. Significant differences in peak resultant linear head accelerations for various surfaces in feet-first free falls

Table IX. Significant differences in HIC15 values for various heights in feet-first free falls

Table X. Significant differences in HIC15 values for various surfaces in feet-first free falls

Table XI. Significant differences in angular head accelerations for various heights in feetfirst free falls

Table XII. Significant differences in angular head accelerations for various surfaces in feet-first free falls

Table XIII. Significant differences in head impact durations for various heights in feetfirst free falls

Table XIV. Significant differences in head impact durations for various surfaces in feetfirst free falls

Table XV. Significant differences in neck injury criteria for various heights in feet-first free falls

Table XVI. Significant differences in neck injury criteria for various surfaces in feet-first free falls 
Table XVII. Significant differences in peak resultant linear head accelerations for various heights in falls from standing

Table XVIII. Significant differences in peak resultant linear head accelerations for various surfaces in falls from standing

Table XIX. Significant differences in peak resultant linear head accelerations for various joint conditions in falls from standing

Table XX. Significant differences in HIC15 values for various heights in falls from standing

Table XXI. Significant differences in HIC15 values for various surfaces in falls from standing

Table XXII. Significant differences in HIC15 values for various joint conditions in falls from standing

Table XXIII. Significant differences in angular head accelerations for various heights in falls from standing

Table XXIV. Significant differences in angular head accelerations for various surfaces in falls from standing

Table XXV. Significant differences in angular head accelerations for various joint conditions in falls from standing

Table XXVI. Significant differences in head impact durations for various heights in falls from standing

Table XXVII. Significant differences in head impact durations for various surfaces in falls from standing

Table XXVIII. Significant differences in head impact durations for various joint conditions in falls from standing

Table XXIX. Significant differences in neck injury criteria for various heights in falls from standing

Table XXX. Significant differences in neck injury criteria for various surfaces in falls from standing

Table XXXI. Significant differences in neck injury criteria for various joint conditions in falls from standing

Table XXXII. Mean peak $\mathrm{N}_{\mathrm{ij}}$ values by fall height, joint stiffness, and impact surface type 


\section{LIST OF FIGURES}

Figure 1 - Probability of skull fracture versus HIC value for mid-size adult male ATD

Figure 2 - DAI Thresholds for Infant and Adult

Figure 3 - External Dimensions for CRABI 12-month-old Dummy

Figure 4 - ATD Suspended for Fall Experiments

Figure 5 - Representative 18", 27", and 47" Free Falls onto (a) Linoleum over Wood, (b) Playground Foam, (c) Carpet, (d) Wood, and (e) Linoleum over Concrete

Figure 6 - Peak Resultant Linear Head Accelerations for Free Falls with Various Impact Surfaces and Fall Heights

Figure 7 - Head Injury Criteria for Free Falls with Various Impact Surfaces and Fall Heights

Figure 8 - Peak Anterior-Posterior Angular Head Accelerations for Free Falls with Various Impact Surfaces and Fall Heights

Figure 9 - Peak Medial-Lateral Angular Head Accelerations for Free Falls with Various Impact Surfaces and Fall Heights

Figure 10 - Experimental Values of Angular Acceleration and Change in Angular Velocity in Free Falls Compared to Diffuse Axonal Injury Criteria

Figure 11 - Head Impact Durations for Free Falls with Various Impact Surfaces and Fall Heights

Figure 12 - Neck Injury Criteria for Combined Tension-Flexion Loading for Free Falls with Various Impact Surfaces and Fall Heights

Figure 13 - Neck Injury Criteria for Combined Tension-Extension Loading for Free Falls with Various Impact Surfaces and Fall Heights

Figure 14 - Neck Injury Criteria for Combined Compression-Flexion Loading for Free Falls with Various Impact Surfaces and Fall Heights

Figure 15 - Neck Injury Criteria for Combined Compression-Extension Loading Free Falls with Various Impact Surfaces and Fall Heights 
Figure 16 - Experimental Values of Neck Compression/Tension Forces and Flexion/Extension Moments in Free Falls Compared to NHTSA Neck Injury Threshold.

Figure 17 - Representative 18" Falls with Normal Joint Stiffness, 27" Falls with Normal Joint Stiffness, 18" Falls with Tight Joint Stiffness, and 27" Falls with Tight Joint Stiffness onto (a) Linoleum over Wood, (b) Playground Foam, (c) Carpet, (d) Wood, and (e) Linoleum over Concrete.

Figure 18 - Mean Hip Flexion Angle with Standard Deviation over Time for 27" Falls from Standing onto Carpet with Normal and Tightened Joints.

Figure 19 - Mean Knee Flexion Angle with Standard Deviation over Time for 27" Falls from Standing onto Carpet with Normal and Tightened Joints.

Figure 20 - Mean Torso Angle Relative to Ground with Standard Deviation over Time for 27' Falls from Standing onto Carpet with Normal and Tightened Joints.

Figure 21 - Mean Neck Flexion with Standard Deviation over Time for 27" Falls from Standing onto Carpet with Normal and Tightened Joints.

Figure 22 - Peak Resultant Linear Head Accelerations for Falls from Standing with Various Impact Surfaces, Fall Heights, and Joint Stiffness.

Figure 23 - Head Injury Criteria for Falls from Standing with Various Impact Surfaces, Fall Heights, and Joint Stiffness.

Figure 24 - Anterior-Posterior Angular Head Accelerations for Falls from Standing with Various Impact Surfaces, Fall Heights, and Joint Stiffness.

Figure 25 - Medial-Lateral Angular Head Accelerations for Falls from Standing with Various Impact Surfaces, Fall Heights, and Joint Stiffness.

Figure 26 - Experimental Values of Angular Acceleration and Change in Angular Velocity in Falls from Standing Compared to Diffuse Axonal Injury Criteria

Figure 27 - Head Impact Durations for Falls from Standing with Various Impact Surfaces, Fall Heights, and Joint Stiffness.

Figure 28 - Neck Injury Criteria for Combined Tension-Flexion Loading for Falls from Standing with Various Impact Surfaces, Fall Heights, and Joint Stiffness.

Figure 29 - Neck Injury Criteria for Combined Tension-Extension Loading for Falls from Standing with Various Impact Surfaces, Fall Heights, and Joint Stiffness.

Figure 30 - Neck Injury Criteria for Combined Compression-Flexion Loading for Falls from Standing with Various Impact Surfaces, Fall Heights, and Joint Stiffness 
Figure 31 - Neck Injury Criteria for Combined Compression-Extension Loading for Falls from Standing with Various Impact Surfaces, Fall Heights, and Joint Stiffness

Figure 32 - Experimental Values of Neck Compression/Tension Forces and Flexion/Extension Moments in Falls from Standing Compared to NHTSA Neck Injury Threshold.

Figure 33 - Representative Linear Head Accelerations for 18”, 27”, and 47" Free Falls onto Linoleum over Concrete.

Figure 34 - Representative Plot of $\mathrm{N}_{\mathrm{TF}}$ vs. Time for Falls from Standing. 


\section{INTRODUCTION}

Child abuse is the leading cause of fatalities due to trauma in children less than four years of age ("Ten Years of Reporting Child Maltreatment," 1999). In the United States alone in 2003 , there were approximately 906,000 victims of child abuse. There were also approximately 1,500 fatalities due to child abuse with $78.7 \%$ of these cases of children aged three years or less ("Child Maltreatment 2003," 2005). In children less than one year of age, serious head injury is more likely to be the result of abuse than unintentional injury (Billmire, 1985). Correct diagnosis of abuse can be very difficult, in part due to a lack of knowledge of injury biomechanics in children. Overlooked abuse often results in further escalating injuries and sometimes death. Conversely, false conclusions of abuse can lead to children being unnecessarily removed from the home.

The purpose of this project is to determine the risk of injury associated with common household pediatric falls. The outcomes from this project may aid clinicians in distinguishing between accidental and inflicted injuries (for which falls are a common excuse) by predicting the likelihood of a particular injury occurring in a certain type of fall.

In this study common household falls will be experimentally simulated using an instrumented anthropomorphic test device (ATD) representing a 12-month-old child. Two different types of falls will be examined: vertical feet-first free falls and falls from standing. For each of these falls, the risk of head injury and neck injury will be investigated. The effects of fall height and impact surface on injury risk will also be examined. In the falls from standing, the stiffness of the ATD's joints will be varied to 
determine if it has an effect on the injury risk. Falls in which the joints are stiff are typically referred to as "matchstick falls." Matchstick type falls have often been presented by defense experts in child abuse legal cases as a worst-case scenario in which severe injuries can occur.

The specific aims for this project are as follows:

1. To determine the risk of head and neck injuries associated with two types of shortdistance falls in 12 month old children.

H01 - There is a low risk of severe head and neck injuries for the two types of short distance free falls that will be tested.

2. To determine the effects of fall height, impact surface, and joint stiffness on injury risk for two types of short-distance falls in 12 month old children.

H02 - There will be an increase in head and neck injury risk for greater fall heights.

H03 - There will be an increase in head and neck injury risk for impact surfaces with increasing stiffness.

H04 - There will be an increase in head and neck injury risk with increasing joint stiffness. 


\section{BACKGROUND}

\section{$\underline{\text { A. Introduction }}$}

Child abuse is the leading cause of fatalities due to trauma in children less than four years of age ("Ten Years of Reporting Child Maltreatment," 1999). In the United States alone in 2003 , there were approximately 906,000 victims of child abuse. There were also approximately 1,500 fatalities due to child abuse with $78.7 \%$ of these cases of children aged three years or less ("Child Maltreatment 2003," 2005). Additionally, it has been estimated that as many as $50-60 \%$ of deaths related to child abuse go unrecorded ("Child Abuse and Neglect Fatalities: Statistics and Interventions," 2004).

Head trauma is the leading cause of fatalities due to child abuse (Ommaya, 2002). In children less than one year of age, serious head injury is more likely to be the result of abuse than unintentional injury (Billmire, 1985). Falls are a common excuse given by caretakers to cover up abusive trauma. Although falls are the leading cause of traumatic brain injury, in children ages 0 to 4 , approximately $32 \%$ of deaths due to traumatic brain injury are caused by assault while only 3\% are caused by falls (Langlois, 2004).

Clinicians are commonly asked to determine whether a child's injuries are consistent with the given cause of the injuries, and the diagnosis of abuse often hinges on this decision. However, there is little scientific evidence in the field of injury biomechanics to aid in this decision. Specific information regarding injury risk associated with common falls will aid clinicians in distinguishing between child abuse 
and accidental injuries. Early detection of abuse may lead to prevention of further escalating injuries and, in some cases, prevent death of the child.

\section{B. Characteristics of Abusive vs. Accidental Injuries}

Much work has been done to identify and distinguish injury characteristics associated with child abuse with those from accidental causes. Perhaps among the earliest of these studies, was that of Caffey, which defined the characteristics of "whiplash shaken infant syndrome" (also commonly called "shaken baby syndrome") to be severe head injuries, specifically subdural hematomas (SDH), and retinal hemorrhages $(\mathrm{RH})$ without any external signs of trauma (Caffey, 1974). Although "shaken baby syndrome" is not the only abusive mechanism, the characteristic injuries remain the same.

Subdural hematomas are known to result from large rotational accelerations of the head. This causes the brain to move relative to the skull, rupturing the bridging veins (Gennarelli, 1982). In a study by Geddes, SDH was found to be the most common injury among patients with abusive head injuries, present in $81 \%$ of cases (Geddes, 2001). Bechtel found a similar result with SDH in $80 \%$ of patients with abusive head trauma and only $27 \%$ of patients with accidental head trauma (Bechtel, 2004). SDHs have been reported in high-energy events such as motor vehicle accidents and falls from great heights. Duhaime found three accidental cases of SDH, all occurring in motor vehicle accidents (Duhaime, 1992). Billmire found one case of SDH among 19 to be the result of a motor vehicle accident (Billmire, 1985). Barlow reported $1 \mathrm{SDH}$ in a fall from greater 
than three stories (Barlow, 1983). Musemeche reported two SDHs in 70 falls from heights of ten feet or greater (Musemeche, 1991).

It has been estimated that between 65 and 95\% of "shaken baby" cases involve retinal hemorrhage (Duhaime, 1998). RHs are likely due to a rise in intracranial pressure secondary to traumatic brain injury (Ommaya, 2002). RHs have been recorded in accidental cases, but these are much rarer and often differ by type and location from those seen in abusive cases. In a study by Bechtel et. al., $60 \%$ of patients classified as having abusive head trauma were found to have RH versus only $10 \%$ in the accidental cases (Bechtel, 2004). Multiple and bilateral RHs were more likely to occur in abuse cases. Abusive RH also more often involved the pre-retinal layer and extended to the periphery of the retina. Another study found RHs in 10 of 100 children sustaining head injuries (Duhaime, 1992). Nine of the ten cases were classified as abusive, with the single accidental RH being the result of a high-speed motor vehicle accident. All 10 patients also had SDH. Geddes found $71 \%$ of 38 children with non-accidental head injury to have RHs (Geddes, 2001). The authors also found a significant association between the presence of RHs and SDH.

Another brain injury commonly associated with abuse is diffuse axonal injury (DAI). DAI results from shear forces on the axons of neurons in the brain and can range from mild concussion to severe comas resulting in death. A recent study suggests that severe DAI is actually a rare result of abusive trauma. In a study of 37 infants with inflicted head injuries, only two were found to have severe DAI (Geddes, 2001). Concussion on the other hand, has been reported commonly in both abusive and accidental cases. One study documents 20 cases of concussion in head-injured infants, 
with 13 due to accidental causes, and two of those were from falls out of bed (Billmire, 1985). The remainder were due to motor vehicle accidents or falls from a caretaker's arms onto a hard surface.

Skull fractures have been shown to occur in both abusive and accidental trauma. Billmire reported $78 \%$ of skull fractures occurring from accidental causes (Billmire, 1985). However, $87 \%$ of the skull fractures were linear parietal fractures. Only four infants had complex, multiple fractures. All of these had associated intracranial hemorrhage and all were due to inflicted trauma. Another study reported $91 \%$ of skull fractures occurring from accidental trauma (Bechtel, 2004). Duhaime reported that autopsies detect fractures in 25\% of "shaken" infants (Duhaime, 1998). These fractures are most commonly in the posterior parietal bone or the occipital bone. Skull fractures have been documented frequently in falls. In a study of 66 free falls in children, there were 10 skull fractures, of which eight occurred from heights greater than two stories and two occurred from heights less than one story (Smith, 1975). Lallier also found 10 cases of skull fractures among 64 children who sustained falls greater than 10 feet (Lallier, 1999). Among short-distance falls, 3 of 246 children who fell from a bed or sofa had skull fractures (Helfer, 1977). Two of the three children were 6 months of age or less. Age was not specified for the third child. Another study of bed falls reported one skull fracture in 207 falls (Lyons, 1993). Five skull fractures were reported in a study of 69 stairway falls (Chiaviello, 1994).

Cervical spine and spinal cord injuries are rarely reported in cases of child abuse. However, they are of interest because the mechanisms of the "shaken baby syndrome" would seem likely to cause whiplash injuries to the neck. One study reported that in 
order to reach acceleration levels necessary to cause the severe head injuries described in shaken baby syndrome, the thresholds for neck injury would be exceeded (Bandak, 2005). This publication was criticized however, and it was determined after repeating the calculations, that neck forces were actually far below the threshold for injury (Margulies, 2006). Few studies have reported cases of neck injuries after inflicted trauma. In a study by Hadley, five of six abuse patients who had retinal and intracranial hemorrhages were also found to have injuries at the cervicomedullary junction after autopsy (Hadley, 1989). These included subdural and epidural hematomas on the spinal cord and cervical spinal cord contusions. Ghatan reported a case an infant who sustained a vertebral atlantoaxial dislocation and rupture of the transverse ligament of the atlas (Ghatan, 2002). Another study reported cases of lower cervical spine injury in two infants as the result of abusive trauma (Rooks, 1998). One had a fracture of the C5 vertebral body and a resulting dislocation of $\mathrm{C} 4$ and spinal cord compression. The other infant had a fracturedislocation of $\mathrm{C} 5$ onto $\mathrm{C} 6$. Although neck injuries are common in motor vehicle accidents, they are rarely reported in falls. Chiaviello reported that 1 of 69 children who fell down stairs sustained a C2 fracture (Chiaviello, 1994). Other studies report spine fractures in falls from heights of 10 feet or more but do not specify whether these are cervical spine injuries (Barlow, 1983; Lallier, 1999; Musemeche, 1991).

Several studies have focused on injuries and fatalities associated with falls in children. It has been well established that fatalities rarely occur in short distance falls. In an early study of 34 free-falls in children, only two fatalities were reported (Snyder, 1969). One was a 9-year-old who fell 40 feet; the other was an 8 -month-old who fell nearly 37 feet head-first. Additionally, for feet-first falls from heights less than 25 feet, 
no injuries were reported. In two additional studies, all children who fell three stories or less survived (Barlow, 1983; Musemeche, 1991). A few studies have reported deaths resulting from short-distance falls, but the validity of these results have been debated. Hall found 18 fatalities in falls from less than or equal to 3 feet, all due to severe head injuries (Hall, 1989). It has been argued that many of these deaths were actually due to abuse (Joffe, 1990). Chadwick found 7 fatalities from falls less than or equal to 4 feet, but only 1 fatality in 183 falls from 5 - 45 feet (Chadwick, 1991). However, the authors concluded that the 7 fatal falls from less than 4 feet likely had false histories. Plunkett reported 18 fatal cases of head injuries due to falls from $2-10$ feet from playground equipment (Plunkett, 2001). Spivack wrote in a letter to the editor concerning Plunkett's report, that this would yield a rate of 1.3 deaths per 100,000 such falls (Spivack, 2001). A few studies have focused on injuries from short distance falls. Two studies of bed falls found no life-threatening injuries in a combined 512 cases (Helfer, 1977; Lyons, 1993). There were 4 fractured clavicles, 4 skull fractures, and 1 humerus fracture, but all were of a non-serious nature.

These studies provide a base of knowledge for the types of injuries that would be expected in falls or in cases of child abuse. However, they are limited by the fact that they rely on an assumption of whether the injuries are abusive or accidental. Incorrect assumptions can result in false conclusions, and cases of child abuse are commonly mistaken for accidental trauma. One study found $31 \%$ of cases of abusive head trauma were missed by a physician (Jenny, 1999). In some cases it took as many as 9 visits to the physician to recognize the abuse. Among the missed cases in this study, $28 \%$ suffered further injuries and $41 \%$ suffered medical complications as a result of the missed 
diagnosis. Some studies have tried to correct for this error by using an algorithm that takes into account injury type, associated injuries, and the given history, but even this relies on the assumption that certain injuries are indicative of abuse (Duhaime, 1992). Another study of injuries resulting from free falls included only falls that were witnessed by someone other than the caretaker (Williams, 1991). A biomechanics approach, rather than case-based approach, eliminates the assumption of whether injuries are the result of accident or abuse by starting with the event and determining the resulting injuries.

\section{Biomechanics-Related Studies of Injury Risk in Falls and Abuse}

Anthropomorphic dummies have been utilized in studies to determine injury risk in falls as well as abusive events such as the shaken baby syndrome. Duhaime first used anthropomorphic surrogates of a 1-month-old infant in simulations of shakes and shakes with impact (Duhaime, 1987). In this study, dolls were modified to match the head and body weight of a 1-month-old. The models were tested with and without an added "skull" for variable deformability of the head. Three different neck models were also tested (one hinge neck and two hollow rubber necks of different thickness and stiffness) to determine the effect of varying neck stiffness on the resulting parameters. Accelerations of the head were measured by a single accelerometer at the top of the head. The surrogates were vigorously shaken and then the back of the head was impacted against either a metal bar or a padded surface. The authors found that the accelerations associated with impact were much greater than those for shaking alone, and that the 
acceleration levels for shaking alone did not exceed injury thresholds for concussion, subdural hematoma, or diffuse axonal injury. However, those accelerations resulting from impact exceeded thresholds for all three injury types. In shaking, the more flexible neck was associated with significantly greater accelerations and significantly shorter durations, but the neck condition had no effect in impact situations. The presence of the added skull was found to have no significant effect. Impacts against a padded surface had significantly smaller accelerations and significantly longer durations than impact onto a metal bar.

A more recent study built upon that by Duhaime by using a more biofidelic infant surrogate (Prange, 2003). Prange simulated shaking and shaking with impact as in the previous study, as well as several short distance falls using a 1.5-month-old surrogate. A hinged neck was used to represent a worst-case scenario, and the "skull" and "scalp" materials were chosen to accurately represent infant skull properties. An angular rate sensor attached to the top of the head measured angular velocities. Angular accelerations were then calculated by taking the derivative of the velocity. Falls were simulated for three different fall heights (1, 3, and 5 feet) and three different surfaces ( 4 inch thick foam, 0.25 inch thick carpet pad, and a concrete floor). The same surfaces were also used in simulations of inflicted impacts, except a stone bench was used instead of the concrete floor. The dummy was initially in a horizontal position for fall experiments with the head slightly lower than the body to ensure that the head would contact first. Overall, falls from greater heights and falls onto harder surfaces resulted in greater angular accelerations. For the shaking and impact scenarios, it was found that inflicted impacts against the carpet pad and stone surfaces resulted in significantly greater accelerations 
and lower time durations than those from impacts against foam or from shaking. The authors concluded that shakes produced responses similar to those from minor falls, but inflicted impacts produced responses that were significantly higher, and therefore were more likely to be associated with brain injuries.

There have been several studies by Bertocci to investigate injury risk associated with short-distance falls using anthropomorphic test dummies. In one study, Bertocci simulated bed falls using a Hybrid II 3-year-old test dummy (Bertocci, 2003). Feet-first free falls were simulated in another study using the same Hybrid II test dummy (Bertocci, 2004). In both studies, linear head acceleration, pelvis acceleration, and femur loads (including compression, bending, and torsional loads) were measured. Head Injury Criteria (HIC) were calculated as a measure of head injury risk. Four different impact surfaces were test (linoleum, wood, padded carpet, and playground foam), and for the free falls, three different heights were tested $(27,47$, and 64 inched measured from the ground to center of mass of the dummy). Only one fall height (27 inches) was tested in the bed fall simulations. In free fall experiments, it was found that fall height had no significant effect on either head acceleration or HIC, although it did have some effect on femur loading. Impact surface type was found to have a significant effect on head acceleration and $\mathrm{HIC}$ in both studies with playground foam producing the lowest values. Despite these effects, there was a low risk of contact-type head injury for all surfaces and heights tested.

Several studies have examined the effects of varying fall conditions on injury risk. In addition to fall height and impact surface which have been tested in the previously mentioned studies, Deemer also investigated the effects of falls onto wet versus dry 
surfaces (Deemer, 2005). Using a 3-year-old Hybrid III test dummy, short-distance feetfirst free falls onto wet and dry linoleum surfaces were simulated. It was found that head acceleration and HIC were significantly greater on the dry surface; however femur compressive and bending loads were significantly greater on the wet surface. Bertocci also investigated the effects of stair characteristics on injury risk in simulated stair falls (Bertocci, 2001). A computer simulation of a 3-year-old child falling down the stairs was developed and the effects of varying stair properties (number of steps, slope of stairs, surface friction, and surface elasticity) on injury risk of the upper leg was determined. It was found that the potential of upper leg injury increases with an increasing number of steps, decreasing surface friction, decreasing surface elasticity, and increasing slope. Cory and Jones developed a simulation system to test the head injury potential of different surface mixtures (Cory, 2006). Several top surface layers, including carpets and linoleums of various thicknesses and types, were tested over three underlying surfaces (wood, concrete, and chipboard). The authors found that while the top surface type and thickness has some effect, the underlying surface primarily dictates the risk of head injury. It was also found that locations on the floor directly over joists produced the greatest head injury risk. 


\section{Injury Criteria}

\section{Head Injury}

The most widely accepted measure of head injury risk in impacts is the Head Injury Criterion (HIC). HIC was developed for use in the automotive industry to assess risk in motor vehicle crash testing. The HIC have also been used to assess head injury risk in falls, particularly in the playground safety area to determine critical fall heights for playground equipment. It has been stated that the HIC is "considered to be the best model available to predict the likelihood of injuries from falls" (Cory, 2001). The HIC evolved primarily from two previous head injury thresholds: the Wayne State Tolerance Curve (WSTC) and the Gadd severity index (GSI) (Eppinger, 1999). The WSTC was the

first head injury threshold to consider both the magnitude of the head acceleration and the duration of the impact. It was based on a combination of animal, cadaver, and human volunteer testing (Cory, 2001). The WSTC has several limitations, one being that it considers only the average linear head acceleration. The GSI improved on the WSTC, taking into account the entire acceleration pulse by integration. An exponential weighting factor of 2.5 was applied so that portions of the pulse with the greatest acceleration magnitudes would contribute more to the overall injury risk calculation than those portions with low magnitudes (Cory, 2001). The value 2.5 was used based on the slope of the WSTC. The HIC addressed limitations in the GSI by considering a fixed time interval that would include only the most injurious portions of the acceleration pulse. 
The HIC is based on the time-history of the linear head acceleration and is defined

as

$$
H I C=\left(t_{2}-t_{1}\right)\left[\frac{1}{\left(t_{2}-t_{1}\right)} \int_{t_{1}}^{t_{2}} a(t) d t\right]_{\max }^{2.5}
$$

where $a(t)$ is the resultant linear head acceleration measured in g's, and $t_{1}$ and $t_{2}$, the start and finish times of the acceleration spike. HIC values are calculated over 15 millisecond durations $\left(\mathrm{HIC}_{15}\right)$ to compare with proposed thresholds. Tolerance limits have been established by the National Highway Traffic Safety Administration (NHTSA) for ages and sizes corresponding to specific anthropomorphic test dummies (ATDs), including a large adult male, mid-size adult male, small adult female, 6-year-old child, 3-year-old child, and a 1-year-old child (Table I). These limits represent a 31\% probability of skull fracture (Eppinger, 1999). A relationship has been established to determine the probability of skull fracture for any HIC value. A probability curve demonstrating this relationship for the mid-size adult male dummy is shown in Figure 1.

TABLE I

SUGGESTED HIC 15 LIMITS FOR VARIOUS DUMMY SIZES

\begin{tabular}{|c|c|c|c|c|c|}
\hline $\begin{array}{c}\text { Large } \\
\text { Male }\end{array}$ & $\begin{array}{c}\text { Mid-size } \\
\text { Male }\end{array}$ & $\begin{array}{c}\text { Small } \\
\text { Female }\end{array}$ & $\begin{array}{c}\text { 6-year- } \\
\text { old }\end{array}$ & $\begin{array}{c}\text { 3-year- } \\
\text { old }\end{array}$ & $\begin{array}{c}1 \text {-year- } \\
\text { old }\end{array}$ \\
\hline \hline 700 & 700 & 700 & 700 & 570 & 390 \\
\hline
\end{tabular}




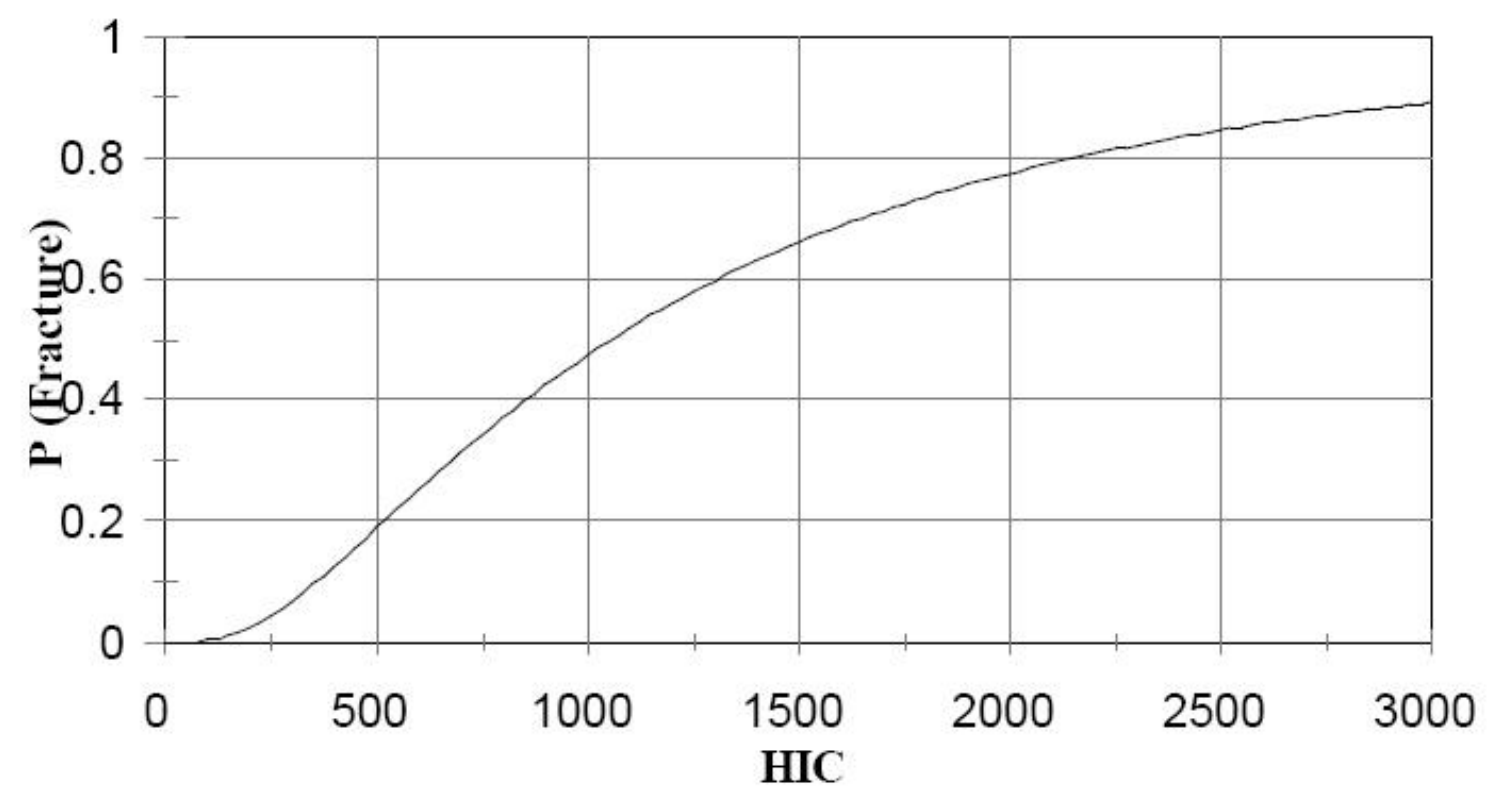

FIGURE 1 - Probability of skull fracture versus HIC value for mid-size adult male ATD (Eppinger, 1999).

Another method of assessing head injury risk has been to simply consider the maximum linear head acceleration recorded during an impact, sometimes called the "peak g" method. However, there is a wide range of tolerance limits suggested by the literature. Sturtz reported a critical load value of $83 \mathrm{~g}$ for impact durations greater than or equal to $3 \mathrm{~ms}$ based on reconstructions of pedestrian accidents (Sturtz, 1980). Above this load irreversible injuries are possible. By using computer simulations to reconstruct free falls resulting in serious head injuries, Mohan proposed conservative tolerance limits of $200-250 \mathrm{~g}$ peak accelerations for children (Mohan, 1979). Others have reported tolerance limits for children ranging from $50-200 \mathrm{~g}$ where $50 \mathrm{~g}$ is the maximum beforeinjury threshold and $200 \mathrm{~g}$ is the threshold for fatal injury (Cory, 2001).

Neither of the previously discussed methods account for head injury due to rotational loads, which often account for severe brain injuries. Subdural hematoma $(\mathrm{SDH})$ and diffuse axonal injury (DAI) both result from exposure to rotational 
acclerations. Sturtz proposed an angular acceleration limit of $2000 \mathrm{rad} / \mathrm{s}^{2}$ for impacts lasting $10 \mathrm{~ms}$ or longer (Sturtz, 1980). Most other studies have related rotational accelerations to particular injury types. Reported rotational accelerations necessary to cause concussion are 4,500 rad/s $\mathrm{s}^{2}$ for an adult and $10,000 \mathrm{rad} / \mathrm{s}^{2}$ for an infant (Ommaya, 2002). Similarly, accelerations necessary to cause severe (DAI) have been reported as approximately $18,000 \mathrm{rad} / \mathrm{s}^{2}$ for an adult and $40,000 \mathrm{rad} / \mathrm{s}^{2}$ for an infant (Ommaya, 2002). Magulies and Thibault established tolerance curves for DAI based on peak rotational acceleration and peak change in rotational velocities (Figure 2) (Margulies, 1992). These curves were derived from a combination of animal experiments, physical models, and analytical model simulations. Duhaime et al. used a tolerance limit of approximately $35,000 \mathrm{rad} / \mathrm{s}^{2}$ for SDH in an infant with a 500 gram brain mass (Duhaime, 1987). It has been reported that accelerations necessary to cause acute SDH and deep intracerebral hemorrhage are much greater than those necessary to produce mild DAI (Ommaya, 2002).

The injury potential is often dependent on the duration of the acceleration pulse. In general, the shorter the acceleration duration, the greater the acceleration necessary to cause injury. This is due to the viscoelastic nature of biological tissues. Also, for a given head acceleration, different types of brain injuries will occur for different durations. Three injury zones have been described for a constant acceleration (Gennarelli, 1996). For very short durations (high strain rates), the brain experiences very little strain, so extremely high accelerations are necessary to cause injury. As the duration increases, strains occur on the surface of the brain and cause damage primarily to vascular tissue resulting in SDH, for example. Lastly, as the duration increases further, the strains 
penetrate deeper into the brain causing damage to the brain tissue. This produces injuries such as concussion and DAI.

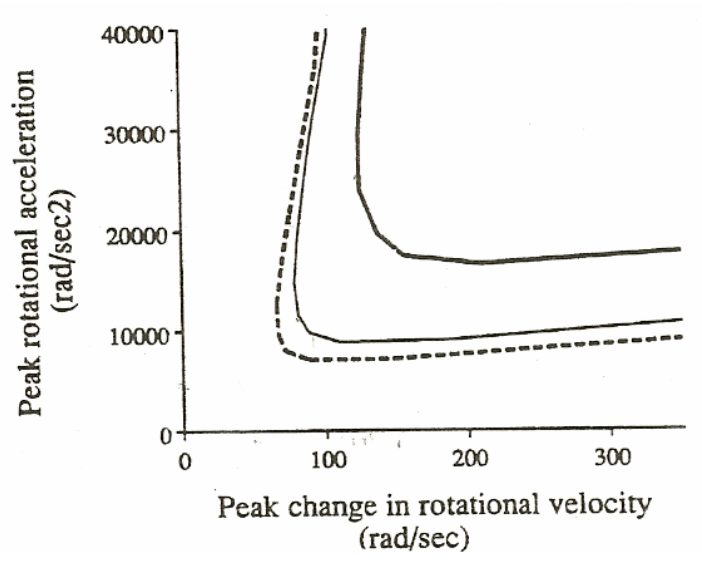

FIGURE 2 - DAI Thresholds for Infant (500 g brain mass, heavy solid line) and Adult (1067 g brain mass, solid line; $1400 \mathrm{~g}$ brain mass, dashed line) (Margulies, 1992)

\section{Neck Injury}

NHTSA has also established Neck Injury Criteria, or $\mathrm{N}_{\mathrm{ij}}$ values, to assess the risk of neck injuries (Eppinger, 1999). These are based on combined axial and rotational loading in the sagittal plane and can be calculated as follows:

$$
N_{i j}=\frac{F_{z}}{F_{\text {int }}}+\frac{M_{y}}{M_{\text {int }}}
$$

where the subscripts $i j$ represent the four combined loading mechanisms: tensionextension (TE), tension-flexion (TF), compression-extension (CE), and compression- 
flexion (CF). $F_{z}$ and $M_{y}$ are the axial force and flexion/extension moment, respectively, and $F_{\text {int }}$ and $M_{\text {int }}$ are the critical load values. The critical load values are specific for age of the test dummy and are used to normalize the $N_{i j}$ values. Critical load values are presented in Table II (Eppinger, 1999). $\mathrm{N}_{\mathrm{ij}}=1$ represents a 22\% probability of an Abbreviated Injury Scale (AIS) 3 injury. Neck injuries may include "vertebral fractures, contusions, lacerations, and transections of the cord, as well as brain stem injuries and basilar skull fractures that occur as a result of loading to the neck (Eppinger, 1999).

Even though the injury tolerance of children is much different from that of adults, due to differences in size, structural, and material properties, much of the injury tolerance information available for the pediatric population has been scaled from adult data. This is due to a lack of cadaver and volunteer testing in children. Scaling often takes into account both geometric and material differences, but the information available is limited in its accuracy.

TABLE II

PROPOSED CRITICAL INTERCEPT VALUES FOR N $\mathrm{IIJ}_{\mathrm{J}}$ CALCULATION

\begin{tabular}{|c|c|c|c|c|}
\hline Dummy & Tension (N) & $\begin{array}{c}\text { Compression } \\
(\mathrm{N})\end{array}$ & Flexion (Nm) & Extension (Nm) \\
\hline \hline 12-month-old & 1465 & 1465 & 43 & 17 \\
\hline 3-year-old & 2120 & 2120 & 68 & 27 \\
\hline 6-year-old & 2800 & 2800 & 93 & 39 \\
\hline Small female & 3370 & 3370 & 155 & 62 \\
\hline Mid-sized male & 4500 & 4500 & 310 & 125 \\
\hline Large male & 5440 & 5440 & 415 & 166 \\
\hline
\end{tabular}

E. Child Restraint/Air Bag Interaction (CRABI) 12-month-old Test Dummy 
The CRABI 12-month-old anthropomorphic test device (ATD) represents a $50^{\text {th }}$ percentile 12-month-old child in terms of overall height and weight, as well as weights and inertial properties for body segments. Table III lists weight specifications for the CRABI. Table IV and Figure 3 describe the external dimensions of the CRABI ("CRABI Twelve and Eighteen Month Infant Dummies User's Manual," 1999).

Biofidelic impact response requirements for the head and neck have been established for the CRABI 12-month-old (Irwin, 1997). These were created by scaling the response requirements of the Hybrid III mid-size adult male ATD based on differences in size, mass, and material properties of bone. The original requirements for the Hybrid III adult ATD were derived from human volunteer and cadaver tests. The head impact response is based on drop tests in which the forehead impacts a flat rigid surface and peak resultant head accelerations are measured. The neck impact response is measured by mounting the ATD head and neck to the end of a pendulum. The pendulum is released and impacted with a block of aluminum honeycomb material. Requirements for neck flexion and extension exist as a function of head to torso angle and the moment about the occipital condyles.

TABLE III

WEIGHT SPECIFICATIONS FOR THE CRABI 12-MONTH-OLD ATD 


\begin{tabular}{|c|c|c|}
\hline \multirow{2}{*}{ Segment Assembly } & \multicolumn{2}{|c|}{ Specified Weight } \\
\cline { 2 - 3 } & Metric $(\mathrm{kg})$ & English (lbs) \\
\hline \hline Head Assembly & $2.64 \pm 0.05$ & $5.81 \pm 0.11$ \\
\hline Neck Assembly & $0.38 \pm 0.03$ & $0.84 \pm 0.07$ \\
\hline Torso Assembly & $3.68 \pm 0.10$ & $8.10 \pm 0.22$ \\
\hline Arm Assembly & $0.60 \pm 0.03$ & $1.32 \pm 0.07$ \\
\hline Leg Assembly & $1.05 \pm 0.03$ & $2.31 \pm 0.07$ \\
\hline Total Weight & $10.00 \pm 0.30$ & $22.00 \pm 0.66$ \\
\hline
\end{tabular}

TABLE IV

EXTERNAL DIMENSIONS FOR CRABI 12-MONTH-OLD DUMMY

\begin{tabular}{|c|c|c|c|}
\hline Dimension & Description & Metric (mm) & English (in) \\
\hline $\mathrm{A}$ & Total sitting height & $469.9 \pm 7.6$ & $18.25 \pm 0.30$ \\
\hline B & Shoulder pivot height & $284.2 \pm 7.6$ & $11.19 \pm 0.30$ \\
\hline $\mathrm{C}$ & Hip pivot height & $33.0 \pm 5.1$ & $1.30 \pm 0.20$ \\
\hline $\mathrm{D}$ & Hip pivot from back line & $45.2 \pm 5.1$ & $1.78 \pm 0.20$ \\
\hline E & Shoulder pivot from back line & $55.4 \pm 5.1$ & $2.18 \pm 0.20$ \\
\hline $\mathrm{F}$ & Thigh Clearance & $68.1 \pm 5.1$ & $2.68 \pm 0.20$ \\
\hline $\mathrm{G}$ & Elbow pivot to fingertip & $184.2 \pm 7.6$ & $7.25 \pm 0.30$ \\
\hline $\mathrm{I}$ & Shoulder pivot to elbow pivot & $106.7 \pm 7.6$ & $4.20 \pm 0.30$ \\
\hline $\mathrm{J}$ & Elbow rest height & $157.7 \pm 7.6$ & $6.21 \pm 0.30$ \\
\hline $\mathrm{K}$ & Buttock to knee length & $210.3 \pm 7.6$ & $8.28 \pm 0.30$ \\
\hline $\mathrm{L}$ & Popliteal height (reference to seat) & $146.3 \pm 7.6$ & $5.76 \pm 0.30$ \\
\hline $\mathrm{M}$ & Knee pivot height & $172.7 \pm 7.6$ & $6.80 \pm 0.30$ \\
\hline $\mathrm{N}$ & Buttock popliteal length & $152.4 \pm 7.6$ & $6.00 \pm 0.30$ \\
\hline $\mathrm{O}$ & Chest depth with jacket & $115.1 \pm 7.6$ & $4.53 \pm 0.30$ \\
\hline $\mathrm{P}$ & Foot length & $97.5 \pm 5.1$ & $3.84 \pm 0.20$ \\
\hline $\mathrm{Q}$ & Stature & $740.4 \pm 12.7$ & $29.15 \pm 0.50$ \\
\hline $\mathrm{R}$ & Buttock to knee pivot length & $183.6 \pm 5.1$ & $7.23 \pm 0.20$ \\
\hline $\mathrm{S}$ & Head breadth & $129.5 \pm 7.6$ & $5.10 \pm 0.30$ \\
\hline $\mathrm{T}$ & Head depth & $157.5 \pm 7.6$ & $6.20 \pm 0.30$ \\
\hline $\mathrm{U}$ & Hip breadth & $166.1 \pm 7.6$ & $6.54 \pm 0.30$ \\
\hline $\mathrm{V}$ & Shoulder breadth & $208.3 \pm 7.6$ & $8.20 \pm 0.30$ \\
\hline $\mathrm{W}$ & Foot breadth & $44.2 \pm 5.1$ & $1.74 \pm 0.20$ \\
\hline $\mathrm{Y}$ & Chest circumference with jacket & $465.1 \pm 12.7$ & $18.31 \pm 0.50$ \\
\hline $\mathrm{Z}$ & Waist circumference & $459.7 \pm 12.7$ & $18.10 \pm 0.50$ \\
\hline AA & $\begin{array}{l}\text { Reference location for chest circumference } \\
\text { and chest depth with jacket }\end{array}$ & $261.6 \pm 5.1$ & $10.30 \pm 0.20$ \\
\hline $\mathrm{BB}$ & Reference location for waist circumference & $111.8 \pm 5.1$ & $4.40 \pm 0.20$ \\
\hline $\mathrm{CC}$ & $\begin{array}{l}\text { Shoulder height } \\
\end{array}$ & $307.3 \pm 7.6$ & $12.10 \pm 0.30$ \\
\hline DD & Chin height & $297.2 \pm 7.6$ & $11.70 \pm 0.30$ \\
\hline
\end{tabular}




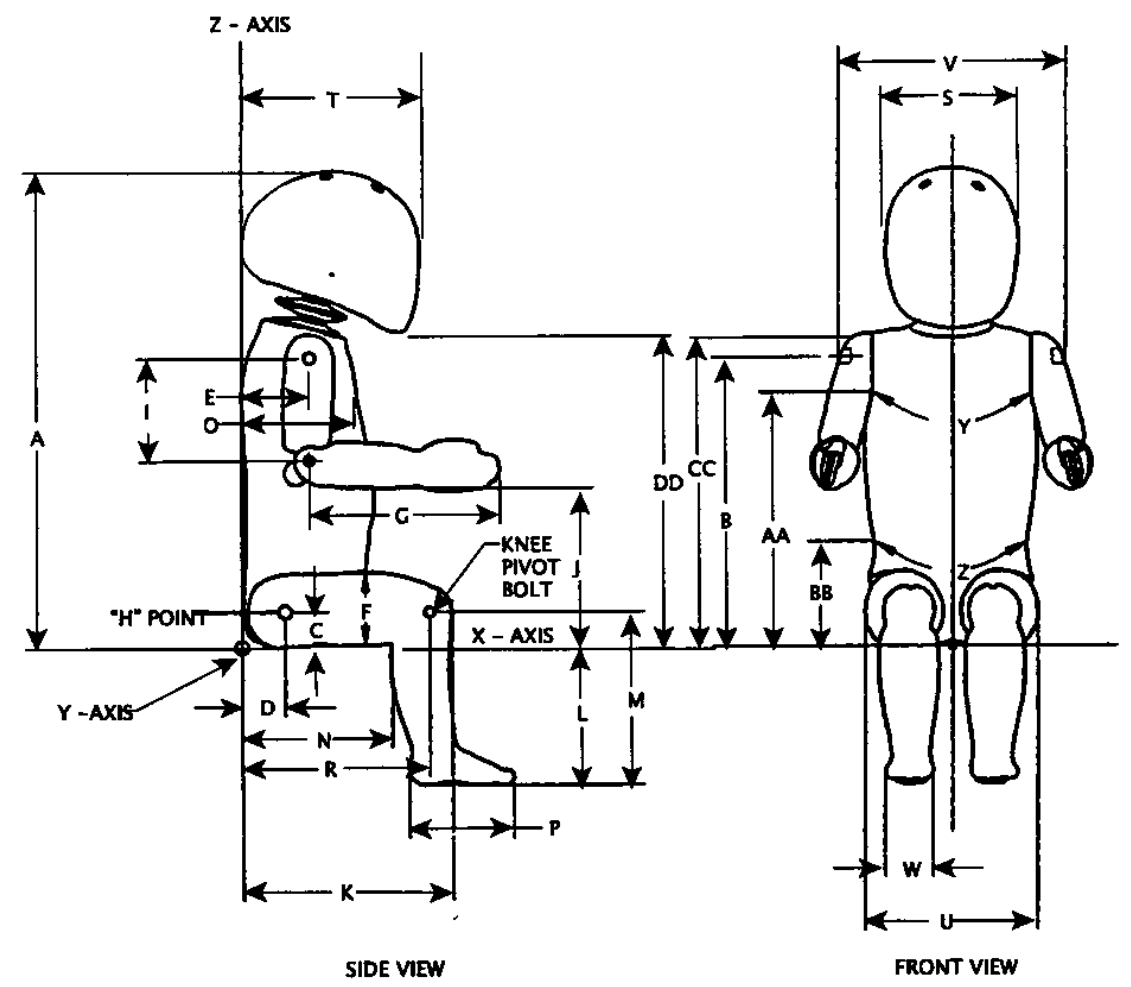

FIGURE 3 - External Dimensions for CRABI 12-month-old Dummy 


\section{METHODS}

The purpose of this study was to investigate head and neck injury risk associated with short distance falls in children. The effects of fall environment factors (including fall height, impact surface type, and joint stiffness) on head and neck injury risk were also examined. To accomplish this, a 12-month-old anthropomorphic test device (ATD) was instrumented and dropped to simulate falls. Two fall types were studied: feet-first free falls and falls from standing.

\section{$\underline{\text { A. Test Setup }}$}

A Child Restraint Air Bag Interaction (CRABI) 12-month-old ATD (First Technology Safety Systems, Plymouth, Michigan) was suspended in a vertical initial posture from various predetermined heights and dropped to simulate a free fall. The ATD was suspended from a rope secured to the neck and then dropped from a releasing mechanism with an external trigger to ensure repeatability of the fall (Figure 4). Table V describes fall scenarios that were tested. 


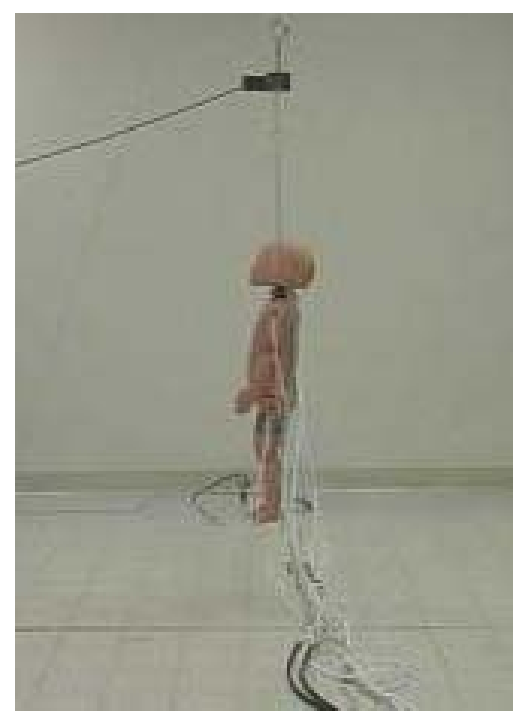

FIGURE 4 - ATD Suspended for Fall Experiments

The ATD represents a $50^{\text {th }}$ percentile 12-month-old child in terms of overall height and mass, as well as geometric and inertial properties of individual body segments. The ATD was instrumented with tri-axial accelerometers at the center of mass of the head. There are also two load cells located at the top and base of the neck (approximately at the $\mathrm{C} 1$ and $\mathrm{C} 7$ vertebrae, respectively) to measure neck loads.

Prior to each fall, ATD joint angles were adjusted using a goniometer to ensure repeated positioning for all testing. Joints were calibrated to manufacturer specifications whereby the joint was tightened until the friction was just sufficient to support the weight of the limb. For the falls from standing, additional tests were performed with the joints tightened so that no joint movement could occur during testing. This allowed for investigation of the effect of joint stiffness on injury risk. 
TABLE V

FALL SCENARIOS EVALUATED

\begin{tabular}{|c|c|c|c|}
\hline Fall Type & Height (in) & Surface Type & $\begin{array}{c}\text { ATD Joint } \\
\text { Stiffness }\end{array}$ \\
\hline \multirow{15}{*}{$\begin{array}{c}\text { Feet - First } \\
\text { Free Falls }\end{array}$} & 18 & Linoleum over wood & \multirow{15}{*}{ Normal } \\
\hline & 18 & Playground foam & \\
\hline & 18 & Padded Carpet & \\
\hline & 18 & Wood & \\
\hline & 18 & Linoleum over Concrete & \\
\hline & 27 & Linoleum over wood & \\
\hline & 27 & Playground foam & \\
\hline & 27 & Padded Carpet & \\
\hline & 27 & Wood & \\
\hline & 27 & Linoleum over Concrete & \\
\hline & 47 & Linoleum over wood & \\
\hline & 47 & Playground foam & \\
\hline & 47 & Padded Carpet & \\
\hline & 47 & Wood & \\
\hline & 47 & Linoleum over Concrete & \\
\hline \multirow{20}{*}{$\begin{array}{c}\text { Falls from } \\
\text { Standing }\end{array}$} & 18 & Linoleum over wood & \multirow{10}{*}{ Normal } \\
\hline & 18 & Playground foam & \\
\hline & 18 & Padded Carpet & \\
\hline & 18 & Wood & \\
\hline & 18 & Linoleum over Concrete & \\
\hline & 27 & Linoleum over wood & \\
\hline & 27 & Playground foam & \\
\hline & 27 & Padded Carpet & \\
\hline & 27 & Wood & \\
\hline & 27 & Linoleum over Concrete & \\
\hline & 18 & Linoleum over wood & \multirow{10}{*}{ Tight } \\
\hline & 18 & Playground foam & \\
\hline & 18 & Padded Carpet & \\
\hline & 18 & Wood & \\
\hline & 18 & Linoleum over Concrete & \\
\hline & 27 & Linoleum over wood & \\
\hline & 27 & Playground foam & \\
\hline & 27 & Padded Carpet & \\
\hline & 27 & Wood & \\
\hline & 27 & Linoleum over Concrete & \\
\hline
\end{tabular}




\section{Feet-First Free Falls}

For the feet-first free fall experiments, the ATD was initially suspended above the floor. The ATD was dropped from three different fall heights. These were 18” (45.7 $\mathrm{cm}), 27 "(68.6 \mathrm{~cm})$, and $47 "(119.4 \mathrm{~cm})$ measured from the ground to the center of mass of the ATD. The center of mass of the ATD is located 18 " vertically above the plantar surface of the feet. Therefore, the ATD's feet were 0, 9" $(22.9 \mathrm{~cm})$ and 29 " $(73.7 \mathrm{~cm})$ off the ground, in the 18", 27 ", and 47 " falls respectively.

\section{$\underline{\text { 2. Falls from Standing }}$}

For the falls from standing experiments, the ATD was suspended so that it was initially standing on the floor or a platform. The ATD was dropped from two different fall heights. These were $18 "(45.7 \mathrm{~cm})$ and $27 "(68.6 \mathrm{~cm})$ measured from the ground to the center of mass of the ATD. Falls were simulated with two joint conditions; normal and tight.

\section{Impact Surfaces}

Five different impact surfaces were tested: linoleum over wood, playground foam, padded carpet, wood, and a linoleum-tiled concrete floor. All surfaces except the linoleum-tiled concrete floor were placed over a 6 x $6 \mathrm{ft}(183 \times 183 \mathrm{~cm})$ wooden platform. The platform, built to standard building codes, consisted of $3 / 4$ inch plywood 
covering $2 \times 4$ inch $(5.1 \times 10.2 \mathrm{~cm})$ joists spaced 16 inches $(40.6 \mathrm{~cm})$ from the center of one joist to the center of the next. The linoleum over wood was no-wax self-adhesive vinyl flooring ( 0.039 inches or $1 \mathrm{~mm}$ thick) adhered to the platform. The linoleum tile over the concrete floor (different from the linoleum used over the wood floor) was $1 / 8$ inch $(0.3175 \mathrm{~cm})$ thick. The playground foam surface consisted of $2 \times 2 \mathrm{ft}(61.0 \times 61.0$ $\mathrm{cm})$ tiles, 2 inches $(5.1 \mathrm{~cm})$ thick. The carpet was open loop and $1 / 2$ inch $(1.3 \mathrm{~cm})$ thick with $3 / 8$ inch $(1.0 \mathrm{~cm})$ thick foam padding underneath and was secured to the platform. A layer of $3 / 4$ inch $(1.9 \mathrm{~cm})$ thick plywood served as the wood surface.

To further describe each impact surface, the coefficients of friction and coefficients of restitution were measured. The static coefficients of friction were determined by pulling a weighted object, with the same "skin" material as the ATD, across the surfaces and recording the force to initiate movement of the object. The coefficient of friction was then calculated as the ratio of the pulling force over the weight of the object. The coefficients of restitution were measured using a resiliency tester (IDM Instruments, model number F0020). A steel ball was dropped from a known height onto each surface and the height the ball returned to on its first bounce was recorded. The coefficients of restitution were then calculated as the square root of the ratio of the bounce height to the drop height. The resulting coefficients are shown in Table VI. 
TABLE VI

COEFFICIENTS OF FRICTION AND RESTITUTION FOR EACH IMPACT

SURFACE

\begin{tabular}{|c|c|c|}
\hline Impact Surface & $\begin{array}{c}\text { Static Coefficient } \\
\text { of Friction }\end{array}$ & $\begin{array}{c}\text { Coefficient of } \\
\text { Restitution }\end{array}$ \\
\hline Padded carpet & 1.10 & 0.58 \\
\hline Playground foam & 0.88 & 0.47 \\
\hline Linoleum over wood* & 0.87 & 0.40 \\
\hline Linoleum over concrete* & 0.78 & 0.41 \\
\hline Wood & 0.70 & 0.45 \\
\hline
\end{tabular}

*Linoleum used over wood is a different product from linoleum used over concrete. Linoleum over wood has a rougher, more pitted surface.

\section{Motion Capture}

All falls were videotaped to capture overall fall dynamics. The camera was positioned so that the line of sight was perpendicular to the ATD sagittal plane. The video was captured at a $30 \mathrm{~Hz}$ frame rate. Select falls were also analyzed using MaxTRAQ video analysis software (Innovision Systems, Inc., Columbiaville, MI) to quantitatively assess the fall dynamics. High contrast markers were placed at five locations (ankle, knee, hip, shoulder, and head) to determine knee, hip, torso and neck angles over time for each fall. Since the falls were approximately two-dimensional, these angles were only determined in the sagittal plane. 


\section{B. Data Acquisition and Analysis}

A LabView program was created for data acquisition. Accelerometer and load cell data were sampled at 10,000 Hz and filtered according to SAE J211 standards ("Instrumentation for Impact Test Part 1 - Electronic Instrumentation," 2003). The filter was a $4^{\text {th }}$ order low-pass Butterworth filter. Head acceleration and neck force data were filtered at 1,000 Hz and neck moments will be filtered at $600 \mathrm{~Hz}$. Ten drops were performed for each test scenario based upon a prior power analysis.

Linear head acceleration was evaluated by examining both the maximum resultant acceleration and by calculating Head Injury Criteria (HIC) as defined in Equation (1). HIC values were calculated over 15 millisecond durations $\left(\mathrm{HIC}_{15}\right)$ that maximize $\mathrm{HIC}$ value and were compared to proposed injury criteria (Eppinger, 1999).

Angular head accelerations were determined in both the anterior-posterior and medial-lateral directions. These are computed about the base of the neck (approximately the C6-C7 location) using the following equation

$$
\alpha=\frac{a(t)}{d}
$$

where $a(t)$ is the linear head acceleration (in $\left./ \mathrm{s}^{2}\right)$ measured in either the $\mathrm{x}$-direction for anterior-posterior accelerations or the y-direction for medial-lateral accelerations, and $d$ is the distance from the accelerometers to the base of the neck ( 4.44 inches or $11.3 \mathrm{~cm}$ for the CRABI 12-month-old ATD). Peak angular accelerations, peak change in angular 
velocities, and impact durations were reported for each fall. Angular accelerations and peak change in angular velocity were compared to published injury thresholds.

Neck forces and moments were measured to calculate Neck Injury Criteria, or $\mathrm{N}_{\mathrm{ij}}$ values, for combined axial loading and moments as established by the National Highway Traffic Safety Administration (NHTSA) (Eppinger, 1999). $\mathrm{N}_{\mathrm{ij}}$ were calculated as defined in Equation (2).

Each of the outcome variables was analyzed separately using one-way analysis of variance (ANOVA) tests to determine if surface type, fall height, or joint stiffness led to significant differences in the outcome measures. Post-hoc Tukey tests were also conducted to further examine where significant differences occurred. Statistical significance was set at $p \leq 0.05$. SPSS v.12.0.1 was used to perform all statistical analysis. 


\section{RESULTS}

\section{$\underline{\text { A. Feet-first Free Falls }}$}

\section{Fall Dynamics - Qualitative Assessment}

a. Effect of Height. In the 18 " falls, after release, the ATD fell to a crouching position with hips and knees flexed, and then fell rearward, rotating about the feet, first contacting the surface with the pelvis and then the posterior aspect of the head (Figure 5). The ATD kinematics upon impact were similar for the 18 " and 27 " falls. In the 47 " falls, the ATD contacted the surface feet-first, followed by hip and knee flexion, then rebounded upward and rearward off the ground, leading to head and torso impact with the ground almost simultaneously. Another difference in dynamics across fall heights was that in the lower falls the ATD most often fell directly rearward. With increasing fall height, the dynamics became less predictable, with the ATD falling to its side as well as on its back.

b. Effect of Surface. The only observable difference due to impact surface was that for the two higher falls (27" and 47') onto linoleum over wood, carpet, and playground foam, the ATD's feet tended to "stick" to the surface upon impact, while in falls onto wood and linoleum-tiled concrete, the ATD's feet tended to slide forward after initial impact with the ground surface. 


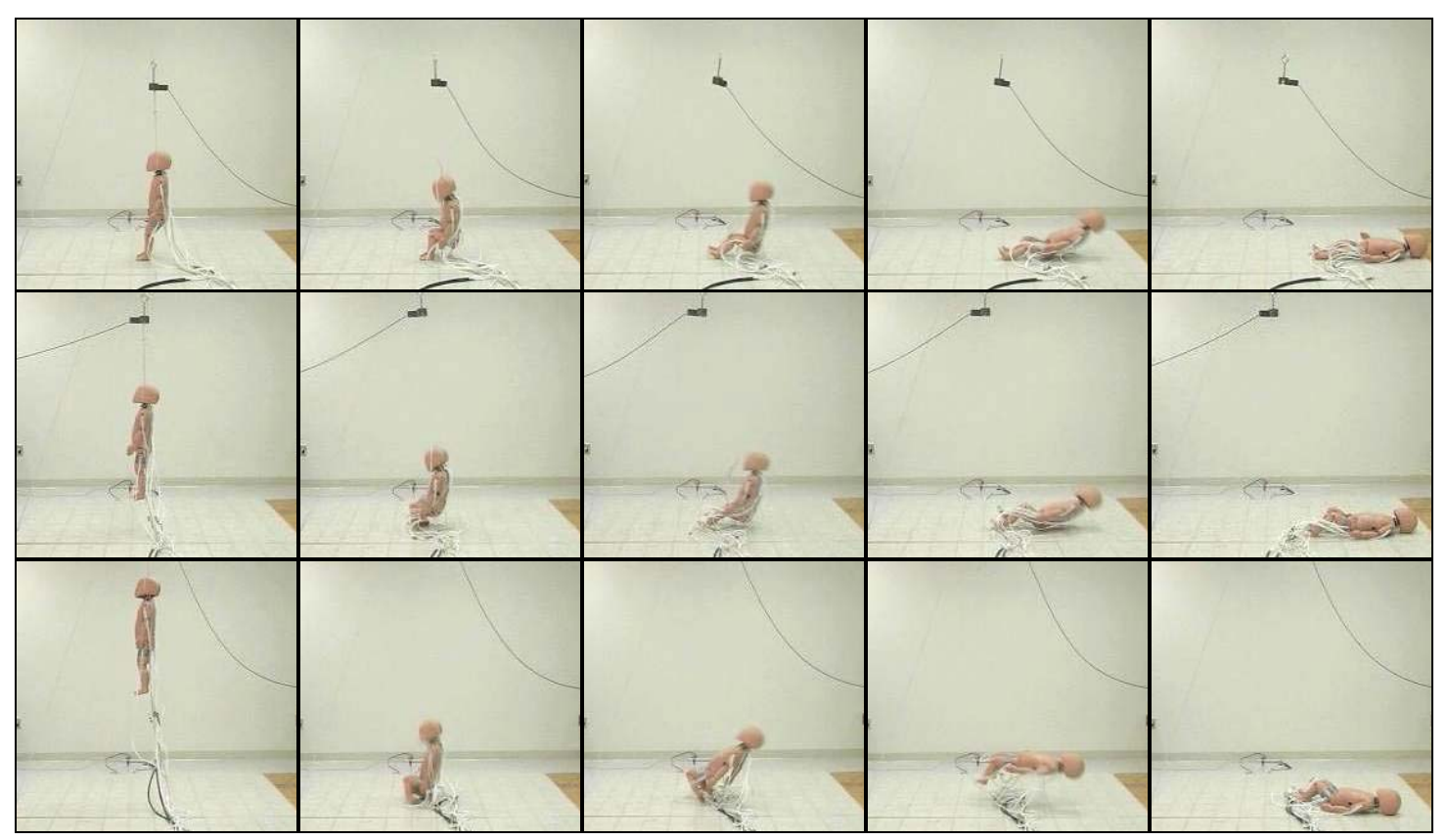

(a)

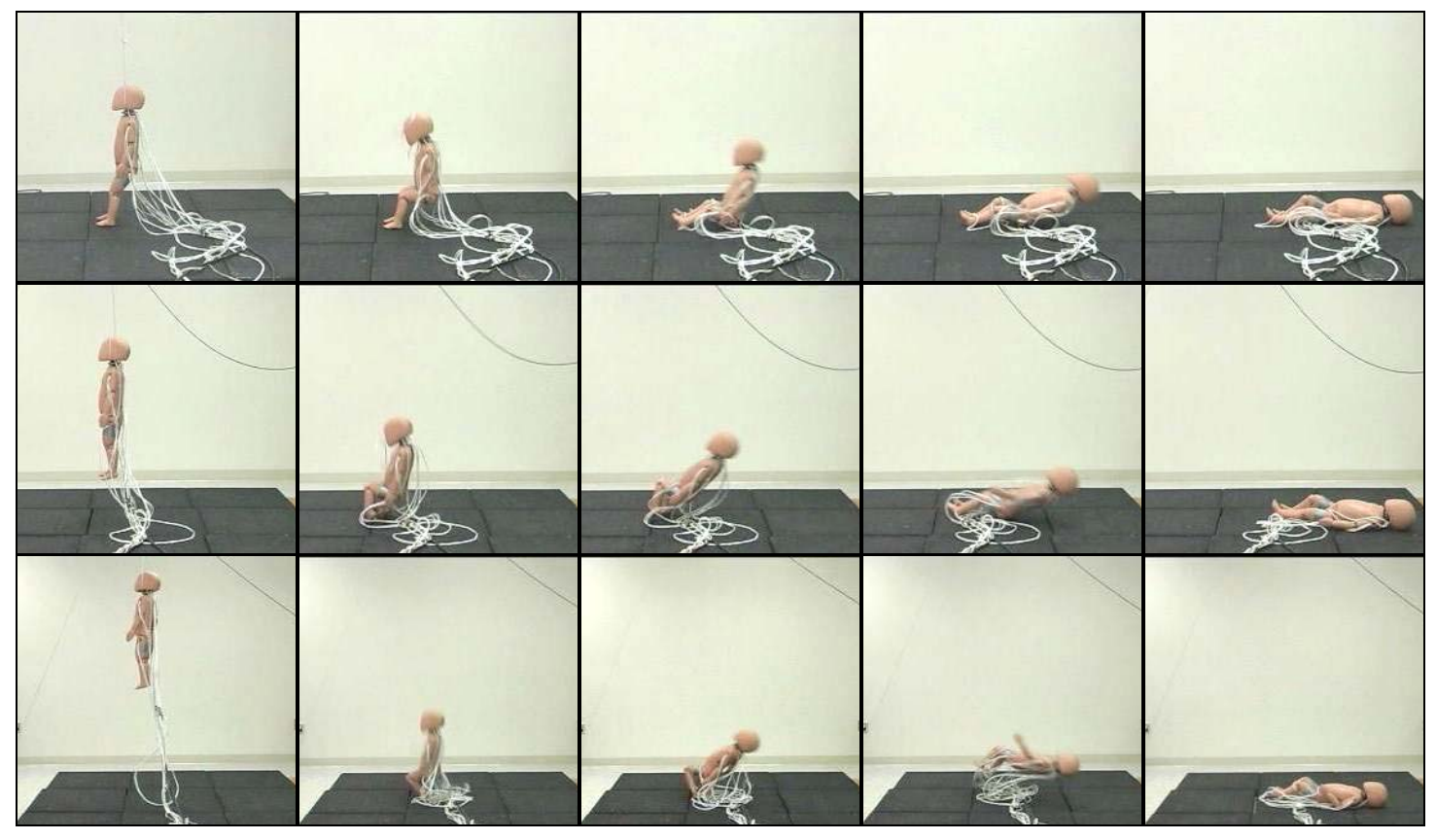

(b) 


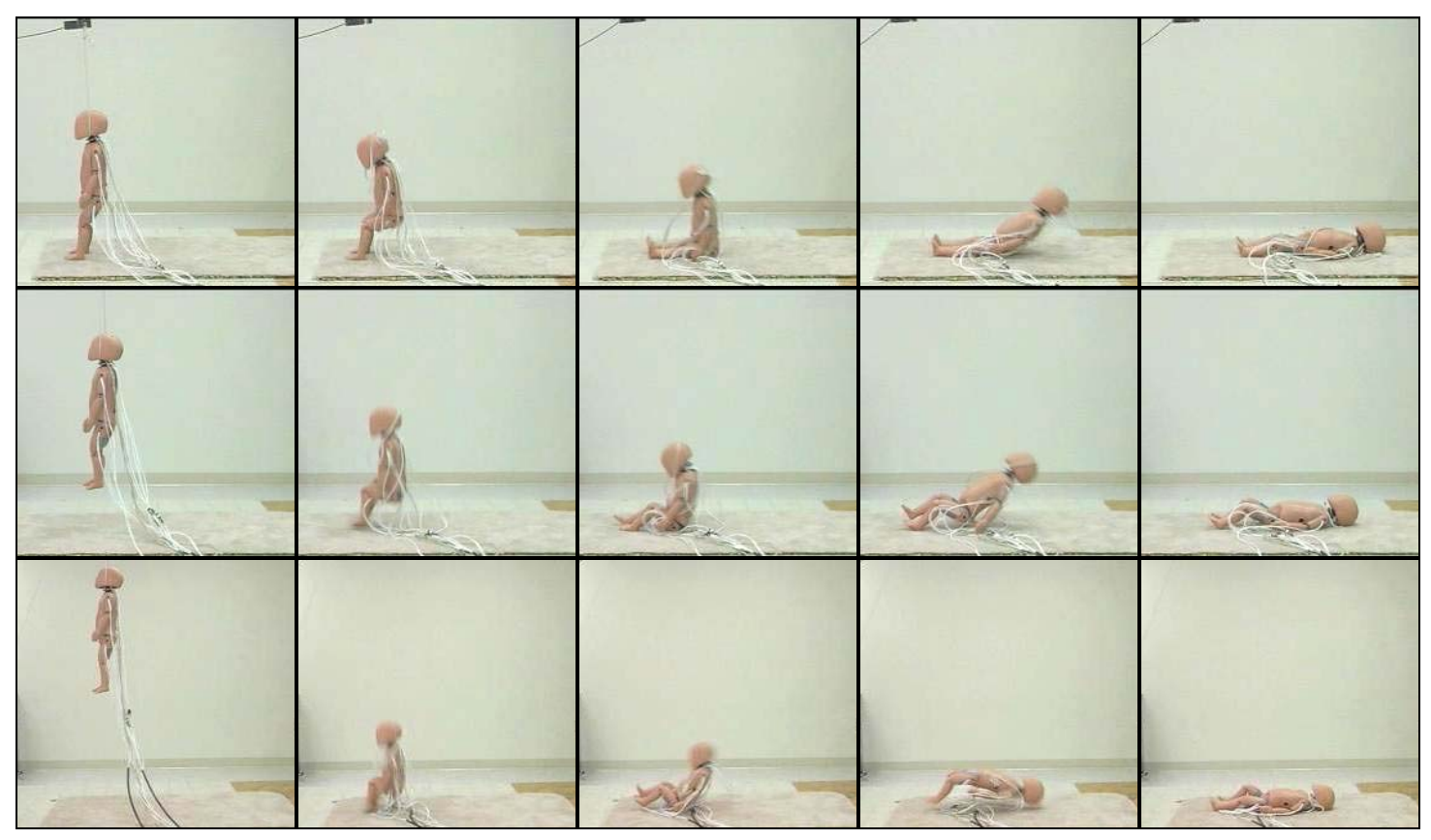

(c)

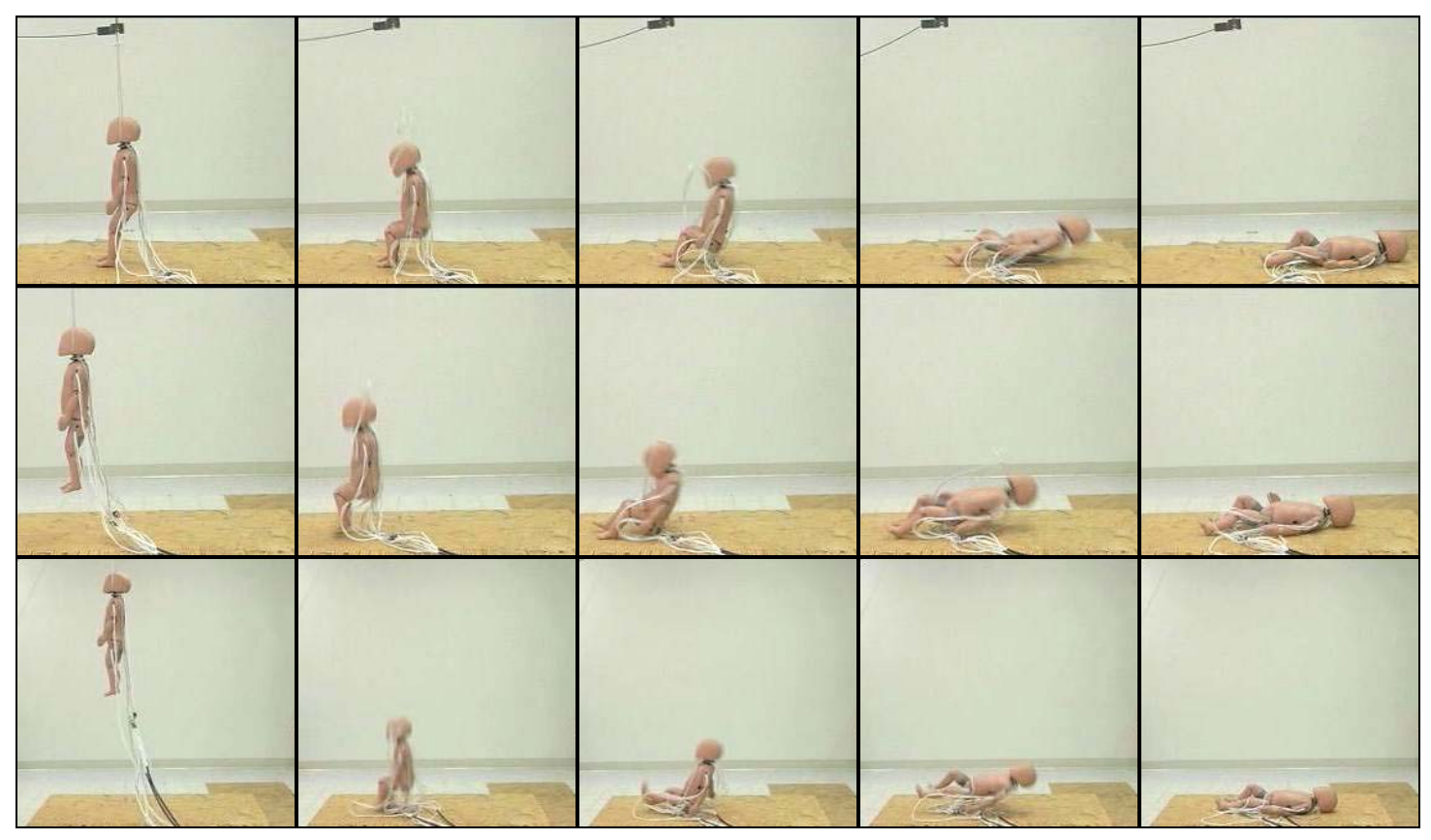

(d) 


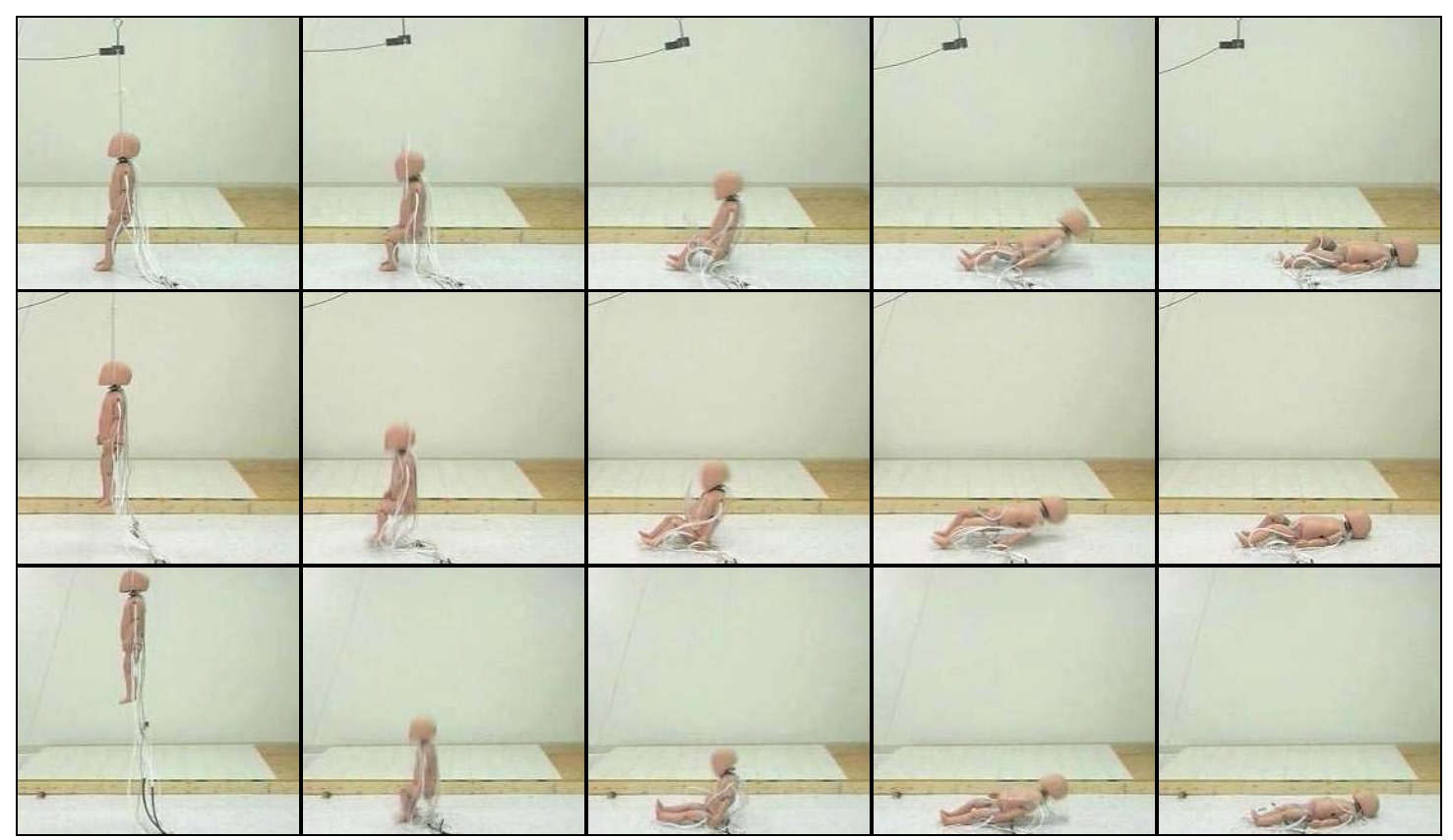

(e)

FIGURE 5 - Representative 18", 27', and 47" (distance from ground to ATD center of mass) Free Falls onto (a) Linoleum over Wood, (b) Playground Foam, (c) Carpet, (d) Wood, and (e) Linoleum over Concrete

\section{Linear Head Acceleration}

The mean peak resultant linear head acceleration across all trials was $52.9 \mathrm{~g}(95 \%$

CI: 49.7-56.1) (Figure 6). The 18" falls onto concrete produced the largest values with a maximum value of $130.6 \mathrm{~g}$.

a. Effect of Height. There were no significant differences in peak resultant linear head acceleration (Figure 6) due to fall height for the linoleum over wood, playground foam, and carpet impact surfaces $(\mathrm{p}>0.05)$. However, for both the wood and linoleum over concrete impact surfaces, the 18 " fall height was associated with significantly greater linear head accelerations than either the $27^{\prime \prime}(p<0.001$ for wood and $p=0.024$ 
for concrete) or the 47 " fall height ( $\mathrm{p}=0.002$ for wood and $\mathrm{p}<0.001$ for concrete) (Table VII).

b. Effect of Surface. There were significant differences in peak resultant linear head acceleration for different impact surfaces across all fall heights tested. For the 18 " falls, wood and linoleum over concrete surfaces were associated with significantly greater accelerations than the linoleum over wood $(\mathrm{p}=0.004)$, playground foam $(\mathrm{p}<0.001)$, and carpet $(\mathrm{p}<0.001)$ surfaces. For the 27 " falls, the linoleum over concrete surface was associated with significantly greater accelerations than the playground foam $(\mathrm{p}<0.001)$, carpet $(p=0.001)$, and wood $(p=0.007)$ surfaces. For the 47 " falls, the linoleum over wood, wood, and linoleum over concrete surfaces were associated with significantly greater linear head accelerations than the playground foam $(p=0.004$ for linoleum over wood and $p=0.023$ for wood and linoleum over concrete $)$ and carpet $(p=0.005$ for linoleum over wood, $\mathrm{p}=0.026$ for wood, and $\mathrm{p}=0.025$ for linoleum over concrete) surfaces (Table VIII). 


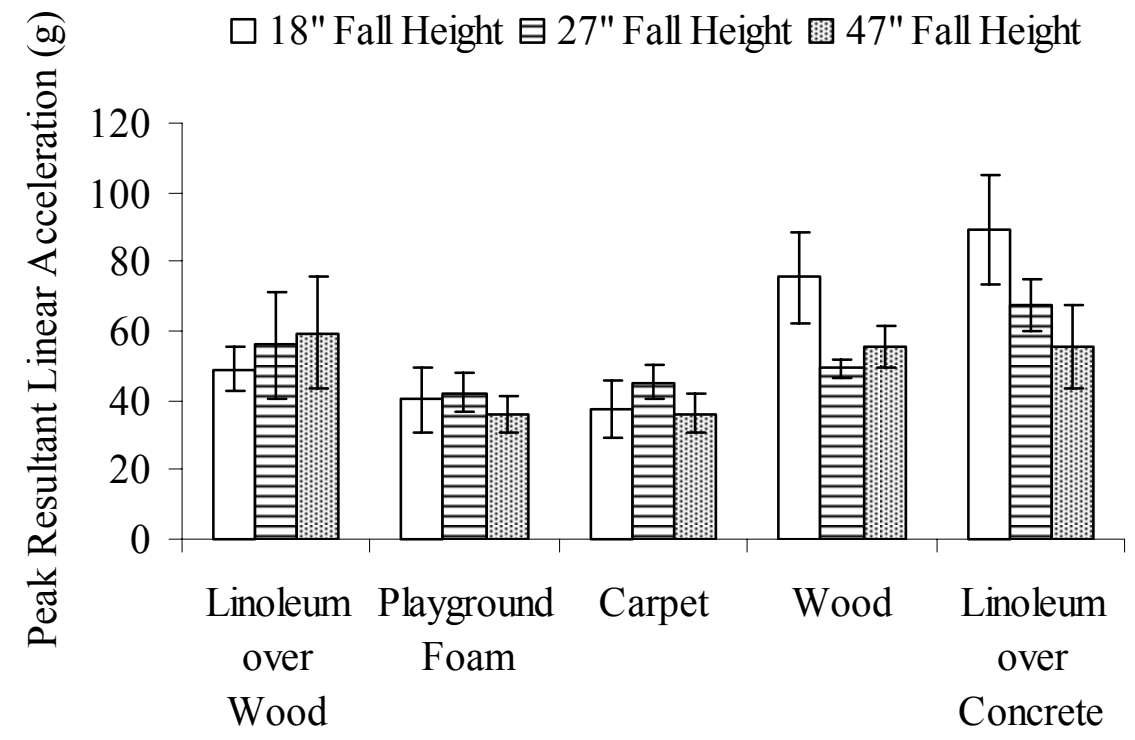

FIGURE 6 - Peak Resultant Linear Head Accelerations for Free Falls with Various Impact Surfaces and Fall Heights (measured from ground to ATD center of mass). Error bars represent $95 \% \mathrm{CI}$

TABLE VII

SIGNIFICANT DIFFERENCES IN PEAK RESULTANT LINEAR HEAD

ACCELERATIONS FOR VARIOUS HEIGHTS IN FEET-FIRST FREE FALLS

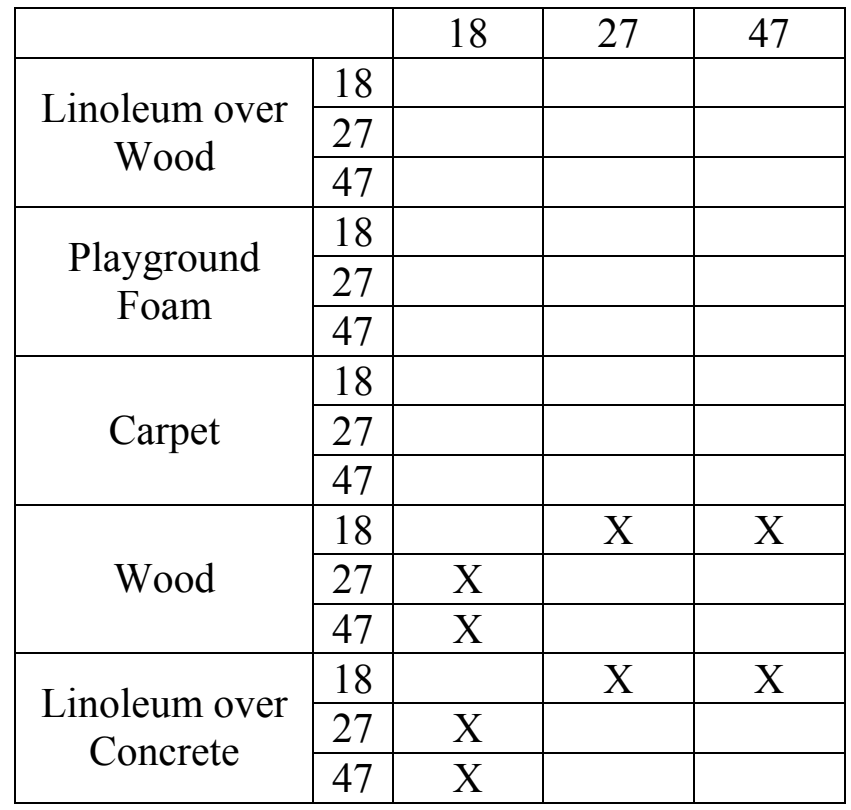

" $\mathrm{X}$ " indicates significant difference $(\mathrm{p}<0.05)$ 
TABLE VIII

SIGNIFICANT DIFFERENCES IN PEAK RESULTANT LINEAR HEAD

ACCELERATIONS FOR VARIOUS SURFACES IN FEET-FIRST FREE FALLS

\begin{tabular}{|c|c|c|c|c|c|c|}
\hline & $\begin{array}{c}\text { Linoleum } \\
\text { over } \\
\text { Wood }\end{array}$ & $\begin{array}{l}\text { Playground } \\
\text { Foam }\end{array}$ & Carpet & Wood & $\begin{array}{l}\text { Linoleum } \\
\text { over } \\
\text { Concrete }\end{array}$ \\
\hline \multirow{5}{*}{18} & Linoleum over Wood & & & & $\mathrm{X}$ & $\mathrm{X}$ \\
\hline & Playground Foam & & & & $\mathrm{X}$ & $\mathrm{X}$ \\
\hline & Carpet & & & & $\mathrm{X}$ & $\mathrm{X}$ \\
\hline & Wood & $\mathrm{X}$ & $\mathrm{X}$ & $\mathrm{X}$ & & \\
\hline & Linoleum over Concrete & $\mathrm{X}$ & $\mathrm{X}$ & $\mathrm{X}$ & & \\
\hline \multirow{5}{*}{27} & Linoleum over Wood & & & & & \\
\hline & Playground Foam & & & & & $\mathrm{X}$ \\
\hline & Carpet & & & & & $\mathrm{X}$ \\
\hline & Wood & & & & & $\mathrm{X}$ \\
\hline & Linoleum over Concrete & & $\mathrm{X}$ & $\mathrm{X}$ & $\mathrm{X}$ & \\
\hline \multirow{5}{*}{47} & Linoleum over Wood & & $\mathrm{X}$ & $\mathrm{X}$ & & \\
\hline & Playground Foam & $\mathrm{X}$ & & & $\mathrm{X}$ & $\mathrm{X}$ \\
\hline & Carpet & $\mathrm{X}$ & & & $\mathrm{X}$ & $\mathrm{X}$ \\
\hline & Wood & & $\mathrm{X}$ & $\mathrm{X}$ & & \\
\hline & Linoleum over Concrete & & $\mathrm{X}$ & $\mathrm{X}$ & & \\
\hline
\end{tabular}

"X" indicates significant difference $(\mathrm{p}<0.05)$

\section{Head Injury Criteria Assessment}

The mean $\mathrm{HIC}_{15}$ value across all trials was 68 (95\% CI: 63-73) (Figure 7). The maximum $\mathrm{HIC}_{15}$ was 173 and occurred during an 18" fall onto linoleum over concrete. This value is well below the injury threshold of 390 for the 12-month-old ATD established by the National Highway Traffic Safety Administration (NHTSA) (Eppinger, 1999). 
a. Effect of Height. As with the linear head acceleration, there were no significant differences in $\mathrm{HIC}_{15}$ values due to fall height for the linoleum over wood, playground foam, and carpet surfaces. For both the wood and linoleum over concrete surfaces, the 18 " fall height was associated with significantly greater $\mathrm{HIC}_{15}$ values than either the 27 " or 47" fall heights $(\mathrm{p}<0.001)$ (Table IX).

b. Effect of Surface. For the 18" fall height, the wood and linoleum over concrete surfaces were associated with significantly greater $\mathrm{HIC}_{15}$ values than the linoleum over wood ( $\mathrm{p}=0.007$ for wood and $\mathrm{p}<0.001$ for linoleum over concrete), playground foam ( $\mathrm{p}$ $=0.001$ for wood and $\mathrm{p}<0.001$ for linoleum over concrete), and carpet $(\mathrm{p}<0.001)$ surfaces. For the 27 " fall height, the linoleum over concrete surface was associated with significantly greater $\mathrm{HIC}_{15}$ values than the carpet surface $(\mathrm{p}=0.014)$. For the 47 ” fall experiments, there were no significant differences in $\mathrm{HIC}_{15}$ values across the various surfaces (Table X).

$\square$ 18" Fall Height $⿴$ 只 27" Fall Height 圈 47" Fall Height

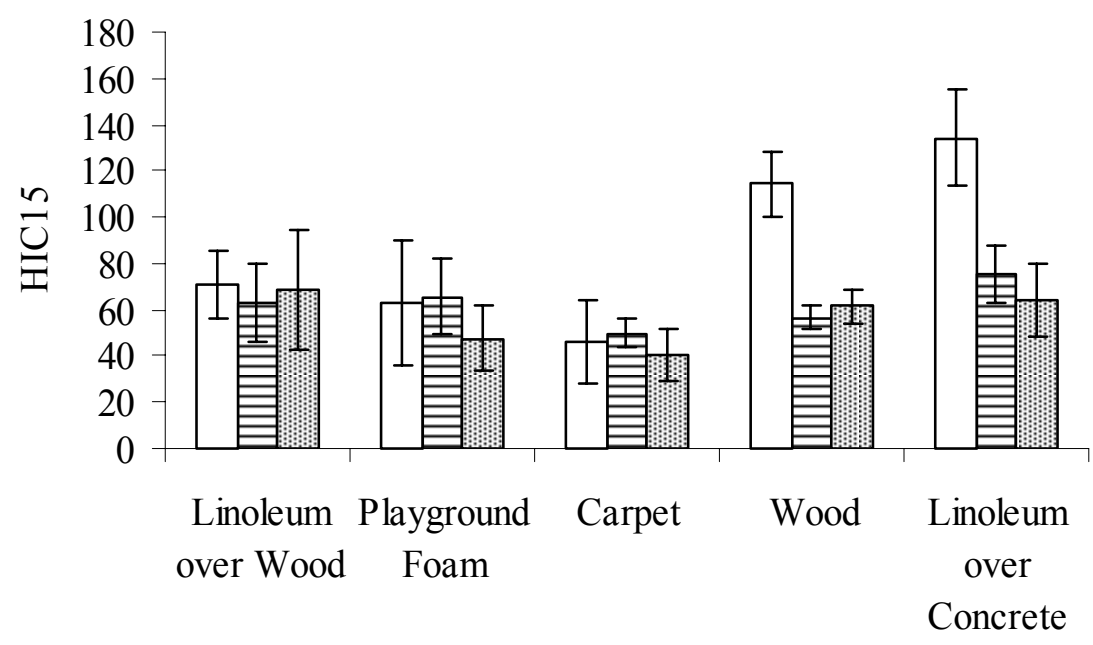

FIGURE 7 - Head Injury Criteria for Free Falls with Various Impact Surfaces and Fall Heights (measured from ground to ATD center of mass). Error bars represent 95\% CI 
TABLE IX

SIGNIFICANT DIFFERENCES IN HIC15 VALUES FOR VARIOUS HEIGHTS IN FEET-FIRST FREE FALLS

\begin{tabular}{|c|c|c|c|c|}
\hline & & 18 & 27 & 47 \\
\hline \multirow{3}{*}{$\begin{array}{l}\text { Linoleum over } \\
\text { Wood }\end{array}$} & 18 & & & \\
\hline & 27 & & & \\
\hline & 47 & & & \\
\hline \multirow{3}{*}{$\begin{array}{l}\text { Playground } \\
\text { Foam }\end{array}$} & 18 & & & \\
\hline & 27 & & & \\
\hline & 47 & & & \\
\hline \multirow{3}{*}{ Carpet } & 18 & & & \\
\hline & 27 & & & \\
\hline & 47 & & & \\
\hline \multirow{3}{*}{ Wood } & 18 & & X & X \\
\hline & 27 & $X$ & & \\
\hline & 47 & $\mathrm{X}$ & & \\
\hline \multirow{3}{*}{$\begin{array}{l}\text { Linoleum over } \\
\text { Concrete }\end{array}$} & 18 & & $\mathrm{X}$ & $X$ \\
\hline & 27 & $X$ & & \\
\hline & 47 & $\mathrm{X}$ & & \\
\hline
\end{tabular}

"X" indicates significant difference $(\mathrm{p}<0.05)$ 
TABLE X

SIGNIFICANT DIFFERENCES IN HIC15 VALUES FOR VARIOUS SURFACES IN

FEET-FIRST FREE FALLS

\begin{tabular}{|c|c|c|c|c|c|c|}
\hline & $\begin{array}{c}\text { Linoleum } \\
\text { over } \\
\text { Wood }\end{array}$ & $\begin{array}{l}\text { Playground } \\
\text { Foam }\end{array}$ & Carpet & Wood & $\begin{array}{c}\text { Linoleum } \\
\text { over } \\
\text { Concrete }\end{array}$ \\
\hline \multirow{5}{*}{18} & Linoleum over Wood & & & & $\mathrm{X}$ & $\mathrm{X}$ \\
\hline & Playground Foam & & & & $\mathrm{X}$ & $\mathrm{X}$ \\
\hline & Carpet & & & & $\mathrm{X}$ & $\mathrm{X}$ \\
\hline & Wood & $\mathrm{X}$ & $\mathrm{X}$ & $\mathrm{X}$ & & \\
\hline & Linoleum over Concrete & $\mathrm{X}$ & $\mathrm{X}$ & $\mathrm{X}$ & & \\
\hline \multirow{5}{*}{27} & Linoleum over Wood & & & & & \\
\hline & Playground Foam & & & & & \\
\hline & Carpet & & & & & $\mathrm{X}$ \\
\hline & Wood & & & & & \\
\hline & Linoleum over Concrete & & & $\mathrm{X}$ & & \\
\hline \multirow{5}{*}{47} & Linoleum over Wood & & & & & \\
\hline & Playground Foam & & & & & \\
\hline & Carpet & & & & & \\
\hline & Wood & & & & & \\
\hline & Linoleum over Concrete & & & & & \\
\hline
\end{tabular}

" $\mathrm{X}$ " indicates significant difference $(\mathrm{p}<0.05)$

\section{Angular Head Acceleration}

Angular head accelerations were measured in both the anterior-posterior (AP) and medial-lateral (ML) directions. The mean peak angular accelerations across all trials were $3986 \mathrm{rad} / \mathrm{sec}^{2}$ (95\% CI: 3717-4256) and $1946 \mathrm{rad} / \mathrm{sec}^{2}$ (95\% CI: 1688-2203) for the AP and ML directions, respectively (Figures 8 and 9). For all trials, the peak angular head accelerations (ML direction only) along with the corresponding peak changes in 
angular velocity were well below thresholds for diffuse axonal injury (Figure 10) (Margulies, 1992).

a. Effect of Height. No significant differences in angular head acceleration between fall heights occurred for the playground foam and carpet surfaces. For the linoleum over wood surface, the 18 " fall height was associated with significantly greater $\mathrm{AP}$ and ML angular accelerations than the 47 " fall height $(\mathrm{p}=0.025$ for AP and $\mathrm{p}=$ 0.001 for ML). The 27 " fall height for this surface was also associated with significantly greater AP angular accelerations than the $47^{\prime \prime}$ fall height $(\mathrm{p}=0.025)$. For the wood surface, the 18 " fall height was associated with significantly greater AP angular accelerations than both the 27" $(\mathrm{p}<0.001)$ and $47^{\prime \prime}(\mathrm{p}=0.005)$ fall heights. For the linoleum over concrete surface, the 18 " fall height was associated with significantly greater AP angular accelerations than the $27^{\prime \prime}(\mathrm{p}=0.047)$ and $47{ }^{\prime \prime}(\mathrm{p}<0.001)$ heights, and greater ML angular accelerations than the 47 " height $(\mathrm{p}=0.029)$. Also for this surface, the 27 " fall height was associated with significantly greater AP angular accelerations than the 47 " fall height $(\mathrm{p}=0.007)$ (Table XI).

b. Effect of Surface. For the 18" fall height, the wood and linoleum over concrete surfaces were associated with significantly greater AP angular accelerations than the linoleum over wood ( $\mathrm{p}=0.011$ for wood and $\mathrm{p}<0.001$ for linoleum over concrete), playground foam $(\mathrm{p}<0.001)$, and carpet $(\mathrm{p}<0.001)$ surfaces. The linoleum over concrete surface was associated with significantly greater ML angular accelerations than the linoleum over wood $(\mathrm{p}<0.001)$, playground foam $(\mathrm{p}=0.001)$, and carpet $(\mathrm{p}<0.001)$ surfaces, and the wood surface was associated with greater ML angular accelerations than the linoleum over wood $(p=0.046)$ and carpet $(p=0.047)$ surfaces. For the 27 " fall 
height, linoleum over concrete was associated with significantly greater AP angular accelerations than any of the other surfaces $(p=0.021, p<0.001, p=0.003, p=0.013$ for linoleum over wood, playground foam, carpet, and wood respectively), and linoleum over wood and linoleum over concrete were both associated with significantly greater ML angular accelerations than carpet $(p=0.019$ for linoleum over wood and $p=0.007$ for linoleum over concrete). For the 47" fall height, the wood and linoleum over concrete surfaces were associated with significantly greater AP angular accelerations than the linoleum over wood $(\mathrm{p}<0.001)$, playground foam $(\mathrm{p}<0.001)$, and carpet $(\mathrm{p}<0.001$ for wood and $p=0.012$ for linoleum over concrete) surfaces. The carpet surface also was associated with significantly greater AP angular accelerations than the playground foam $(p=0.036)$. The linoleum over wood surface was associated with significantly greater ML angular accelerations than the carpet $(p=0.001)$ and wood $(p=0.022)$ surfaces (Table XII).

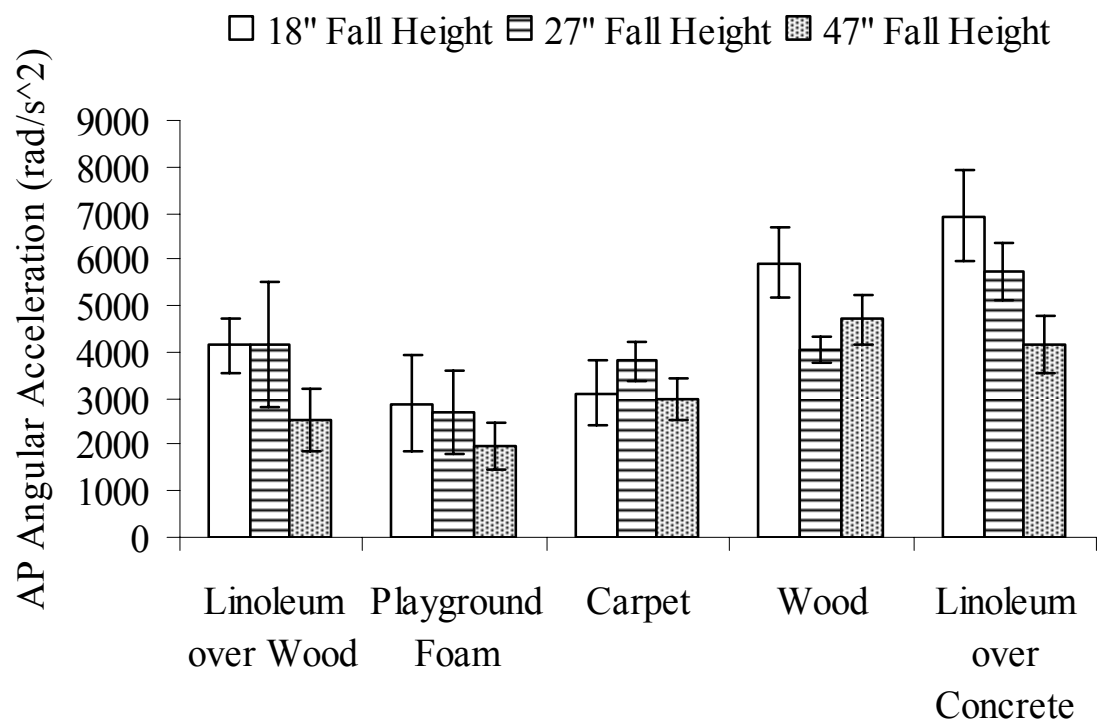

FIGURE 8 - Peak Anterior-Posterior Angular Head Accelerations for Free Falls with Various Impact Surfaces and Fall Heights (measured from ground to ATD center of mass). Error bars represent 95\% CI. 


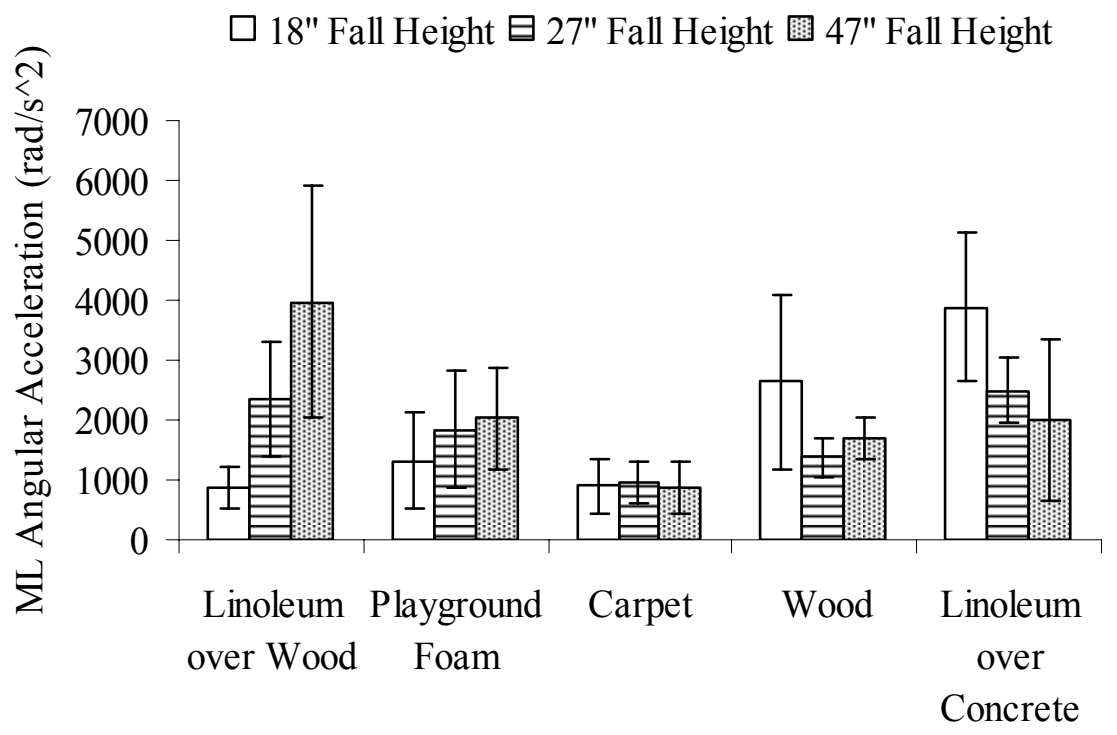

FIGURE 9 - Peak Medial-Lateral Angular Head Accelerations for Free Falls with Various Impact Surfaces and Fall Heights (measured from ground to ATD center of mass). Error bars represent 95\% CI.

TABLE XI

SIGNIFICANT DIFFERENCES IN ANGULAR HEAD ACCELERATIONS FOR VARIOUS HEIGHTS IN FEET-FIRST FREE FALLS

\begin{tabular}{|c|c|c|c|c|}
\hline & & 18 & 27 & 47 \\
\hline \multirow{3}{*}{$\begin{array}{c}\text { Linoleum over } \\
\text { Wood }\end{array}$} & 18 & & & AP,ML \\
\hline & 27 & & & AP \\
\hline & 47 & AP,ML & AP & \\
\hline \multirow{3}{*}{$\begin{array}{l}\text { Playground } \\
\text { Foam }\end{array}$} & 18 & & & \\
\hline & 27 & & & \\
\hline & 47 & & & \\
\hline \multirow{3}{*}{ Carpet } & 18 & & & \\
\hline & 27 & & & \\
\hline & 47 & & & \\
\hline \multirow{3}{*}{ Wood } & 18 & & AP & AP \\
\hline & 27 & AP & & \\
\hline & 47 & AP & & \\
\hline \multirow{3}{*}{$\begin{array}{l}\text { Linoleum over } \\
\text { Concrete }\end{array}$} & 18 & & AP & $\mathrm{AP}, \mathrm{ML}$ \\
\hline & 27 & AP & & AP \\
\hline & 47 & AP,ML & AP & \\
\hline
\end{tabular}

"AP" and "ML" indicate significant difference $(\mathrm{p}<0.05)$ in anterior-posterior and medial lateral accelerations, respectively 
TABLE XII

SIGNIFICANT DIFFERENCES IN ANGULAR HEAD ACCELERATIONS FOR

VARIOUS SURFACES IN FEET-FIRST FREE FALLS

\begin{tabular}{|c|c|c|c|c|c|c|}
\hline & & $\begin{array}{c}\text { Linoleum } \\
\text { over } \\
\text { Wood }\end{array}$ & $\begin{array}{c}\text { Playground } \\
\text { Foam }\end{array}$ & Carpet & Wood & $\begin{array}{c}\text { Linoleum } \\
\text { over } \\
\text { Concrete }\end{array}$ \\
\hline \multirow{5}{*}{18} & Linoleum over Wood & & & & $\mathrm{AP}, \mathrm{ML}$ & AP,ML \\
\hline & Playground Foam & & & & $\mathrm{AP}$ & AP,ML \\
\hline & Carpet & & & & AP,ML & AP,ML \\
\hline & Wood & $\mathrm{AP}, \mathrm{ML}$ & $\mathrm{AP}$ & AP,ML & & \\
\hline & Linoleum over Concrete & AP,ML & AP,ML & AP,ML & & \\
\hline \multirow{5}{*}{27} & Linoleum over Wood & & & ML & & AP \\
\hline & Playground Foam & & & & & AP \\
\hline & Carpet & ML & & & & AP,ML \\
\hline & Wood & & & & & AP \\
\hline & Linoleum over Concrete & $\mathrm{AP}$ & $\mathrm{AP}$ & $\mathrm{AP}, \mathrm{ML}$ & $\mathrm{AP}$ & \\
\hline \multirow{5}{*}{47} & Linoleum over Wood & & & ML & AP,ML & $\mathrm{AP}$ \\
\hline & Playground Foam & & & $\mathrm{AP}$ & AP & $\mathrm{AP}$ \\
\hline & Carpet & ML & AP & & AP & AP \\
\hline & Wood & AP,ML & $\mathrm{AP}$ & AP & & \\
\hline & Linoleum over Concrete & AP & $\mathrm{AP}$ & $\mathrm{AP}$ & & \\
\hline
\end{tabular}

"AP" and "ML" indicate significant difference $(\mathrm{p}<0.05)$ in anterior-posterior and medial lateral accelerations, respectively 


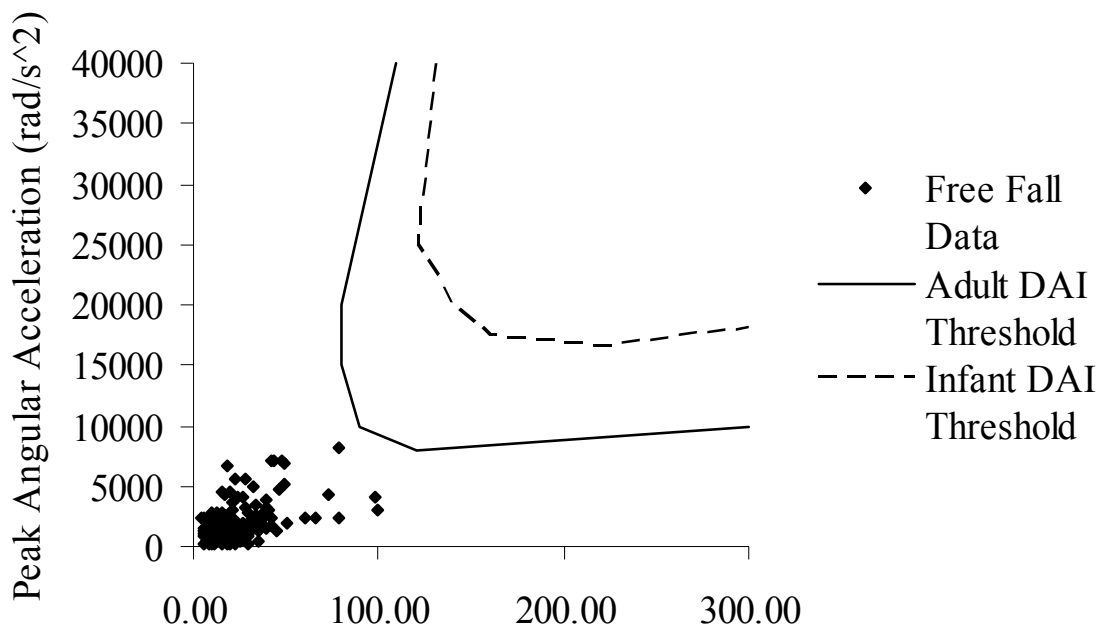

Peak Change in Angular Velocity ( $\mathrm{rad} / \mathrm{s})$

FIGURE 10 - Experimental Values of Angular Acceleration and Change in Angular Velocity in Free Falls Compared to Diffuse Axonal Injury Criteria (Margulies, 1992). (Adult and infant thresholds are a function of brain mass).

\section{$\underline{\text { 5. Impact Duration }}$}

The mean impact duration across all trials was 19.6 msec (95\% CI: 19.0-20.2) (Figure 11).

a. Effect of Height. There were no significant differences in impact durations due to varying fall height for the linoleum over wood, playground foam, and carpet surfaces. For the wood surface, the 18 " fall height was associated with significantly smaller durations than the $27^{\prime \prime}(\mathrm{p}=0.007)$ and $47^{\prime \prime}(\mathrm{p}=0.021)$. For the linoleum over concrete surface, the 18 " fall height was associated with significantly smaller durations than the 47" fall height $(\mathrm{p}=0.006)$ (Table XIII).

b. Effect of Surface. For the 18" fall height, falls onto carpet were associated with significantly longer impact durations than all other surfaces $(\mathrm{p}<0.001)$. Playground foam 
was associated with significantly longer durations than linoleum over wood, wood, and linoleum over concrete $(\mathrm{p}<0.001)$. Also, linoleum over wood was associated with significantly longer durations than wood and linoleum over concrete $(p<0.001)$. For both the 27 " and 47 " fall heights, playground foam and carpet were associated with significantly longer durations than linoleum over wood, wood, and linoleum over concrete surfaces $(p<0.001)$. For the 27 " fall height, linoleum over concrete was also associated with significantly smaller durations than the linoleum over wood $(\mathrm{p}=0.011)$ and $\operatorname{wood}(p=0.002)$ surfaces (Table XIV).

18" Fall Height 目 27" Fall Height 圈 47" Fall Height

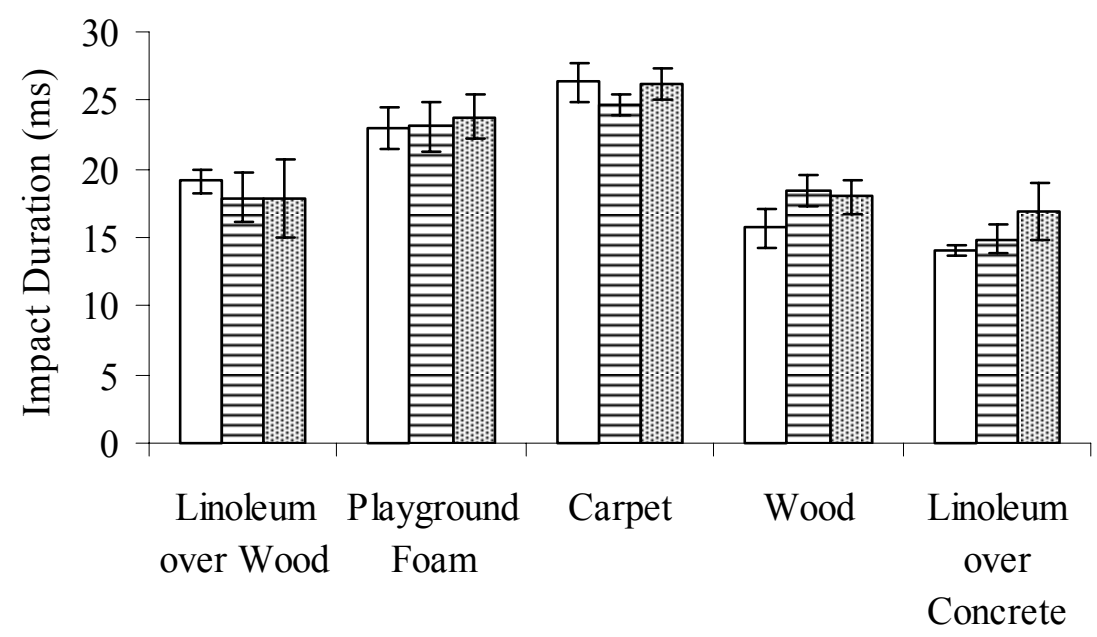

FIGURE 11 - Head Impact Durations for Free Falls with Various Impact Surfaces and Fall Heights (measured from ground to ATD center of mass). Error bars represent 95\% CI. 


\section{TABLE XIII}

SIGNIFICANT DIFFERENCES IN HEAD IMPACT DURATIONS FOR VARIOUS HEIGHTS IN FEET-FIRST FREE FALLS

\begin{tabular}{|c|c|c|c|c|}
\hline & & 18 & 27 & 47 \\
\hline \multirow{3}{*}{$\begin{array}{l}\text { Linoleum over } \\
\text { Wood }\end{array}$} & 18 & & & \\
\hline & 27 & & & \\
\hline & 47 & & & \\
\hline \multirow{3}{*}{$\begin{array}{l}\text { Playground } \\
\text { Foam }\end{array}$} & 18 & & & \\
\hline & 27 & & & \\
\hline & 47 & & & \\
\hline \multirow{3}{*}{ Carpet } & 18 & & & \\
\hline & 27 & & & \\
\hline & 47 & & & \\
\hline \multirow{3}{*}{ Wood } & 18 & & $X$ & $X$ \\
\hline & 27 & $\mathrm{X}$ & & \\
\hline & 47 & $\mathrm{X}$ & & \\
\hline \multirow{3}{*}{$\begin{array}{c}\text { Linoleum over } \\
\text { Concrete }\end{array}$} & 18 & & & $X$ \\
\hline & 27 & & & \\
\hline & 47 & $\mathrm{X}$ & & \\
\hline
\end{tabular}


TABLE XIV

SIGNIFICANT DIFFERENCES IN HEAD IMPACT DURATIONS FOR VARIOUS SURFACES IN FEET-FIRST FREE FALLS

\begin{tabular}{|c|c|c|c|c|c|c|}
\hline & \multirow[t]{2}{*}{$\begin{array}{c}\text { Linoleum } \\
\text { over } \\
\text { Wood }\end{array}$} & \multirow{2}{*}{$\begin{array}{c}\begin{array}{c}\text { Playground } \\
\text { Foam }\end{array} \\
\mathrm{X}\end{array}$} & \multirow{2}{*}{$\begin{array}{c}\text { Carpet } \\
\mathrm{X}\end{array}$} & \multirow[t]{2}{*}{ Wood } & \multirow[t]{2}{*}{$\begin{array}{c}\text { Linoleum } \\
\text { over } \\
\text { Concrete }\end{array}$} \\
\hline \multirow{5}{*}{18} & Linoleum over Wood & & & & & \\
\hline & Playground Foam & $\mathrm{X}$ & & $\mathrm{X}$ & $\mathrm{X}$ & $\mathrm{X}$ \\
\hline & Carpet & $\mathrm{X}$ & $\mathrm{X}$ & & $\mathrm{X}$ & $\mathrm{X}$ \\
\hline & Wood & & $\mathrm{X}$ & $\mathrm{X}$ & & \\
\hline & Linoleum over Concrete & & $\mathrm{X}$ & $\mathrm{X}$ & & \\
\hline \multirow{5}{*}{27} & Linoleum over Wood & & $\mathrm{X}$ & $\mathrm{X}$ & & $\mathrm{X}$ \\
\hline & Playground Foam & $\mathrm{X}$ & & & $\mathrm{X}$ & $\mathrm{X}$ \\
\hline & Carpet & $\mathrm{X}$ & & & $\mathrm{X}$ & $\mathrm{X}$ \\
\hline & Wood & & $\mathrm{X}$ & $\mathrm{X}$ & & $\mathrm{X}$ \\
\hline & Linoleum over Concrete & $\mathrm{X}$ & $\mathrm{X}$ & $\mathrm{X}$ & $\mathrm{X}$ & \\
\hline \multirow{5}{*}{47} & Linoleum over Wood & & $\mathrm{X}$ & $\mathrm{X}$ & & \\
\hline & Playground Foam & $\mathrm{X}$ & & & $\mathrm{X}$ & $\mathrm{X}$ \\
\hline & Carpet & $\mathrm{X}$ & & & $\mathrm{X}$ & $\mathrm{X}$ \\
\hline & Wood & & $\mathrm{X}$ & $\mathrm{X}$ & & \\
\hline & Linoleum over Concrete & & $\mathrm{X}$ & $\mathrm{X}$ & & \\
\hline
\end{tabular}

"X" indicates significant difference $(\mathrm{p}<0.05)$

\section{$\underline{\text { 6. Neck Injury Assessment }}$}

For each trial, neck injury measures $\left(\mathrm{N}_{\mathrm{ij}}\right.$ values) were computed for four combined loading conditions on the neck: tension-flexion $\left(\mathrm{N}_{\mathrm{TF}}\right)$, tension-extension $\left(\mathrm{N}_{\mathrm{TE}}\right)$, compression-flexion $\left(\mathrm{N}_{\mathrm{CF}}\right)$, and compression-extension $\left(\mathrm{N}_{\mathrm{CE}}\right)$. The mean peak $\mathrm{N}_{\mathrm{TF}}, \mathrm{N}_{\mathrm{TE}}$, $\mathrm{N}_{\mathrm{CF}}$, and $\mathrm{N}_{\mathrm{CE}}$ values across all trials were 0.21 (95\% CI: $\left.0.20-0.23\right), 0.14$ (95\% CI: 0.13$0.16), 0.27$ (95\% CI: $0.25-0.28$ ), and 0.32 (95\% CI: 0.28-35), respectively (Figures $12-$ 15). The $\mathrm{N}_{\mathrm{ij}}$ values are normalized so that a value of $\mathrm{N}_{\mathrm{ij}}=1$ represents a threshold for 
neck injury. This threshold was only exceeded once across all trials (Figure 16). This occurred in a 27" fall onto the wood surface with $\mathrm{N}_{\mathrm{CE}}=1.10$.

a. Effect of Height. Generally, greater fall heights were associated with greater $\mathrm{N}_{\mathrm{ij}}$ values. For the linoleum over wood and playground foam surfaces, the 47" fall height was associated with significantly greater $\mathrm{N}_{\mathrm{TF}}$ and $\mathrm{N}_{\mathrm{CF}}$ values than the $18^{\prime \prime}(\mathrm{p}<0.001$ for all cases except for playground foam $\mathrm{N}_{\mathrm{CF}}$ where $\left.\mathrm{p}=0.008\right)$ and 27 ' fall heights $(\mathrm{p}<$ 0.001 for all cases except for playground foam $\mathrm{N}_{\mathrm{CF}}$ where $\mathrm{p}=0.003$ ). For falls onto carpet, the 47 " fall height was associated with significantly greater $\mathrm{N}_{\mathrm{TE}}$ and $\mathrm{N}_{\mathrm{CE}}$ values than the 18 " $\left(\mathrm{N}_{T E} \mathrm{p}=0.002\right.$ and $\left.\mathrm{N}_{\mathrm{CE}} \mathrm{p}=0.008\right)$ and 27 " fall heights $\left(\mathrm{N}_{\mathrm{TE}} \mathrm{p}<0.001\right.$ and $\mathrm{N}_{\mathrm{CE}} \mathrm{p}=0.012$ ), and the 27 " and 47 " fall heights were associated with significantly greater $\mathrm{N}_{\mathrm{CF}}$ values than the 18 " fall height $(\mathrm{p}<0.001)$. For falls onto wood, the 47 " fall height was associated with significantly greater $\mathrm{N}_{\mathrm{TF}}$ and $\mathrm{N}_{\mathrm{CF}}$ values than the 27 " height $\left(\mathrm{N}_{\mathrm{TF}} \mathrm{p}<0.001\right.$ and $\left.\mathrm{N}_{\mathrm{CF}} \mathrm{p}=0.024\right)$, and the 27 " and 47 " fall heights were associated with significantly greater $\mathrm{N}_{\mathrm{CF}}$ values than the 18 ” fall height ((27” $\mathrm{p}=0.012$ and 47 ” $\mathrm{p}<$ 0.001). For falls onto linoleum over concrete, the 27 " and 47 " fall heights were associated with significantly greater $\mathrm{N}_{\mathrm{CF}}$ values than the 18 " fall height $((27 " \mathrm{p}=0.003$ and $47 " \mathrm{p}<0.001$ ). The only exception to significantly greater $\mathrm{N}_{\mathrm{ij}}$ values for greater fall heights occurred on the wood surface with the 18 " falls associated with significantly greater $\mathrm{N}_{\mathrm{TF}}$ values than the 27' falls $(\mathrm{p}<0.001)$ (Table XV).

b. Effect of Surface. Unlike the effects of fall height, significant differences in $\mathrm{N}_{\mathrm{ij}}$ values across varying surfaces were not as consistent. For all fall heights, falls onto linoleum over wood and playground foam were associated with significantly lower $\mathrm{N}_{\mathrm{CE}}$ values than falls onto wood $(\mathrm{p}<0.001$ for all cases except for 47 " falls onto playground 
foam where $p=0.002)$ and linoleum over concrete $(p<0.001$ for 18 " falls, $p=0.011$ for 27 " falls onto linoleum over wood, $\mathrm{p}=0.009$ for 27 " falls onto playground foam, $\mathrm{p}=$ 0.003 for 47 " falls onto linoleum over wood, and $\mathrm{p}=0.017$ for 47 " falls onto playground foam). However for the 18 " falls, playground foam was associated with significantly greater $\mathrm{N}_{\mathrm{CF}}$ values than wood $(\mathrm{p}=0.016)$ and linoleum over concrete $(\mathrm{p}=0.005)$. Also for the 18 " falls, carpet was associated with significantly lower $\mathrm{N}_{\mathrm{TF}}$ values than wood ( $\mathrm{p}$ $=0.001)$ and linoleum over concrete $(\mathrm{p}=0.003)$ and significantly greater $\mathrm{N}_{\mathrm{CE}}$ values than linoleum over wood and playground foam $(\mathrm{p} \leq 0.001)$. For the 27 " fall height, linoleum over wood and linoleum over concrete were associated with significantly greater $\mathrm{N}_{\mathrm{TF}}$ values than the carpet $(\mathrm{p}=0.026$ for linoleum over wood and $\mathrm{p}=0.028$ for linoleum over concrete) and wood surfaces ( $p=0.044$ for linoleum over wood and $p=0.048$ for linoleum over concrete). Linoleum over concrete was also associated with significantly greater $\mathrm{N}_{\mathrm{CF}}$ values than linoleum over wood $(\mathrm{p}=0.035)$ and playground foam $(\mathrm{p}=$ 0.021). Carpet was associated with significantly lower $\mathrm{N}_{\mathrm{CE}}$ values than wood $(\mathrm{p}=$ 0.039). For the 47 " fall height, linoleum over wood and playground foam were associated with significantly greater $\mathrm{N}_{\mathrm{TF}}$ values than carpet, wood, and linoleum over concrete $(\mathrm{p}<0.001)$. Also, the wood surface was associated with significantly greater $\mathrm{N}_{\mathrm{TF}}$ and $\mathrm{N}_{\mathrm{CF}}$ values than carpet $\left(\mathrm{N}_{\mathrm{TF}} \mathrm{p}=0.005\right.$ and $\left.\mathrm{N}_{\mathrm{CF}} \mathrm{p}=0.010\right)$. However, carpet was associated with significantly greater $\mathrm{N}_{\mathrm{CE}}$ values than any other surface $(\mathrm{p}<0.001$ for all cases except wood where $\mathrm{p}=0.004$ ). There were no significant differences in $\mathrm{N}_{T E}$ values due to impact surface type (Table XVI). 
$\square$ 18" Fall Height 目 27" Fall Height 臤 47" Fall Height

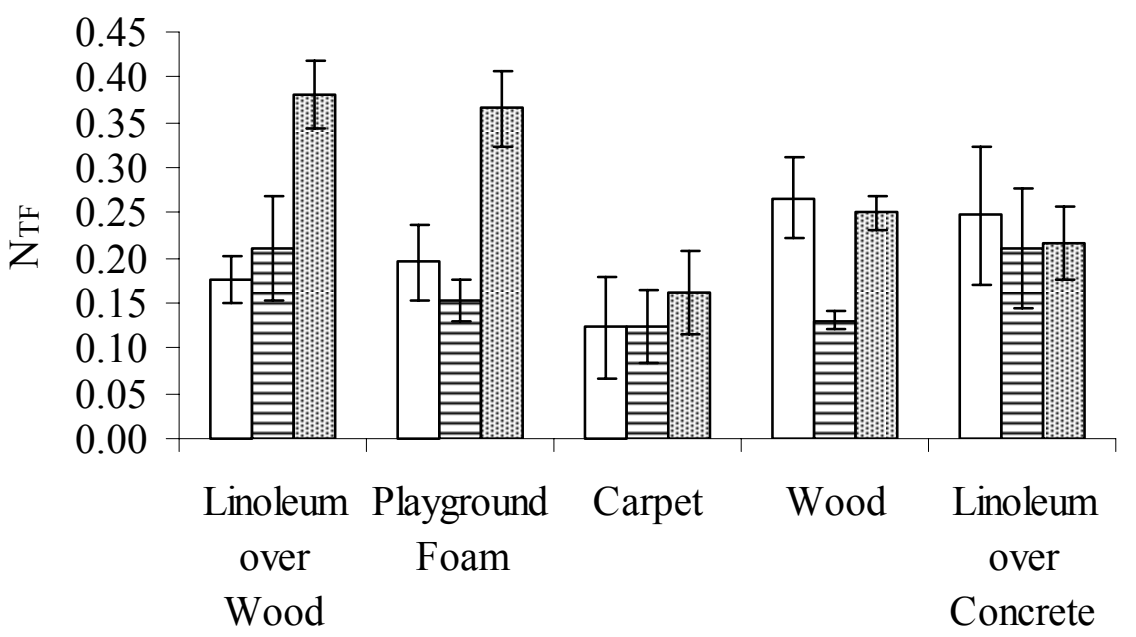

FIGURE 12 - Neck Injury Criteria for Combined Tension-Flexion Loading for Free Falls with Various Impact Surfaces and Fall Heights (measured from ground to ATD center of mass). Error bars represent $95 \% \mathrm{CI}$.

$\square$ 18" Fall Height 目 27" Fall Height 粼 47" Fall Height

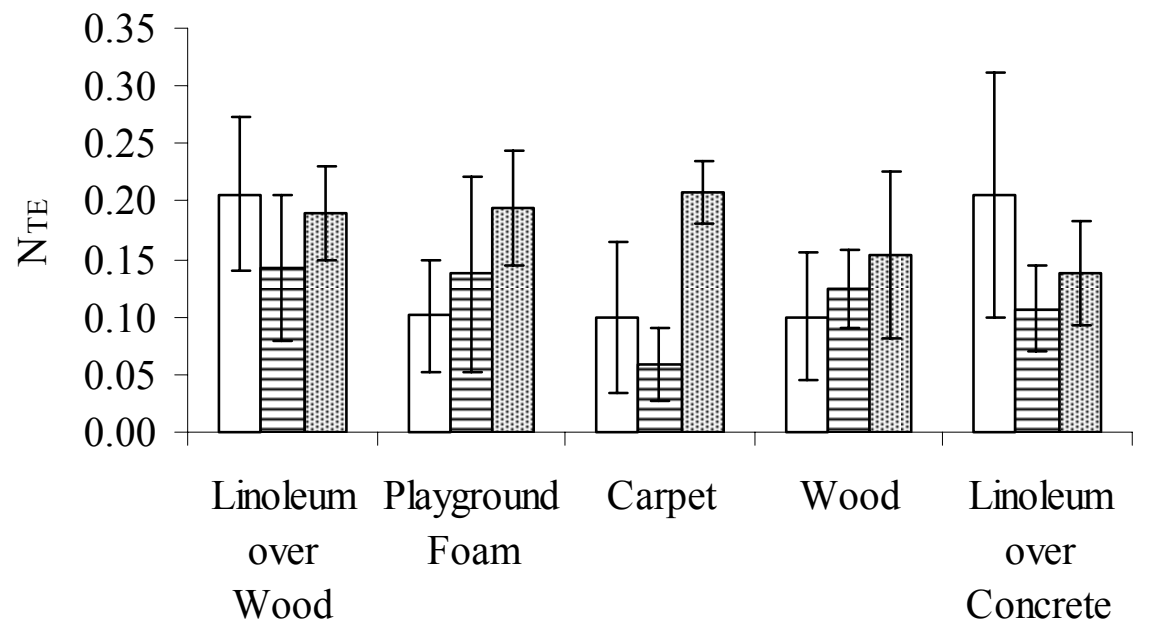

FIGURE 13 - Neck Injury Criteria for Combined Tension-Extension Loading for Free Falls with Various Impact Surfaces and Fall Heights (measured from ground to ATD center of mass). Error bars represent $95 \%$ CI. 
18" Fall Height $\boxminus 27$ " Fall Height 橉 47" Fall Height

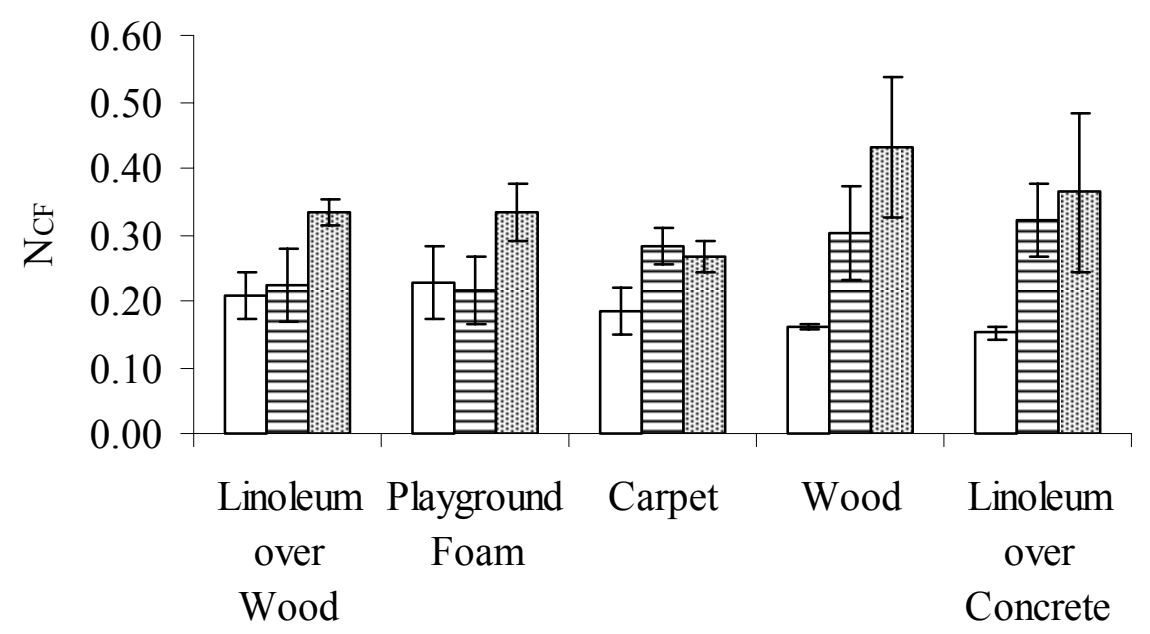

FIGURE 14 - Neck Injury Criteria for Combined Compression-Flexion Loading for Free Falls with Various Impact Surfaces and Fall Heights (measured from ground to ATD center of mass). Error bars represent 95\% CI.

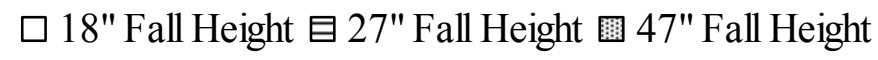

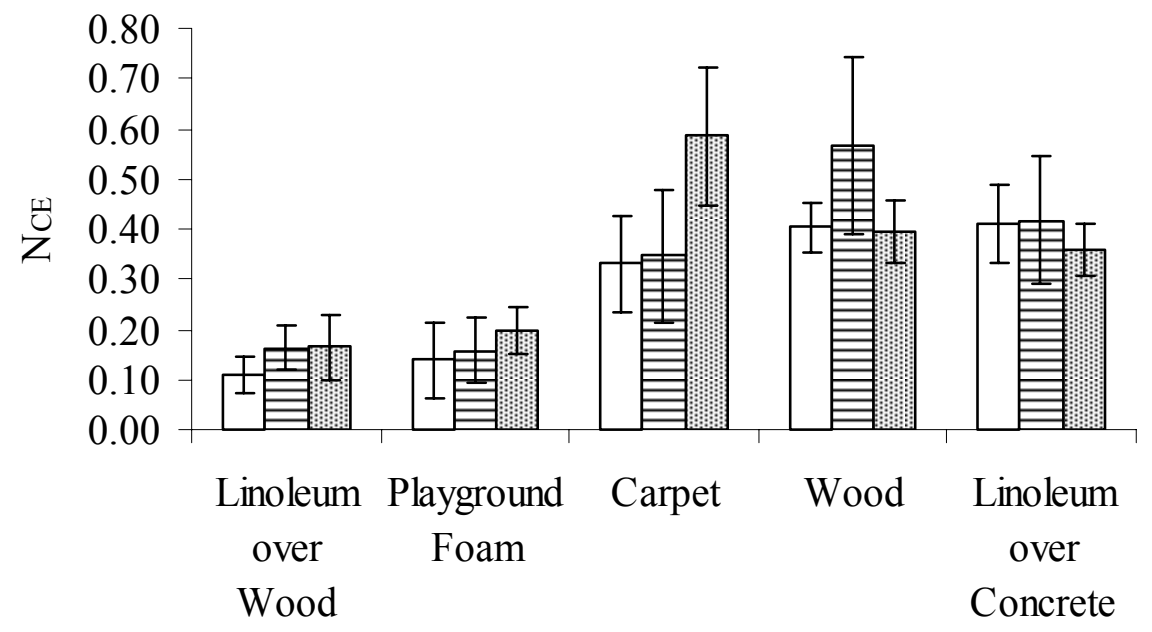

FIGURE 15 - Neck Injury Criteria for Combined Compression-Extension Loading for Free Falls with Various Impact Surfaces and Fall Heights (measured from ground to ATD center of mass). Error bars represent 95\% CI. 
TABLE XV

SIGNIFICANT DIFFERENCES IN NECK INJURY CRITERIA FOR VARIOUS

HEIGHTS IN FEET-FIRST FREE FALLS

\begin{tabular}{|c|c|c|c|c|}
\hline & & 18 & 27 & 47 \\
\hline \multirow{3}{*}{$\begin{array}{c}\text { Linoleum over } \\
\text { Wood }\end{array}$} & 18 & & & TF,CF \\
\hline & 27 & & & TF,CF \\
\hline & 47 & TF,CF & $\mathrm{TF}, \mathrm{CF}$ & \\
\hline \multirow{3}{*}{$\begin{array}{l}\text { Playground } \\
\text { Foam }\end{array}$} & 18 & & & $\mathrm{TF}, \mathrm{CF}$ \\
\hline & 27 & & & TF,CF \\
\hline & 47 & TF,CF & TF,CF & \\
\hline \multirow{3}{*}{ Carpet } & 18 & & $\mathrm{CF}$ & CF,TE,CE \\
\hline & 27 & $\mathrm{CF}$ & & TE,CE \\
\hline & 47 & $\mathrm{CF}, \mathrm{TE}, \mathrm{CE}$ & TE,CE & \\
\hline \multirow{3}{*}{ Wood } & 18 & & TF,CF & $\mathrm{CF}$ \\
\hline & 27 & TF,CF & & TF,CF \\
\hline & 47 & CF & TF,CF & \\
\hline \multirow{3}{*}{$\begin{array}{l}\text { Linoleum over } \\
\text { Concrete }\end{array}$} & 18 & & $\mathrm{CF}$ & $\mathrm{CF}$ \\
\hline & 27 & $\mathrm{CF}$ & & \\
\hline & 47 & $\mathrm{CF}$ & & \\
\hline
\end{tabular}

"TF", "CF", "TE", and "CE" indicate significant differences $(p<0.05)$ in tensionflexion, compression-flexion, tension-extension, and compression-extension neck loading measures, respectively. 
TABLE XVI

SIGNIFICANT DIFFERENCES IN NECK INJURY CRITERIA FOR VARIOUS

SURFACES IN FEET-FIRST FREE FALLS

\begin{tabular}{|c|c|c|c|c|c|c|}
\hline & & $\begin{array}{c}\text { Linoleum } \\
\text { over } \\
\text { Wood }\end{array}$ & $\begin{array}{l}\text { Playground } \\
\text { Foam }\end{array}$ & Carpet & Wood & $\begin{array}{c}\text { Linoleum } \\
\text { over } \\
\text { Concrete }\end{array}$ \\
\hline \multirow{5}{*}{18} & Linoleum over Wood & & & $\mathrm{CE}$ & $\mathrm{CE}$ & $\mathrm{CE}$ \\
\hline & Playground Foam & & & $\mathrm{CE}$ & CF,CE & CF,CE \\
\hline & Carpet & $\mathrm{CE}$ & $\mathrm{CE}$ & & $\mathrm{TF}$ & $\mathrm{TF}$ \\
\hline & Wood & $\mathrm{CE}$ & $\mathrm{CF}, \mathrm{CE}$ & $\mathrm{TF}$ & & \\
\hline & Linoleum over Concrete & $\mathrm{CE}$ & $\mathrm{CF}, \mathrm{CE}$ & $\mathrm{TF}$ & & \\
\hline \multirow{5}{*}{27} & Linoleum over Wood & & & $\mathrm{TF}$ & TF,CE & CF,CE \\
\hline & Playground Foam & & & & $\mathrm{CE}$ & CF,CE \\
\hline & Carpet & $\mathrm{TF}$ & & & $\mathrm{CE}$ & $\mathrm{TF}$ \\
\hline & Wood & TF,CE & $\mathrm{CE}$ & $\mathrm{CE}$ & & $\mathrm{TF}$ \\
\hline & Linoleum over Concrete & $\mathrm{CF}, \mathrm{CE}$ & $\mathrm{CF}, \mathrm{CE}$ & $\mathrm{TF}$ & $\mathrm{TF}$ & \\
\hline \multirow{5}{*}{47} & Linoleum over Wood & & & $\mathrm{TF}, \mathrm{CE}$ & $\mathrm{TF}, \mathrm{CE}$ & $\mathrm{TF}, \mathrm{CE}$ \\
\hline & Playground Foam & & & $\mathrm{TF}, \mathrm{CE}$ & $\mathrm{TF}, \mathrm{CE}$ & $\mathrm{TF}, \mathrm{CE}$ \\
\hline & Carpet & $\mathrm{TF}, \mathrm{CE}$ & $\mathrm{TF}, \mathrm{CE}$ & & $\mathrm{TF}, \mathrm{CF}, \mathrm{CE}$ & $\mathrm{CE}$ \\
\hline & Wood & $\mathrm{TF}, \mathrm{CE}$ & $\mathrm{TF}, \mathrm{CE}$ & TF,CF,CE & & \\
\hline & Linoleum over Concrete & TF,CE & TF,CE & $\mathrm{CE}$ & & \\
\hline
\end{tabular}

"TF", "CF", "TE", and "CE" indicate significant differences $(p<0.05)$ in tensionflexion, compression-flexion, tension-extension, and compression-extension neck loading measures, respectively. 


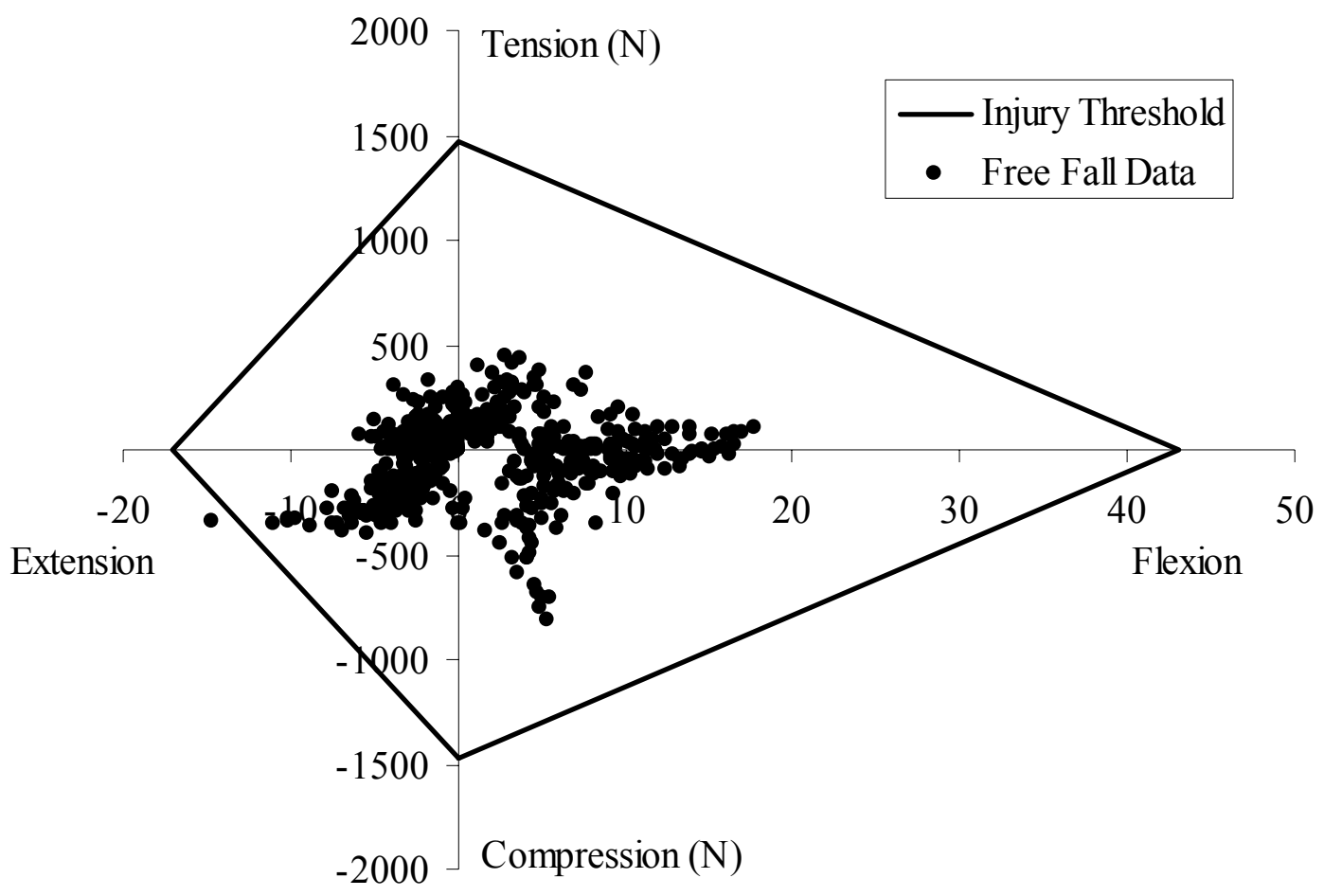

FIGURE 16 - Experimental Values of Neck Compression/Tension Forces and Flexion/Extension Moments in Free Falls Compared to NHTSA Neck Injury Threshold.

\section{B. Falls from Standing}

\section{$\underline{\text { 1. Fall Dynamics - Qualitative Assessment }}$}

a. Effect of Height. For the two fall heights tested (18" and 27" measured from ground to ATD center of mass), the fall dynamics were similar for falls onto the same surface with the same joint condition (Figure 17). One difference occurred only in those falls with normal ATD joint stiffness. In the 18 " falls with normal joint stiffness, the ATD's pelvis first impacted the ground followed by a rearward rotation of the torso about 
the pelvis leading to a second impact of the torso and head with the ground. However, in the 27 " falls with normal joint stiffness, the torso impacted the ground almost simultaneously with the pelvis. Another difference that occurred in all falls is that after the initial torso impact with the ground, the ATD rebounded up off the ground, and this rebound was higher in those falls from the greater fall height.

b. Effect of Surface. The fall kinematics appeared similar for varying surfaces with the same fall height and joint condition (Figure 17).

c. Effect of Joint Stiffness. The joint condition, whether the joints were adjusted to the normal specifications or tightened to allow no movement, had the greatest observable effect on fall dynamics. For falls with the normal joint stiffness, the ATD fell to a crouching position after release with hips and knees flexed, then fell rearward rotating about the feet. The initial impact occurred at the pelvis, followed by the torso and head. For falls with the joints tightened, the ATD did not fall to a crouching position but simply rotated rearward about the feet impacting the pelvis, torso, and head with the ground almost simultaneously (Figure 17). 


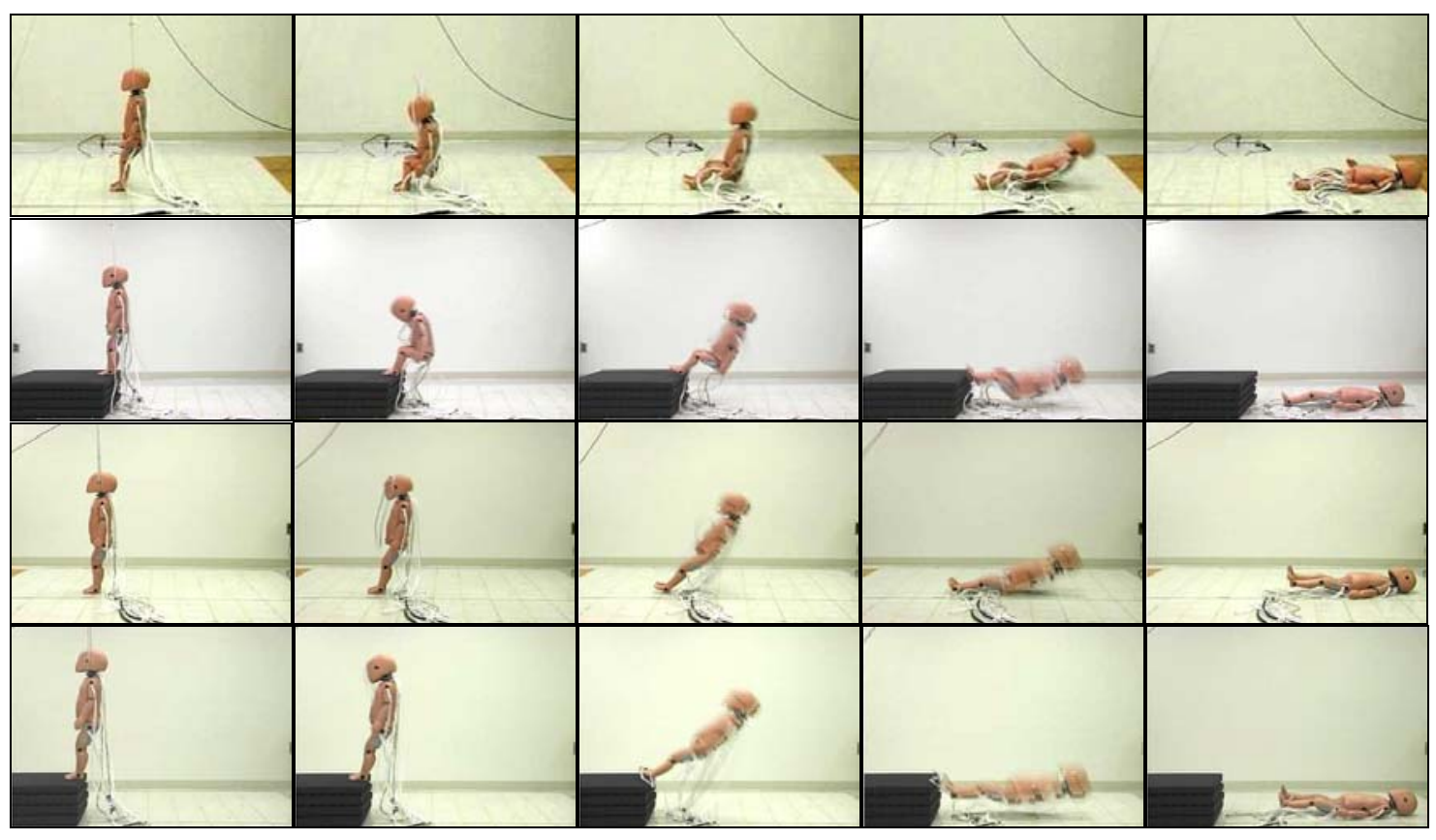

(a)

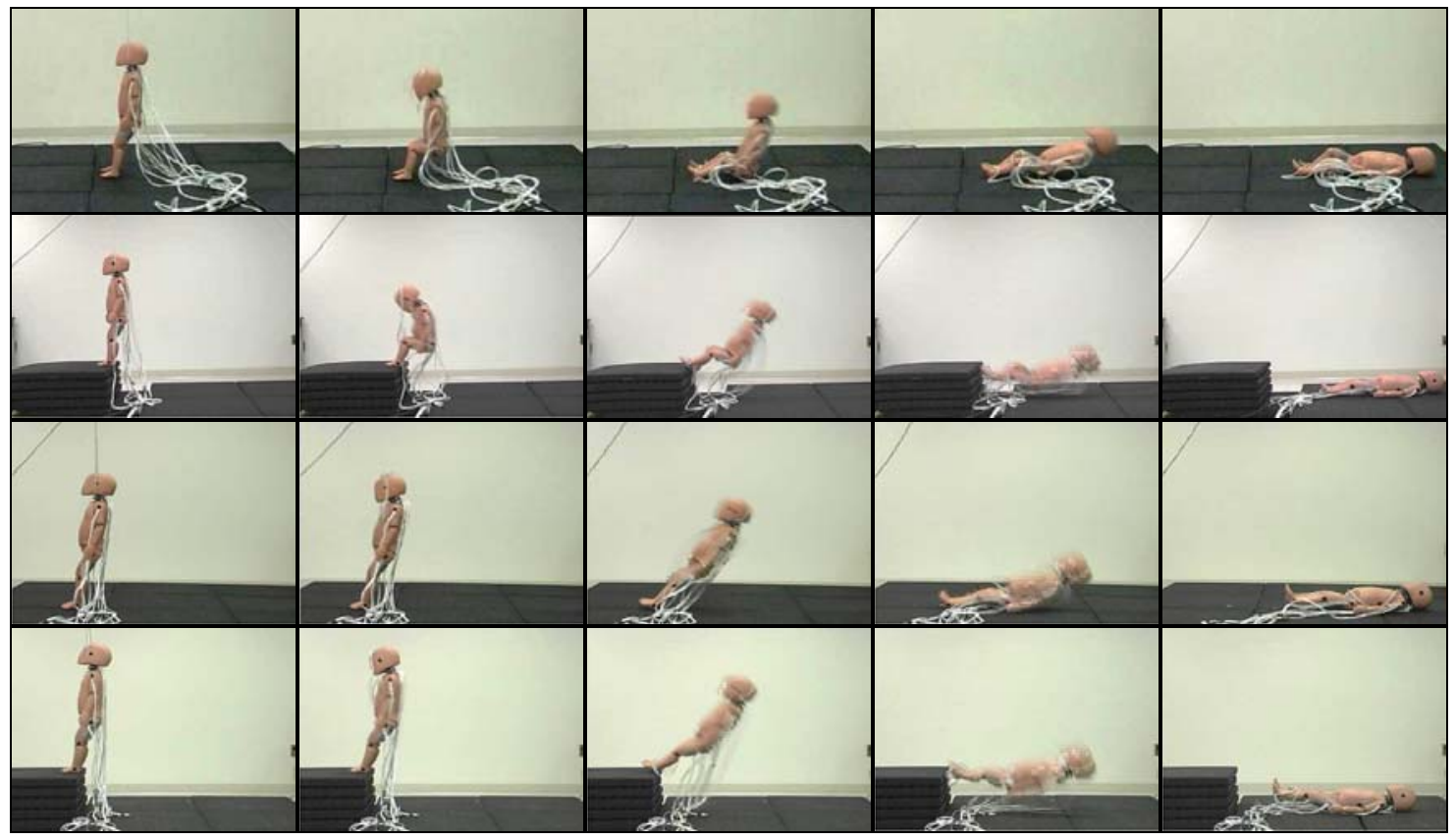

(b) 


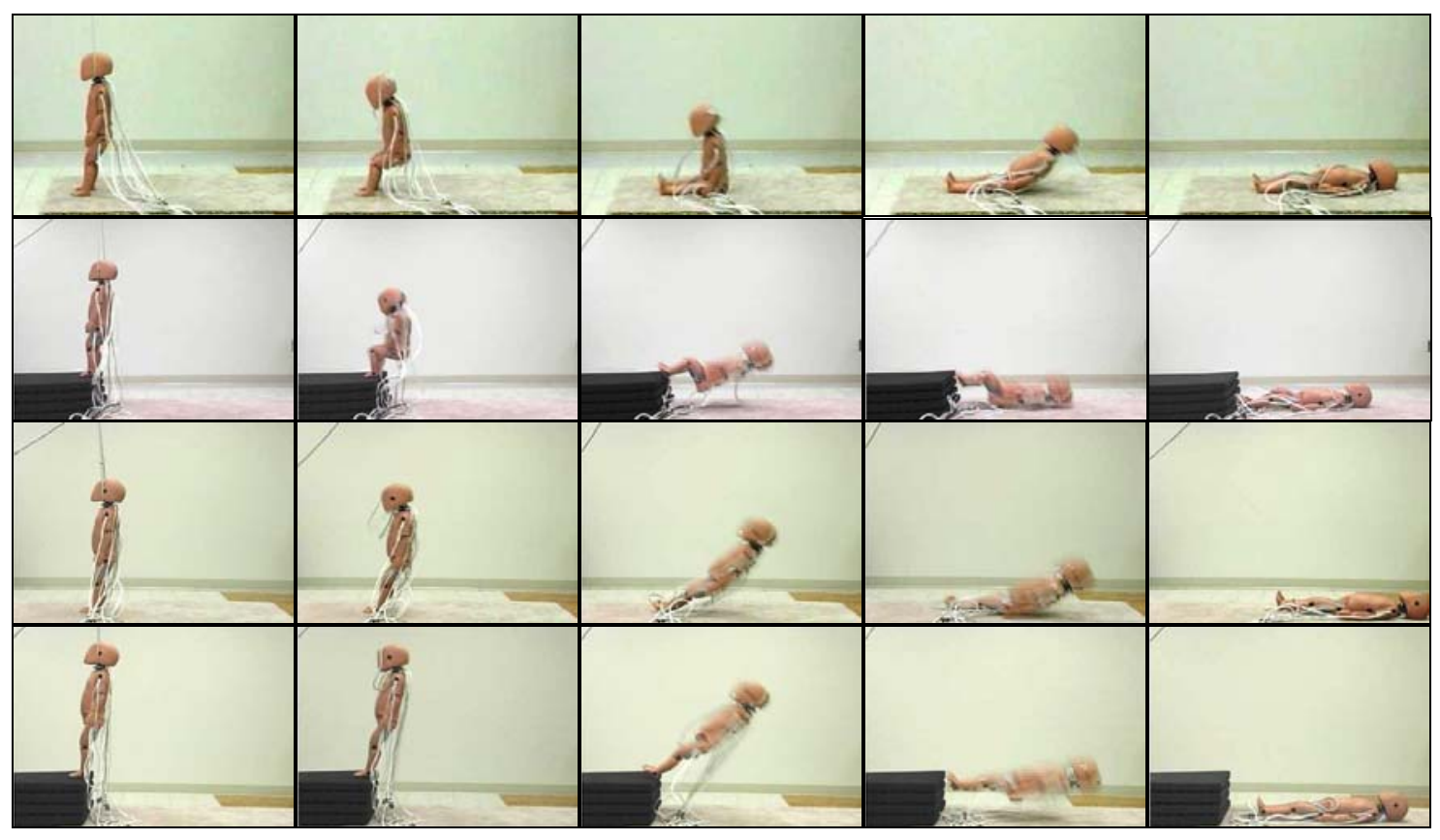

(c)

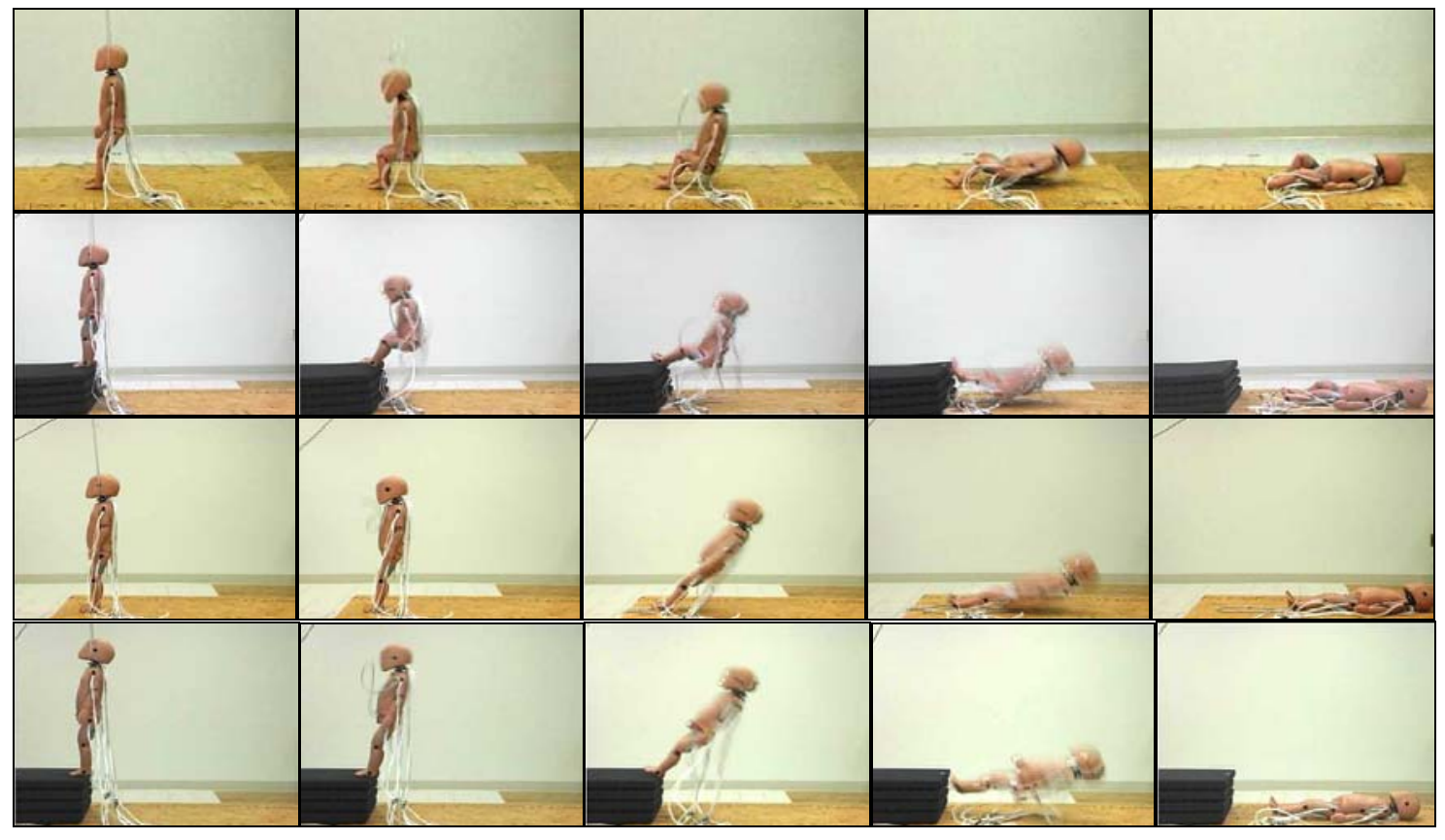

(d) 


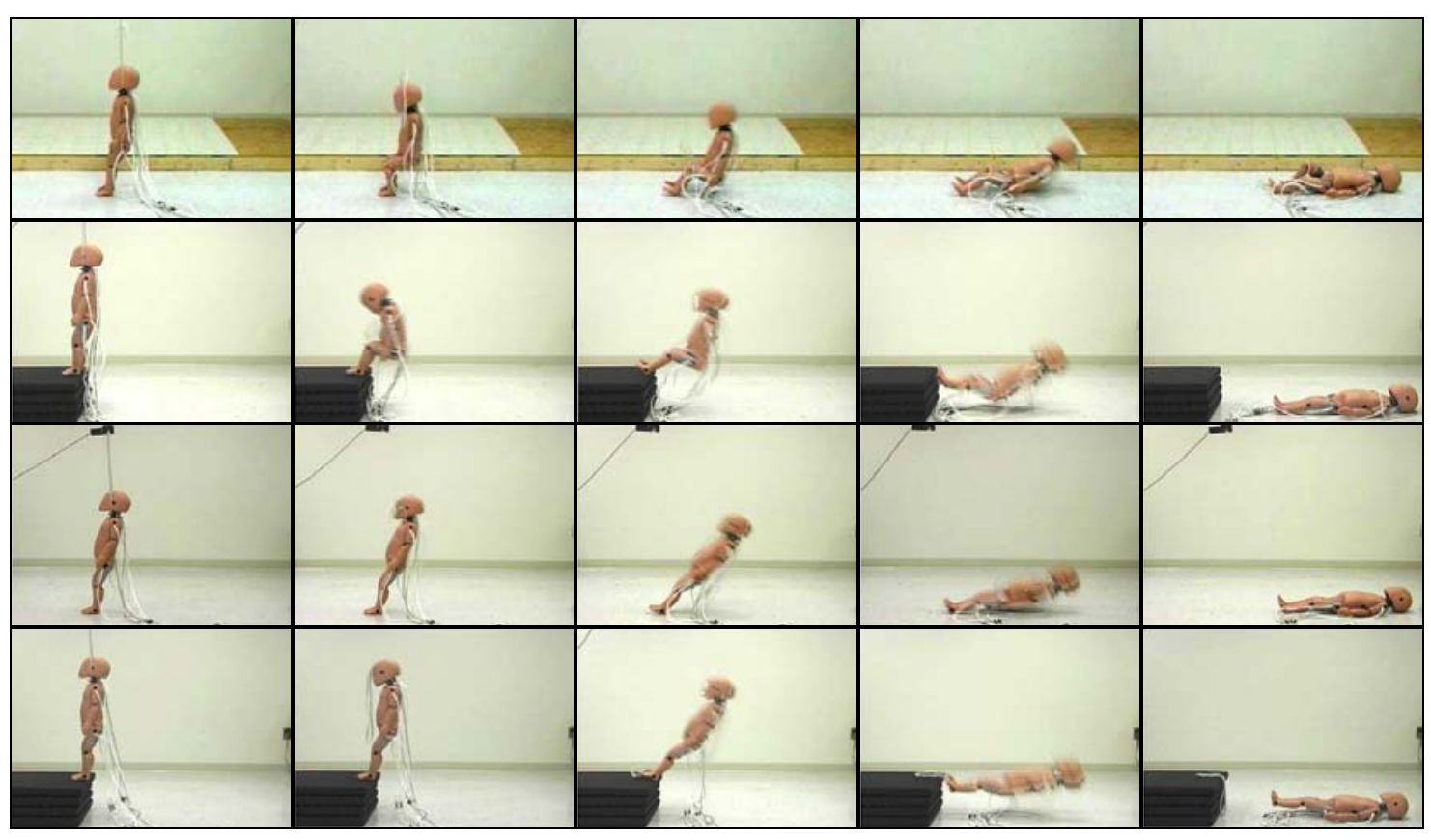

(e)

FIGURE 17 - Representative 18" Falls with Normal Joint Stiffness, 27" Falls with Normal Joint Stiffness, 18" Falls with Tight Joint Stiffness, and 27" Falls with Tight Joint Stiffness onto (a) Linoleum over Wood, (b) Playground Foam, (c) Carpet, (d) Wood, and (e) Linoleum over Concrete.

\section{Fall Dynamics - Quantitative Assessment}

Marker data from two fall scenarios, 27" falls from standing onto carpet with both normal and tightened joint stiffness, were analyzed. Hip flexion-extension angles, knee flexion-extension angles, neck flexion-extension angles, and the torso angles relative to ground were calculated to describe the kinematics of the fall. For the hip, knee, and neck angles, values less than 180 degrees were flexion angles and values greater than 180 degrees were extension angles. Figures 18-21 show these angles over time. For the falls with tightened joints, the hip and knee joint angles stayed approximately constant over time as expected. Both joints were adjusted to 160 degrees before each fall. For the falls 
with normal joint stiffness, the knee and hip angles followed a similar pattern over the duration of the fall. Both angles decreased from the initial 160 degrees to approximately 90 degrees while the torso angle relative to the ground plane stayed approximately constant. During this time the neck angle also decreased to its minimum value of approximately 145 degrees. At this point the torso angle rapidly decreased as the ATD fell rearward and the knee, hip, and neck angles gradually straightened out reaching about 120,115 , and 165 degrees, respectively, as the torso impacted the ground (around 0.8 seconds after release). The head impact occurred slightly after the torso impact as can be seen from the rapid decrease then increase in neck angle around this time. After the initial impact the ATD rebounded off the ground. This can be seen from the torso angle which increased slightly (to about 20 degrees) and then fell back to zero after the first impact. During this time the knee and hip angles continued to increase with the hip angle returning to 160 degrees and the knee angle returning to about 140 degrees at the end of the fall. The neck angle increased and decreased slightly, hovering around 150 degrees. The neck angle and torso angle in the falls with tightened joints followed a similar pattern to that in falls with normal joints. However, the initial impact with the ground occurred about 0.1 seconds later in falls with tight joints than in the falls with normal joints due to a larger radius of rotation. 


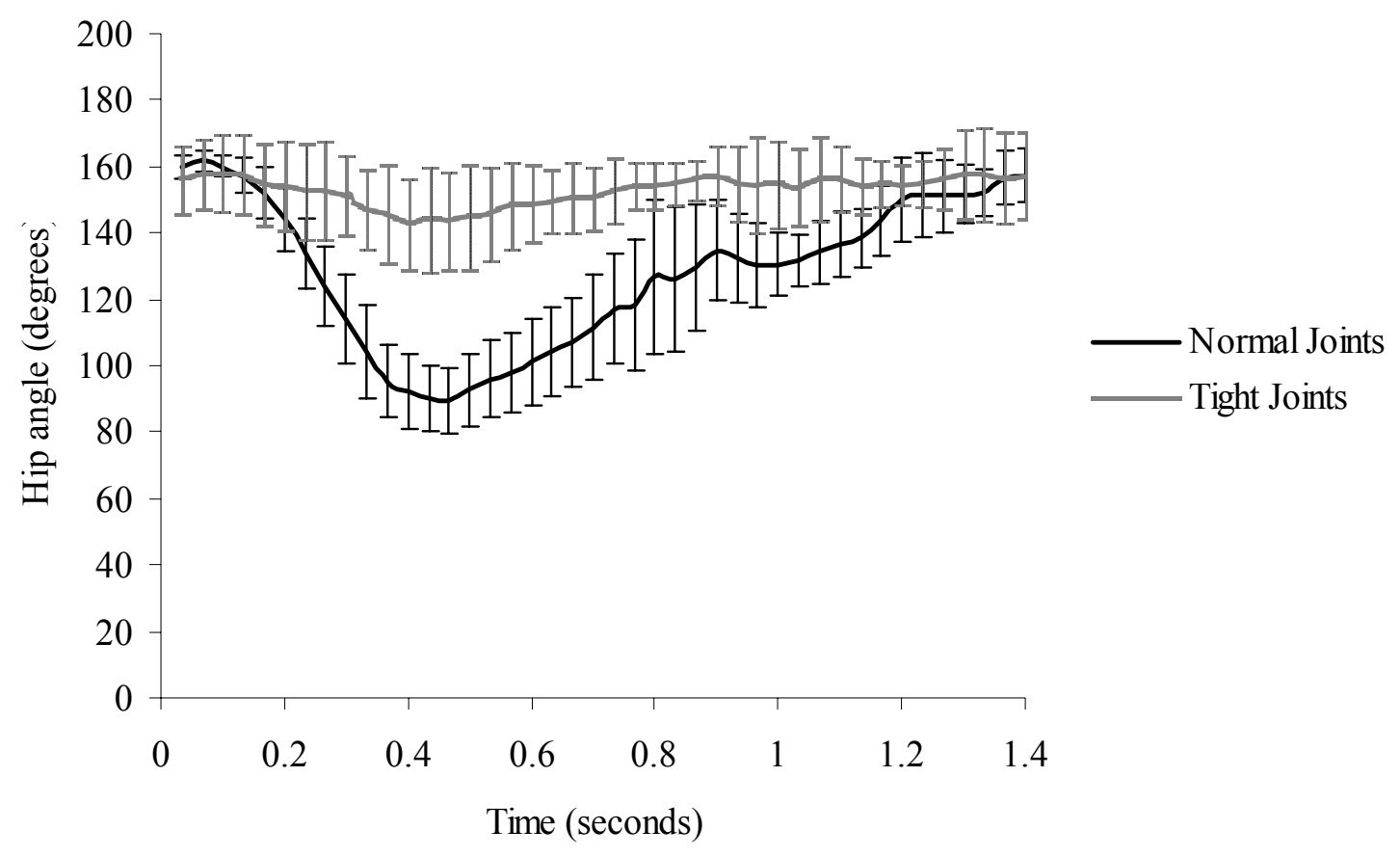

FIGURE 18 - Mean Hip Flexion Angle over Time for 27" Falls from Standing onto Carpet with Normal and Tightened Joints. Error bars represent standard deviation.

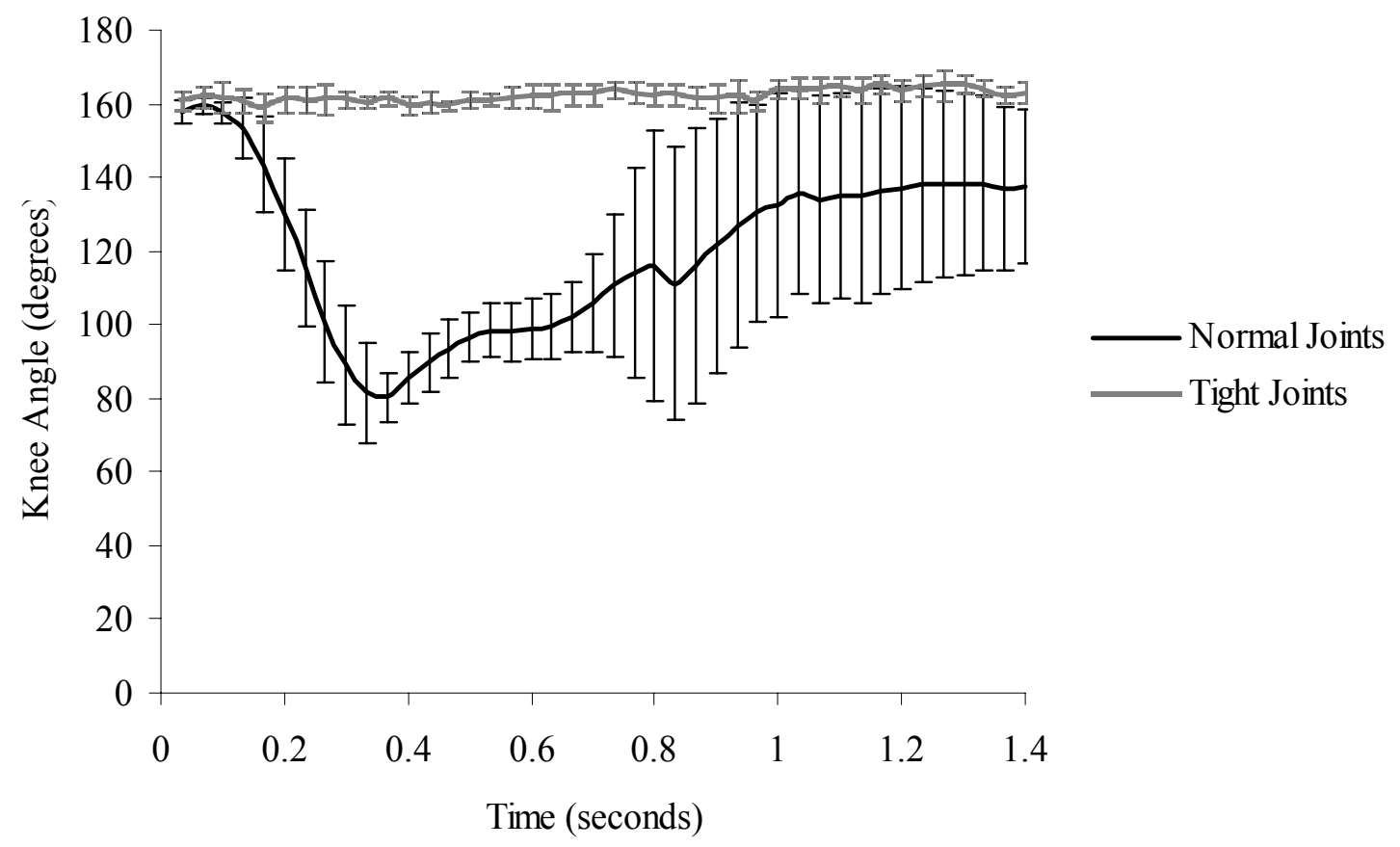

FIGURE 19 - Mean Knee Flexion over Time for 27" Falls from Standing onto Carpet with Normal and Tightened Joints. Error bars represent standard deviation. 


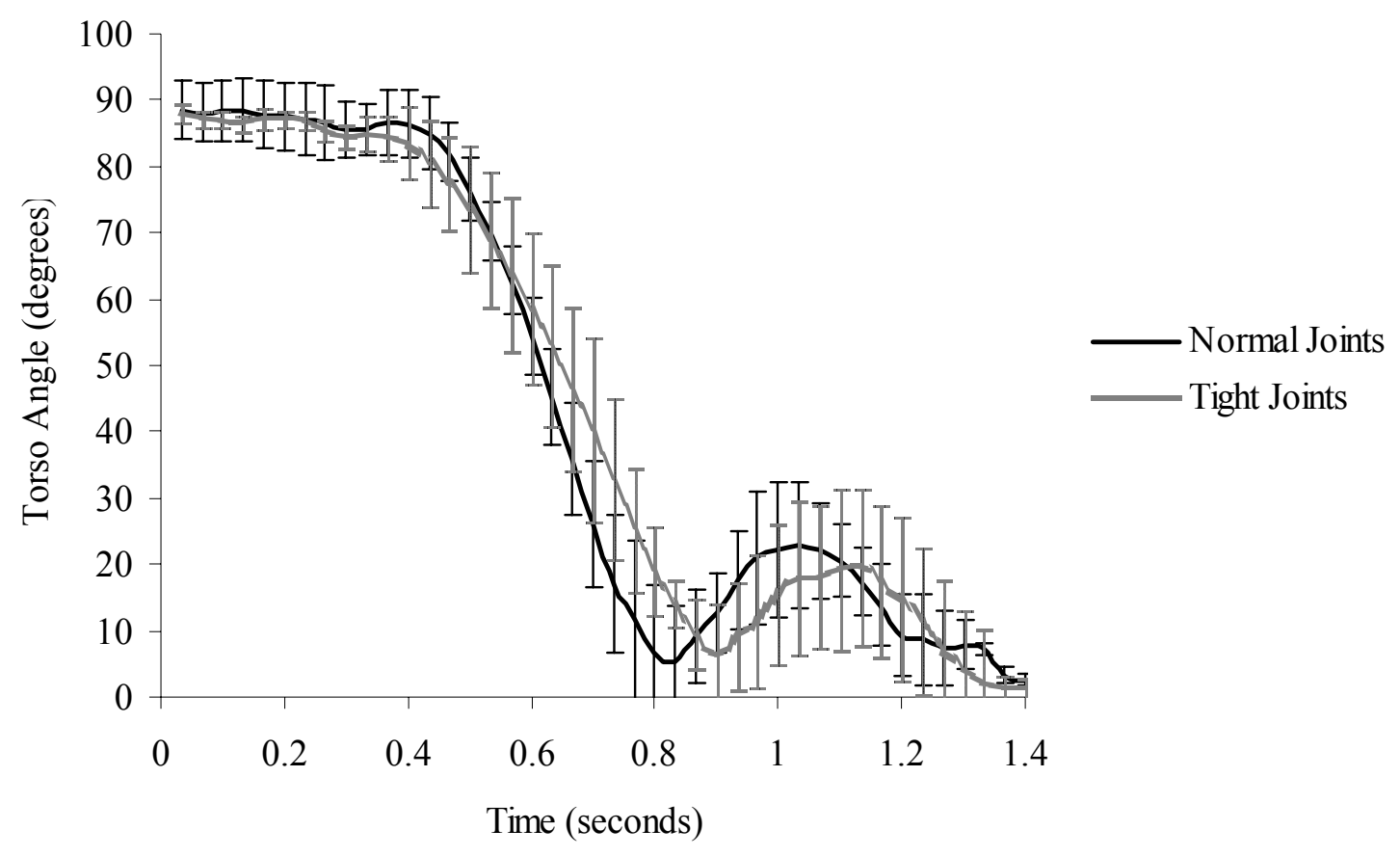

FIGURE 20 - Mean Torso Angle Relative to Ground over Time for 27" Falls from Standing onto Carpet with Normal and Tightened Joints. Error bars represent standard deviation.

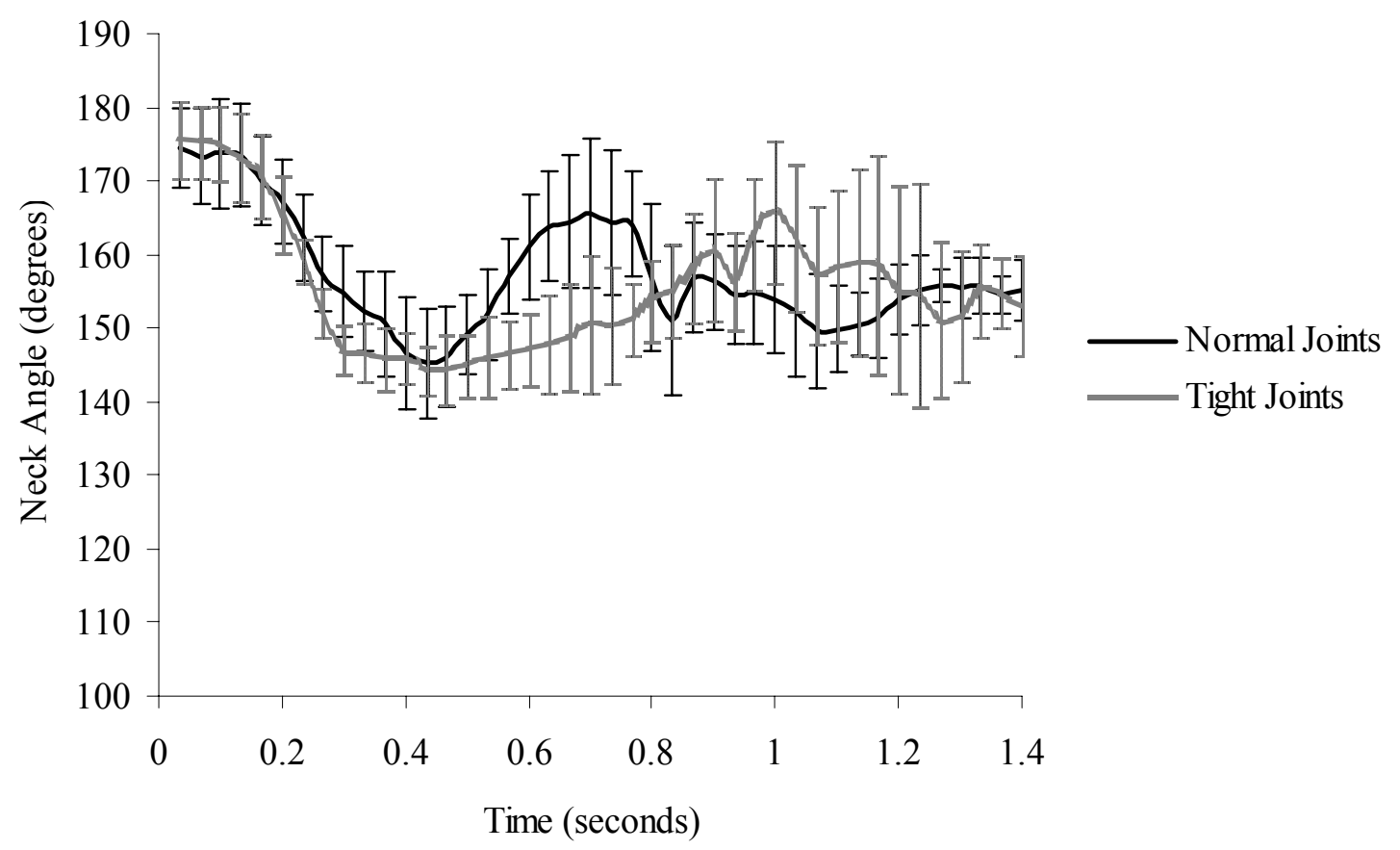

FIGURE 21 - Mean Neck Flexion Angle over Time for 27" Falls from Standing onto Carpet with Normal and Tightened Joints. Error bars represent standard deviation. 


\section{Linear Head Acceleration}

The mean peak resultant linear head acceleration across all falls from standing was $80.2 \mathrm{~g}(95 \% \mathrm{CI}$ : 77.0-83.5) (Figure 22). Overall the largest resultant linear head acceleration values occurred for 27 " falls with tight joints onto the linoleum over concrete surface. However the maximum value for a single trial was $130.6 \mathrm{~g}$ which occurred in an 18 " fall with normal joints onto the linoleum over concrete surface.

a. Effect of Height. For all falls with normal joint stiffness except those onto linoleum over concrete, the 27 " fall height was associated with significantly greater linear head accelerations than the 18 " fall height $(\mathrm{p}<0.001)$. For all falls with tight joints, the 27 " fall height was associated with significantly greater linear head accelerations than the 18 " fall height $(\mathrm{p}<0.001$ for playground foam, carpet, and linoleum over concrete surfaces; $p=0.019$ for linoleum over wood; $p=0.005$ for wood) (Table XVII).

b. Effect of Surface. For 18" falls with both normal joints and tight joints, wood and linoleum over concrete were associated with significantly greater linear head accelerations than linoleum over wood, playground foam, and carpet $(\mathrm{p}<0.001$ for all combinations except wood and linoleum over wood with normal joints for which $\mathrm{p}=$ $0.004)$. Additionally for 18 " falls with tight joints, linoleum over wood was associated with significantly greater accelerations than both carpet and playground foam $(\mathrm{p}<0.001)$, and carpet was associated with significantly greater accelerations than playground foam $(\mathrm{p}<0.001)$. For 27 " falls with normal joint stiffness, playground foam was associated with significantly lower linear head accelerations than linoleum over wood, wood, and linoleum over concrete $(\mathrm{p} \leq 0.001)$. Also, carpet was associated with significantly lower 
accelerations than linoleum over wood $(p=0.021)$ and wood $(p=0.001)$. For 27 ' falls with tight joint stiffness, linoleum over concrete was associated with significantly greater linear head accelerations than all other surfaces $(\mathrm{p}<0.001$ for linoleum over wood, playground foam, and carpet, and $\mathrm{p}=0.016$ for wood). Playground foam and carpet were associated with significantly lower accelerations than linoleum over wood $(\mathrm{p}<0.001$ for playground foam and $\mathrm{p}=0.007$ for carpet) and wood $(\mathrm{p}<0.001)$, and playground foam was associated with significantly lower linear head accelerations than carpet $(\mathrm{p}<0.001)$ (Table XVIII).

c. Effect of Joint Stiffness. For the 18" fall height, falls with tight joints were associated with significantly greater linear head accelerations than falls with normal joint stiffness for all surfaces except linoleum over concrete $(p<0.001$ for linoleum over wood, playground foam, and carpet; $\mathrm{p}=0.002$ for wood). For the 27 " fall height, falls with tight joints were associated with significantly greater linear head accelerations than falls with normal joint stiffness for playground foam $(p=0.025)$, carpet $(p=0.002)$, and linoleum over concrete $(\mathrm{p}=0.016)$ (Table XIX). 


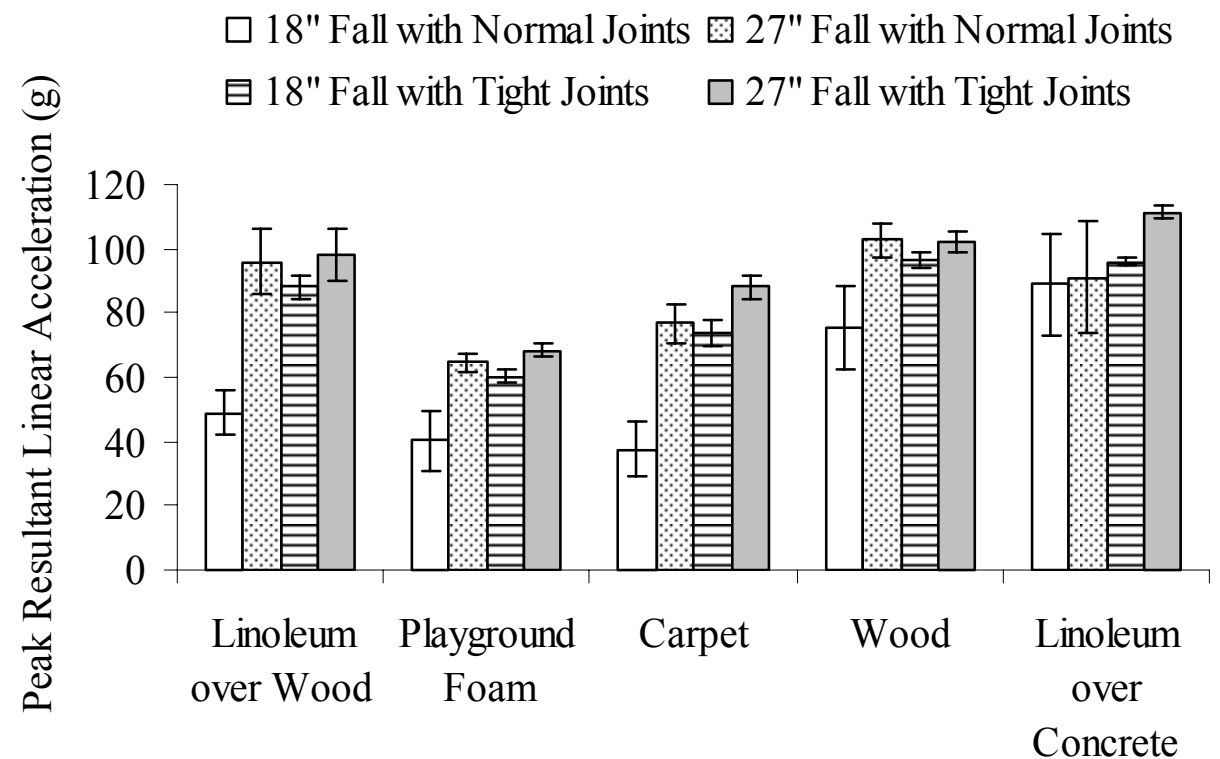

FIGURE 22 - Peak Resultant Linear Head Accelerations for Falls from Standing with Various Impact Surfaces, Fall Heights, and Joint Stiffness. Error bars represent 95\% CI.

\section{TABLE XVII}

SIGNIFICANT DIFFERENCES IN PEAK LINEAR HEAD ACCELERATIONS FOR VARIOUS HEIGHTS IN FALLS FROM STANDING

\begin{tabular}{|c|c|c|c|c|c|}
\hline & \multicolumn{2}{|c|}{ Normal Joints } & \multicolumn{2}{|c|}{ Tightened Joints } \\
\hline & & 18 & 27 & 18 & 27 \\
\hline \multirow{2}{*}{$\begin{array}{l}\text { Linoleum } \\
\text { over Wood }\end{array}$} & 18 & & $\mathrm{X}$ & & $\mathrm{X}$ \\
\hline & 27 & $\mathrm{X}$ & & $\mathrm{X}$ & \\
\hline \multirow{2}{*}{$\begin{array}{l}\text { Playground } \\
\text { Foam }\end{array}$} & 18 & & $\mathrm{X}$ & & $\mathrm{X}$ \\
\hline & 27 & $\mathrm{X}$ & & $\mathrm{X}$ & \\
\hline \multirow{2}{*}{ Carpet } & 18 & & $\mathrm{X}$ & & $\mathrm{X}$ \\
\hline & 27 & $X$ & & $\mathrm{X}$ & \\
\hline \multirow{2}{*}{ Wood } & 18 & & $\mathrm{X}$ & & $\mathrm{X}$ \\
\hline & 27 & $X$ & & $\mathrm{X}$ & \\
\hline \multirow{2}{*}{$\begin{array}{l}\text { Linoleum } \\
\text { over Concrete }\end{array}$} & 18 & & & & $\mathrm{X}$ \\
\hline & 27 & & & $\mathrm{X}$ & \\
\hline
\end{tabular}

"X" indicates significant difference $(\mathrm{p}<0.05)$ 
TABLE XVIII

SIGNIFICANT DIFFERENCES IN PEAK LINEAR HEAD ACCELERATIONS FOR VARIOUS SURFACES IN FALLS FROM STANDING

\begin{tabular}{|c|c|c|c|c|c|c|c|}
\hline & & & $\begin{array}{c}\text { Linoleum } \\
\text { over } \\
\text { Wood }\end{array}$ & $\begin{array}{c}\text { Playground } \\
\text { Foam }\end{array}$ & Carpet & Wood & $\begin{array}{c}\text { Linoleum } \\
\text { over } \\
\text { Concrete }\end{array}$ \\
\hline \multirow{10}{*}{ 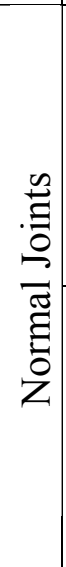 } & \multirow{5}{*}{18} & Linoleum over Wood & & & & $\mathrm{X}$ & $\mathrm{X}$ \\
\hline & & Playground Foam & & & & $\mathrm{X}$ & $\mathrm{X}$ \\
\hline & & Carpet & & & & $\mathrm{X}$ & $\mathrm{X}$ \\
\hline & & Wood & $\mathrm{X}$ & $\mathrm{X}$ & $\mathrm{X}$ & & \\
\hline & & Linoleum over Concrete & $\mathrm{X}$ & $\mathrm{X}$ & $\mathrm{X}$ & & \\
\hline & \multirow{5}{*}{27} & Linoleum over Wood & & $\mathrm{X}$ & $\mathrm{X}$ & & \\
\hline & & Playground Foam & $\mathrm{X}$ & & & $\mathrm{X}$ & $\mathrm{X}$ \\
\hline & & Carpet & $\mathrm{X}$ & & & $\mathrm{X}$ & \\
\hline & & Wood & & $\mathrm{X}$ & $\mathrm{X}$ & & \\
\hline & & Linoleum over Concrete & & $\mathrm{X}$ & & & \\
\hline \multirow{10}{*}{ 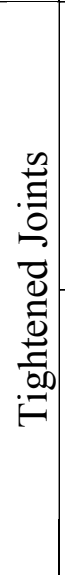 } & \multirow{5}{*}{18} & Linoleum over Wood & & $\mathrm{X}$ & $\mathrm{X}$ & $\mathrm{X}$ & $\mathrm{X}$ \\
\hline & & Playground Foam & $\mathrm{X}$ & & $\mathrm{X}$ & $\mathrm{X}$ & $\mathrm{X}$ \\
\hline & & Carpet & $\mathrm{X}$ & $\mathrm{X}$ & & $\mathrm{X}$ & $\mathrm{X}$ \\
\hline & & Wood & $\mathrm{X}$ & $\mathrm{X}$ & $\mathrm{X}$ & & \\
\hline & & Linoleum over Concrete & $\mathrm{X}$ & $\mathrm{X}$ & $\mathrm{X}$ & & \\
\hline & \multirow{5}{*}{27} & Linoleum over Wood & & $\mathrm{X}$ & $\mathrm{X}$ & & $\mathrm{X}$ \\
\hline & & Playground Foam & $\mathrm{X}$ & & $\mathrm{X}$ & $\mathrm{X}$ & $\mathrm{X}$ \\
\hline & & Carpet & $\mathrm{X}$ & $\mathrm{X}$ & & $\mathrm{X}$ & $\mathrm{X}$ \\
\hline & & Wood & & $\mathrm{X}$ & $\mathrm{X}$ & & $\mathrm{X}$ \\
\hline & & Linoleum over Concrete & $\mathrm{X}$ & $\mathrm{X}$ & $\mathrm{X}$ & $\mathrm{X}$ & \\
\hline
\end{tabular}

"X" indicates significant difference $(\mathrm{p}<0.05)$ 


\section{TABLE XIX}

SIGNIFICANT DIFFERENCES IN PEAK LINEAR HEAD ACCELERATIONS FOR VARIOUS JOINT CONDITIONS IN FALLS FROM STANDING

\begin{tabular}{|c|c|c|c|c|c|}
\hline & \multicolumn{2}{|c|}{18} & \multicolumn{2}{|c|}{27} \\
\hline & & $\begin{array}{c}\text { Normal } \\
\text { Joints }\end{array}$ & $\begin{array}{l}\text { Tightened } \\
\text { Joints }\end{array}$ & $\begin{array}{c}\text { Normal } \\
\text { Joints }\end{array}$ & $\begin{array}{l}\text { Tightened } \\
\text { Joints }\end{array}$ \\
\hline \multirow{2}{*}{$\begin{array}{l}\text { Linoleum } \\
\text { over Wood }\end{array}$} & Normal & & $\mathrm{X}$ & & \\
\hline & Tight & $\mathrm{X}$ & & & \\
\hline \multirow{2}{*}{$\begin{array}{l}\text { Playground } \\
\text { Foam }\end{array}$} & Normal & & X & & $\mathrm{X}$ \\
\hline & Tight & $\mathrm{X}$ & & $X$ & \\
\hline \multirow{2}{*}{ Carpet } & Normal & & $\mathrm{X}$ & & $\mathrm{X}$ \\
\hline & Tight & $\mathrm{X}$ & & X & \\
\hline \multirow{2}{*}{ Wood } & Normal & & $X$ & & \\
\hline & Tight & & & & \\
\hline \multirow{2}{*}{$\begin{array}{c}\text { Linoleum } \\
\text { over Concrete }\end{array}$} & Normal & & & & $\mathrm{X}$ \\
\hline & Tight & & & $X$ & \\
\hline
\end{tabular}

\section{Head Injury Criteria Assessment}

The mean $\mathrm{HIC}_{15}$ value across all falls from standing was 159 (95\% CI: 152-167) (Figure 23). The maximum $\mathrm{HIC}_{15}$ was 261 and occurred on a 27" fall with normal joints onto the linoleum over concrete surface. This value is well below the injury threshold of 390 for the 12-month-old ATD established by NHTSA.

a. Effect of Height. For all falls with normal joint stiffness except those onto linoleum over concrete, the 27 " fall height was associated with significantly greater $\mathrm{HIC}_{15}$ values than the 18 " fall height $(\mathrm{p}<0.001)$. For all falls with tight joints except those onto the wood surface, the 27 " fall height was associated with significantly greater $\mathrm{HIC}_{15}$ values than the 18 " fall height $(\mathrm{p}<0.001$ for playground foam and carpet, $\mathrm{p}=$ 0.003 for linoleum over wood; $p=0.008$ for linoleum over concrete) (Table XX). 
b. Effect of Surface. For 18" falls with both normal joints and tight joints, wood and linoleum over concrete were associated with significantly greater $\mathrm{HIC}_{15}$ values than all other surfaces $(\mathrm{p} \leq 0.001$ for all combinations except for wood and linoleum over wood with normal joints for which $\mathrm{p}=0.007$ ). Additionally, for 18 " falls with tight joints, linoleum over wood was associated with significantly greater $\mathrm{HIC}_{15}$ values than playground foam and carpet $(\mathrm{p}<0.001)$. For 27 " falls with normal joint stiffness, the only significant differences occurred for wood which was associated with significantly greater $\mathrm{HIC}_{15}$ values than playground foam $(\mathrm{p}=0.036)$ and linoleum over concrete $(\mathrm{p}=$ 0.034). For 27" falls with tight joints, linoleum over wood, wood, and linoleum over concrete were associated with significantly greater $\mathrm{HIC}_{15}$ values than playground foam ( $\mathrm{p}$ $<0.001$ for wood and linoleum over concrete, $\mathrm{p}=0.019$ for linoleum over wood) and carpet $(\mathrm{p} \leq 0.001)$ (Table XXI).

c. Effect of Joint Stiffness. For the 18" fall height, falls with tight joints were associated with significantly greater $\mathrm{HIC}_{15}$ values than falls with normal joint stiffness for all surfaces $(\mathrm{p}<0.001)$. For the 27 " fall height, falls with tight joints were associated with significantly greater $\mathrm{HIC}_{15}$ values than falls with normal joint stiffness for playground foam $(\mathrm{p}=0.036)$, but falls with tight joints were associated with significantly lower $\mathrm{HIC}_{15}$ values than falls with normal joint stiffness for wood $(\mathrm{p}=0.040)($ Table XXII). 


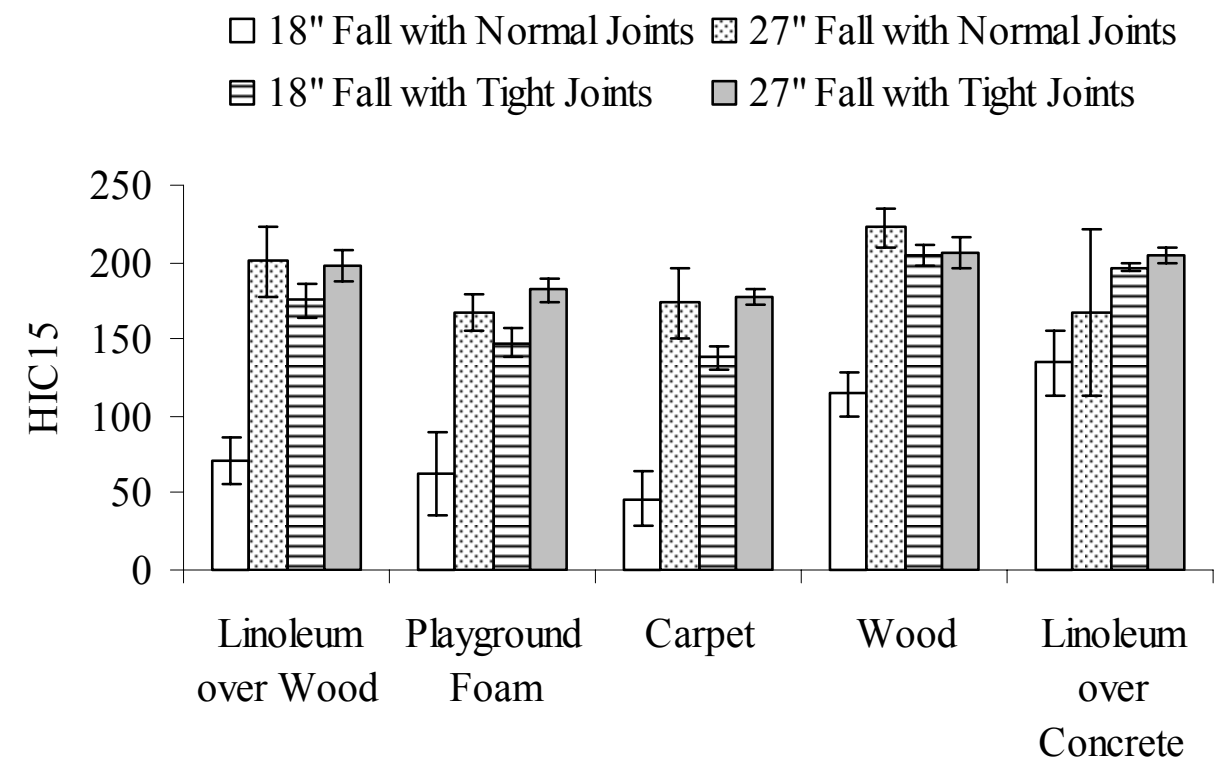

FIGURE 23 - Head Injury Criteria values for Falls from Standing with Various Impact Surfaces, Fall Heights, and Joint Stiffness. Error bars represent 95\% CI.

TABLE XX

SIGNIFICANT DIFFERENCES IN HIC15 VALUES FOR VARIOUS HEIGHTS IN

FALLS FROM STANDING

\begin{tabular}{|c|c|c|c|c|c|}
\hline & \multicolumn{2}{|c|}{ Normal Joints } & \multicolumn{2}{|c|}{ Tightened Joints } \\
\hline & & 18 & 27 & 18 & 27 \\
\hline \multirow{2}{*}{$\begin{array}{l}\text { Linoleum } \\
\text { over Wood }\end{array}$} & 18 & & $\mathrm{X}$ & & $\mathrm{X}$ \\
\hline & 27 & $\mathrm{X}$ & & $\mathrm{X}$ & \\
\hline \multirow{2}{*}{$\begin{array}{l}\text { Playground } \\
\text { Foam }\end{array}$} & 18 & & $\mathrm{X}$ & & $\mathrm{X}$ \\
\hline & 27 & $\mathrm{X}$ & & $\mathrm{X}$ & \\
\hline \multirow{2}{*}{ Carpet } & 18 & & $\mathrm{X}$ & & $X$ \\
\hline & 27 & $\mathrm{X}$ & & $\mathrm{X}$ & \\
\hline \multirow{2}{*}{ Wood } & 18 & & $\mathrm{X}$ & & \\
\hline & 27 & $\mathrm{X}$ & & & \\
\hline \multirow{2}{*}{$\begin{array}{l}\text { Linoleum } \\
\text { over Concrete }\end{array}$} & 18 & & & & $X$ \\
\hline & 27 & & & $\mathrm{X}$ & \\
\hline
\end{tabular}

" $\mathrm{X}$ " indicates significant difference $(\mathrm{p}<0.05)$ 
TABLE XXI

SIGNIFICANT DIFFERENCES IN HIC15 VALUES FOR VARIOUS SURFACES IN

FALLS FROM STANDING

\begin{tabular}{|c|c|c|c|c|c|c|c|}
\hline & & & $\begin{array}{c}\text { Linoleum } \\
\text { over } \\
\text { Wood }\end{array}$ & $\begin{array}{c}\text { Playground } \\
\text { Foam }\end{array}$ & Carpet & Wood & $\begin{array}{c}\text { Linoleum } \\
\text { over } \\
\text { Concrete }\end{array}$ \\
\hline \multirow{10}{*}{ 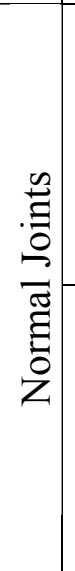 } & \multirow{5}{*}{18} & Linoleum over Wood & & & & $\mathrm{X}$ & $\mathrm{X}$ \\
\hline & & Playground Foam & & & & $\mathrm{X}$ & $\mathrm{X}$ \\
\hline & & Carpet & & & & $\mathrm{X}$ & $\mathrm{X}$ \\
\hline & & Wood & $\mathrm{X}$ & $\mathrm{X}$ & $\mathrm{X}$ & & \\
\hline & & Linoleum over Concrete & $\mathrm{X}$ & $\mathrm{X}$ & $\mathrm{X}$ & & \\
\hline & \multirow{5}{*}{27} & Linoleum over Wood & & & & & \\
\hline & & Playground Foam & & & & $\mathrm{X}$ & \\
\hline & & Carpet & & & & & \\
\hline & & Wood & & $\mathrm{X}$ & & & $\mathrm{X}$ \\
\hline & & Linoleum over Concrete & & & & $\mathrm{X}$ & \\
\hline \multirow{10}{*}{ 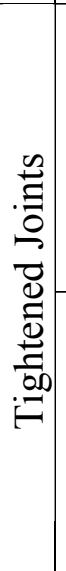 } & \multirow{5}{*}{18} & Linoleum over Wood & & $\mathrm{X}$ & $\mathrm{X}$ & $\mathrm{X}$ & $\mathrm{X}$ \\
\hline & & Playground Foam & $\mathrm{X}$ & & & $\mathrm{X}$ & $\mathrm{X}$ \\
\hline & & Carpet & $\mathrm{X}$ & & & $\mathrm{X}$ & $\mathrm{X}$ \\
\hline & & Wood & $\mathrm{X}$ & $\mathrm{X}$ & $\mathrm{X}$ & & \\
\hline & & Linoleum over Concrete & $\mathrm{X}$ & $\mathrm{X}$ & $\mathrm{X}$ & & \\
\hline & \multirow{5}{*}{27} & Linoleum over Wood & & $\mathrm{X}$ & $\mathrm{X}$ & & \\
\hline & & Playground Foam & $\mathrm{X}$ & & & $\mathrm{X}$ & $\mathrm{X}$ \\
\hline & & Carpet & $\mathrm{X}$ & & & $\mathrm{X}$ & $\mathrm{X}$ \\
\hline & & Wood & & $\mathrm{X}$ & $\mathrm{X}$ & & \\
\hline & & Linoleum over Concrete & & $\mathrm{X}$ & $\mathrm{X}$ & & \\
\hline
\end{tabular}

"X" indicates significant difference $(\mathrm{p}<0.05)$ 
TABLE XXII

SIGNIFICANT DIFFERENCES IN HIC15 VALUES FOR VARIOUS JOINT CONDITIONS IN FALLS FROM STANDING

\begin{tabular}{|c|c|c|c|c|c|}
\hline & \multicolumn{2}{|c|}{18} & \multicolumn{2}{|c|}{27} \\
\hline & & $\begin{array}{c}\text { Normal } \\
\text { Joints }\end{array}$ & $\begin{array}{l}\text { Tightened } \\
\text { Joints }\end{array}$ & $\begin{array}{c}\text { Normal } \\
\text { Joints }\end{array}$ & $\begin{array}{l}\text { Tightened } \\
\text { Joints }\end{array}$ \\
\hline \multirow{2}{*}{$\begin{array}{l}\text { Linoleum } \\
\text { over Wood }\end{array}$} & Normal & & $\mathrm{X}$ & & \\
\hline & Tight & $\mathrm{X}$ & & & \\
\hline \multirow{2}{*}{$\begin{array}{l}\text { Playground } \\
\text { Foam }\end{array}$} & Normal & & X & & $\mathrm{X}$ \\
\hline & Tight & $\mathrm{X}$ & & $\mathrm{X}$ & \\
\hline \multirow{2}{*}{ Carpet } & Normal & & $\mathrm{X}$ & & \\
\hline & Tight & $\mathrm{X}$ & & & \\
\hline \multirow{2}{*}{ Wood } & Normal & & $\mathrm{X}$ & & $\mathrm{X}$ \\
\hline & Tight & $\mathrm{X}$ & & $\mathrm{X}$ & \\
\hline \multirow{2}{*}{$\begin{array}{l}\text { Linoleum } \\
\text { over Concrete }\end{array}$} & Normal & & $X$ & & \\
\hline & Tight & $\mathrm{X}$ & & & \\
\hline
\end{tabular}

\section{Angular Head Acceleration}

Angular head accelerations were measured in both the anterior-posterior (AP) and medial-lateral (ML) directions. The mean peak angular head accelerations across all falls from standing were 6,581 $\mathrm{rad} / \mathrm{sec}^{2}$ (95\% CI: 6,307-6,854) and 1,813 $\mathrm{rad} / \mathrm{sec}^{2}(95 \% \mathrm{CI}$ : 1,601-2,026) for the AP and ML directions, respectively (Figures 24 and 25). For all falls from standing, the peak angular head accelerations (ML direction only) along with the corresponding peak changes in angular velocity were well below thresholds for diffuse axonal injury (Figure 26).

a. Effect of Height. The effect of height on AP angular head acceleration is similar to its effect on linear head acceleration. For all falls with normal joint stiffness except those onto linoleum over concrete, the 27 " fall height was associated with 
significantly greater AP angular head accelerations than the 18 " fall height $(\mathrm{p}<0.001$ for linoleum over wood, playground foam, and carpet; $\mathrm{p}=0.021$ for wood). For all falls with tight joints, the 27" fall height was associated with significantly greater AP angular head accelerations than the 18 " fall height $(\mathrm{p}<0.001$ for carpet and linoleum over concrete; $p=0.023$ for linoleum over wood $; p=0.013$ for playground foam; $p=0.015$ for wood) (Table XXIII).

For ML angular head accelerations, the 27 " fall height was associated with significantly greater values than the 18 " fall height for carpet $(\mathrm{p}=0.027)$ and wood $(\mathrm{p}=$ $0.018)$ in falls with normal joint stiffness, and for playground foam $(\mathrm{p}=0.001)$ in falls with tight joint stiffness. The 18 " fall height was associated with significantly greater ML angular accelerations than the 27" fall height for falls with normal joints onto linoleum over concrete $(p=0.010)$. There were no significant differences in ML angular head accelerations due to fall height for the linoleum over wood surface.

b. Effect of Surface. For 18" falls with both normal and tight joint stiffness, AP angular head accelerations were significantly greater for falls onto wood and linoleum over concrete than for falls onto linoleum over wood, playground foam, and carpet ( $\mathrm{p}<$ 0.001 for all combinations except wood and linoleum over wood for which $\mathrm{p}=0.011$ ). Additionally for 18 " falls with tight joints, linoleum over wood was associated with significantly greater accelerations than both carpet and playground foam $(\mathrm{p}<0.001)$, and carpet was associated with significantly greater accelerations than playground foam ( $\mathrm{p}<$ 0.001). For 27 " falls with normal joint stiffness, playground foam was associated with significantly lower AP angular accelerations than linoleum over wood $(\mathrm{p}<0.001)$, wood $(\mathrm{p}=0.025)$, and linoleum over concrete $(\mathrm{p}=0.002)$. Also, carpet was associated with 
significantly lower accelerations than linoleum over wood $(p=0.002)$ and linoleum over concrete $(p=0.024)$. For 27 " falls with tight joint stiffness, linoleum over concrete was associated with significantly greater AP angular head accelerations than all other surfaces $(\mathrm{p} \leq 0.001)$. Also, playground foam was associated with significantly lower AP accelerations than linoleum over wood, carpet, and wood ( $\mathrm{p}<0.001)$; and carpet was associated with significantly lower AP accelerations than linoleum over wood $(p=0.003)$ and $\operatorname{wood}(\mathrm{p}<0.001)$.

For 18" falls with normal joint stiffness, ML angular head accelerations were significantly greater for falls onto linoleum over concrete than for falls onto linoleum over wood, playground foam, and carpet $(\mathrm{p} \leq 0.001)$. Also, wood was associated with significantly greater ML accelerations than linoleum over wood $(p=0.046)$ and carpet $(p$ $=0.047$ ). For 18 " falls with tight joints, the only significant differences occurred for the carpet surface which was associated with significantly greater ML accelerations than playground foam $(\mathrm{p}=0.030)$, wood $(\mathrm{p}=0.021)$, and linoleum over concrete $(\mathrm{p}=0.024)$. For 27" falls with normal joints, wood was associated with significantly greater ML angular head accelerations than linoleum over wood, playground foam, and linoleum over concrete $(\mathrm{p} \leq 0.001)$ and carpet $(\mathrm{p}=0.009)$. For 27 ' falls with tight joints, no significant differences were found except for falls onto playground foam which were associated with significantly greater ML accelerations than linoleum over concrete $(\mathrm{p}=$ 0.039) (Table XXIV).

c. Effect of Joint Stiffness. AP angular head accelerations were significantly greater for falls with tight joints than falls with normal joint stiffness for all surfaces with the 18 " fall height $(\mathrm{p}<0.001$ for linoleum over wood, playground foam, carpet, and 
wood; $p=0.008$ for linoleum over concrete), and only for the carpet $(p<0.001)$, wood $(p$ $<0.001)$, and linoleum over concrete $(\mathrm{p}=0.004)$ with the 27 " fall height.

ML angular head accelerations were significantly greater for falls with tight joints than falls with normal joint stiffness only for 18 " falls onto carpet $(\mathrm{p}=0.002)$ and for 27 " falls onto playground foam $(\mathrm{p}<0.001)$. However, falls with tight joints were associated with significantly lower ML angular head accelerations than falls with normal joints for 18 " falls onto wood $(\mathrm{p}=0.033)$ and linoleum over concrete $(\mathrm{p}<0.001)$, and for 27 " falls onto $\operatorname{wood}(p=0.001)($ Table XXV).

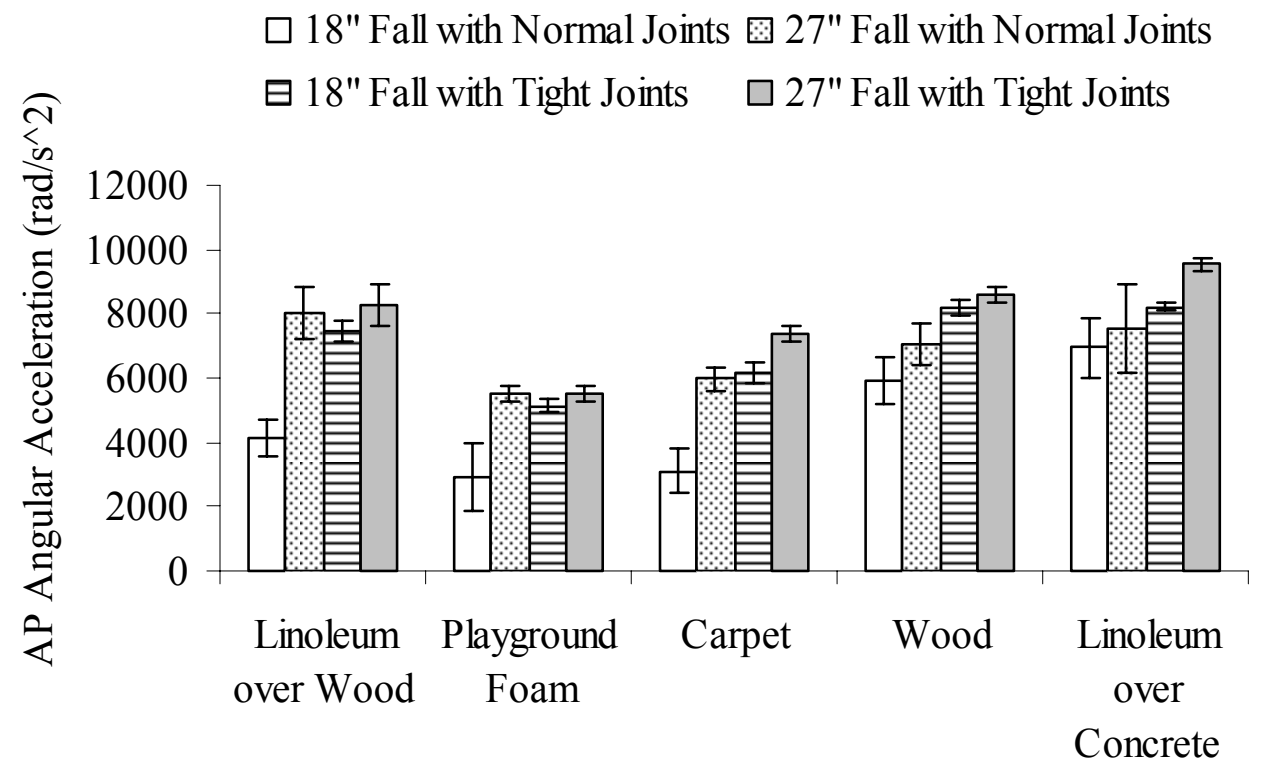

FIGURE 24 - Anterior-Posterior Angular Head Accelerations for Falls from Standing with Various Impact Surfaces, Fall Heights, and Joint Stiffness. Error bars represent 95\% CI. 


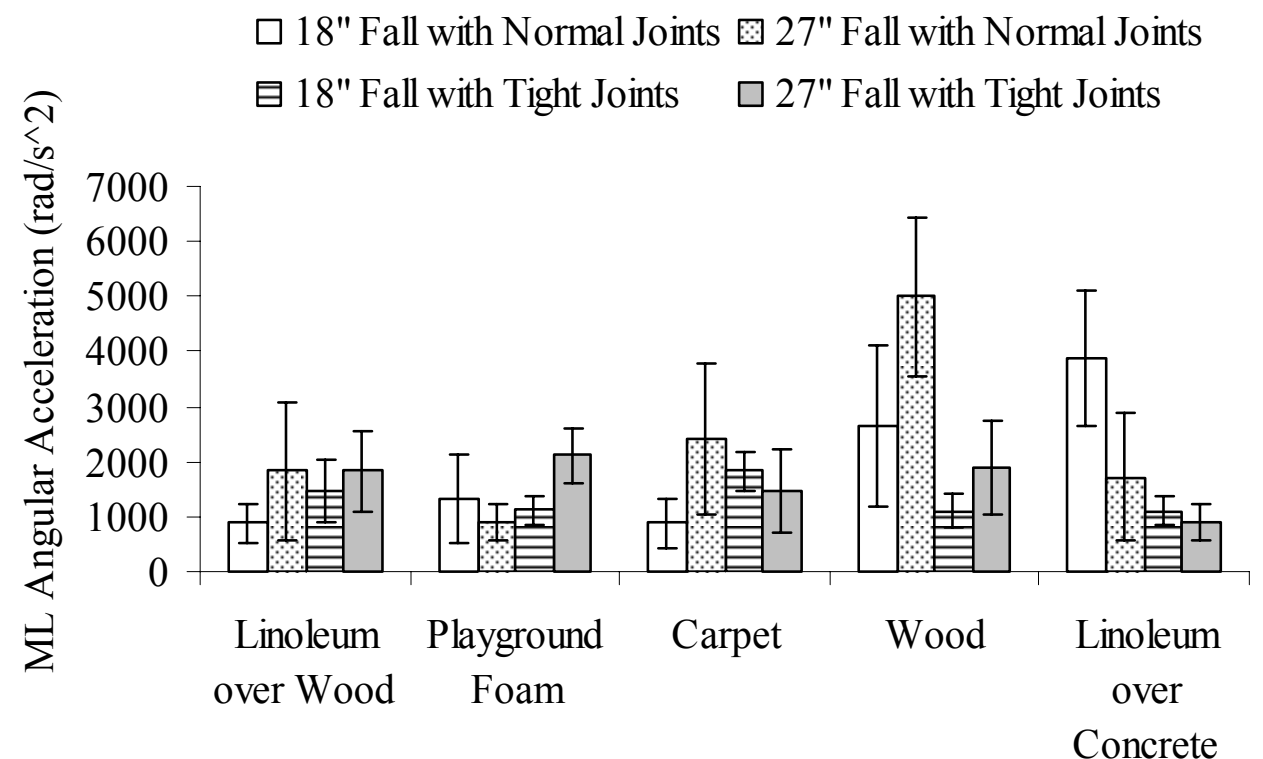

FIGURE 25 - Medial-Lateral Angular Head Accelerations for Falls from Standing with Various Impact Surfaces, Fall Heights, and Joint Stiffness. Error bars represent 95\% CI.

TABLE XXIII

\section{SIGNIFICANT DIFFERENCES IN ANGULAR HEAD ACCELERATIONS FOR}

VARIOUS HEIGHTS IN FALLS FROM STANDING

\begin{tabular}{|c|c|c|c|c|c|}
\hline & \multicolumn{2}{|c|}{ Normal Joints } & \multicolumn{2}{|c|}{ Tightened Joints } \\
\hline & & 18 & 27 & 18 & 27 \\
\hline \multirow{2}{*}{$\begin{array}{l}\text { Linoleum } \\
\text { over Wood }\end{array}$} & 18 & & AP & & AP \\
\hline & 27 & $\mathrm{AP}$ & & AP & \\
\hline \multirow{2}{*}{$\begin{array}{l}\text { Playground } \\
\text { Foam }\end{array}$} & 18 & & $\mathrm{AP}$ & & $\mathrm{AP}, \mathrm{ML}$ \\
\hline & 27 & AP & & AP,ML & \\
\hline \multirow{2}{*}{ Carpet } & 18 & & AP,ML & & $\mathrm{AP}$ \\
\hline & 27 & AP,ML & & $\mathrm{AP}$ & \\
\hline \multirow{2}{*}{ Wood } & 18 & & AP,ML & & AP \\
\hline & 27 & AP,ML & & $\mathrm{AP}$ & \\
\hline \multirow{2}{*}{$\begin{array}{l}\text { Linoleum } \\
\text { over Concrete }\end{array}$} & 18 & & ML & & $\mathrm{AP}$ \\
\hline & 27 & ML & & AP & \\
\hline
\end{tabular}

"AP" and "ML" indicate significant difference $(\mathrm{p}<0.05)$ in anterior-posterior and medial lateral accelerations, respectively 
TABLE XXIV

SIGNIFICANT DIFFERENCES IN ANGULAR HEAD ACCELERATIONS FOR

VARIOUS SURFACES IN FALLS FROM STANDING

\begin{tabular}{|c|c|c|c|c|c|c|c|}
\hline & & & $\begin{array}{c}\text { Linoleum } \\
\text { over } \\
\text { Wood }\end{array}$ & $\begin{array}{l}\text { Playground } \\
\text { Foam }\end{array}$ & Carpet & Wood & $\begin{array}{c}\text { Linoleum } \\
\text { over } \\
\text { Concrete }\end{array}$ \\
\hline \multirow{10}{*}{ 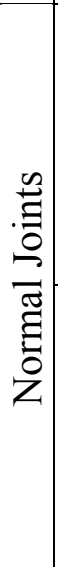 } & \multirow{5}{*}{18} & Linoleum over Wood & & & & AP,ML & $\mathrm{AP}, \mathrm{ML}$ \\
\hline & & Playground Foam & & & & AP & $\mathrm{AP}, \mathrm{ML}$ \\
\hline & & Carpet & & & & AP,ML & $\mathrm{AP}, \mathrm{ML}$ \\
\hline & & Wood & $\mathrm{AP}, \mathrm{ML}$ & $\mathrm{AP}$ & $\mathrm{AP}, \mathrm{ML}$ & & \\
\hline & & Linoleum over Concrete & AP,ML & AP,ML & $\mathrm{AP}, \mathrm{ML}$ & & \\
\hline & \multirow{5}{*}{27} & Linoleum over Wood & & AP & AP & ML & \\
\hline & & Playground Foam & AP & & & $\mathrm{AP}, \mathrm{ML}$ & $\mathrm{AP}$ \\
\hline & & Carpet & $\mathrm{AP}$ & & & ML & $\mathrm{AP}$ \\
\hline & & Wood & ML & $\mathrm{AP}, \mathrm{ML}$ & ML & & ML \\
\hline & & Linoleum over Concrete & & AP & $\mathrm{AP}$ & ML & \\
\hline \multirow{10}{*}{ 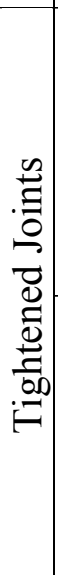 } & \multirow{5}{*}{18} & Linoleum over Wood & & AP & $\mathrm{AP}$ & $\mathrm{AP}$ & AP \\
\hline & & Playground Foam & $\mathrm{AP}$ & & $\mathrm{AP}, \mathrm{ML}$ & $\mathrm{AP}$ & $\mathrm{AP}$ \\
\hline & & Carpet & AP & AP,ML & & AP,ML & AP,ML \\
\hline & & Wood & AP & AP & $\mathrm{AP}, \mathrm{ML}$ & & \\
\hline & & Linoleum over Concrete & $\mathrm{AP}$ & $\mathrm{AP}$ & AP,ML & & \\
\hline & \multirow{5}{*}{27} & Linoleum over Wood & & AP & AP & & AP \\
\hline & & Playground Foam & $\mathrm{AP}$ & & AP & AP & $\mathrm{AP}, \mathrm{ML}$ \\
\hline & & Carpet & $\mathrm{AP}$ & $\mathrm{AP}$ & & $\mathrm{AP}$ & $\mathrm{AP}$ \\
\hline & & Wood & & $\mathrm{AP}$ & $\mathrm{AP}$ & & $\mathrm{AP}$ \\
\hline & & Linoleum over Concrete & AP & $\mathrm{AP}, \mathrm{ML}$ & $\mathrm{AP}$ & $\mathrm{AP}$ & \\
\hline
\end{tabular}

"AP" and "ML" indicate significant difference $(\mathrm{p}<0.05)$ in anterior-posterior and medial lateral accelerations, respectively 


\section{TABLE XXV}

SIGNIFICANT DIFFERENCES IN ANGULAR HEAD ACCELERATIONS FOR

VARIOUS JOINT CONDITIONS IN FALLS FROM STANDING

\begin{tabular}{|c|c|c|c|c|c|}
\hline & \multicolumn{2}{|c|}{18} & \multicolumn{2}{|c|}{27} \\
\hline & & \multirow[t]{2}{*}{$\begin{array}{c}\text { Normal } \\
\text { Joints }\end{array}$} & \multirow{2}{*}{$\begin{array}{c}\text { Tightened } \\
\text { Joints } \\
\text { AP }\end{array}$} & \multirow[t]{2}{*}{$\begin{array}{c}\text { Normal } \\
\text { Joints }\end{array}$} & \multirow[t]{2}{*}{$\begin{array}{l}\text { Tightened } \\
\text { Joints }\end{array}$} \\
\hline \multirow{2}{*}{$\begin{array}{l}\text { Linoleum } \\
\text { over Wood }\end{array}$} & Normal & & & & \\
\hline & Tight & $\mathrm{AP}$ & & & \\
\hline \multirow{2}{*}{$\begin{array}{l}\text { Playground } \\
\text { Foam }\end{array}$} & Normal & & $\mathrm{AP}$ & & ML \\
\hline & Tight & AP & & ML & \\
\hline \multirow{2}{*}{ Carpet } & Normal & & $\mathrm{AP}, \mathrm{ML}$ & & AP \\
\hline & Tight & $\mathrm{AP}, \mathrm{ML}$ & & $\mathrm{AP}$ & \\
\hline \multirow{2}{*}{ Wood } & Normal & & AP,ML & & $\mathrm{AP}, \mathrm{ML}$ \\
\hline & Tight & $\mathrm{AP}, \mathrm{ML}$ & & AP,ML & \\
\hline \multirow{2}{*}{$\begin{array}{c}\text { Linoleum } \\
\text { over Concrete }\end{array}$} & Normal & & $\mathrm{AP}, \mathrm{ML}$ & & $\mathrm{AP}$ \\
\hline & Tight & $\mathrm{AP}, \mathrm{ML}$ & & AP & \\
\hline
\end{tabular}

"AP" and "ML" indicate significant difference $(\mathrm{p}<0.05)$ in anterior-posterior and medial lateral accelerations, respectively

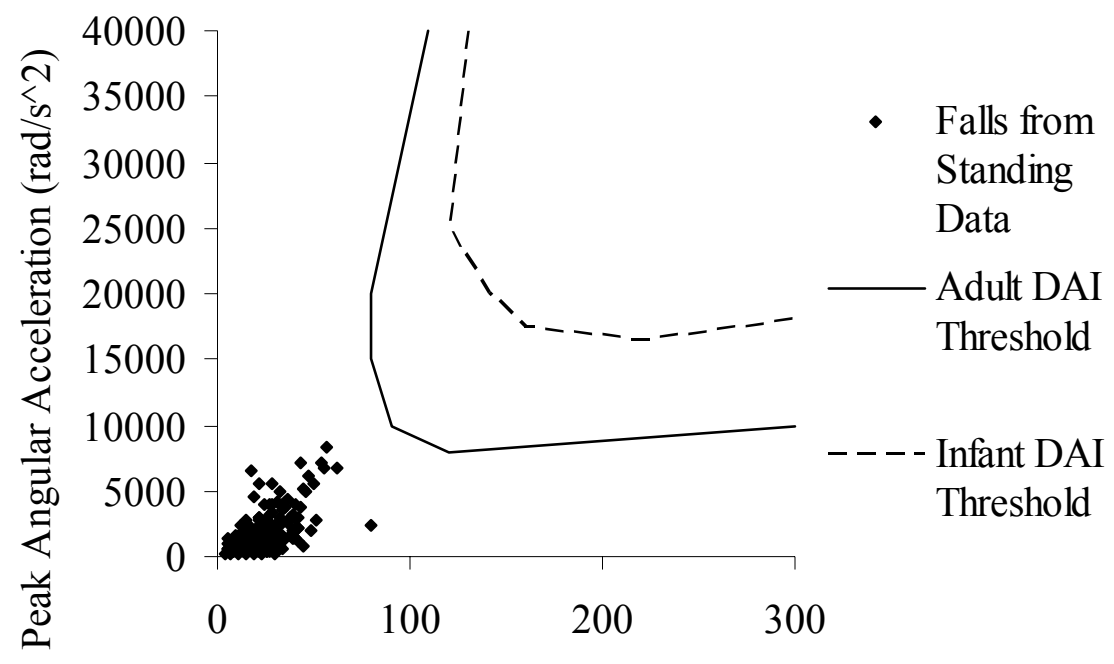

Peak Change in Angular Velocity ( $\mathrm{rad} / \mathrm{s})$

FIGURE 26 - Experimental Values of Angular Acceleration and Change in Angular Velocity in Falls from Standing Compared to Diffuse Axonal Injury Criteria (Margulies, 1992). (Adult and infant thresholds are a function of brain mass). 


\section{Impact Duration}

The mean impact duration across all trials was $17.4 \mathrm{msec}$ (95\% CI: 16.9-17.9) (Figure 27). The smallest impact duration was $12.1 \mathrm{msec}$ and occurred during a fall with tight joints from a 27" height onto linoleum over concrete.

a. Effect of Height. Few significant differences were found in impact durations for different heights. The 18 " fall height was associated with significantly longer impact durations than the 27 " fall height for falls with normal joint stiffness onto linoleum over wood, carpet, and playground foam $(\mathrm{p}<0.001)$, and for falls with tight joint stiffness onto linoleum over concrete $(\mathrm{p}=0.002)$ (Table XXVI).

b. Effect of Surface. For all combinations of falls, playground foam and carpet were associated with significantly longer impact durations than the other surfaces $(\mathrm{p}<$ 0.001). Additionally, for the 18 " falls with normal joint stiffness, carpet was associated with significantly longer durations than playground foam $(\mathrm{p}<0.001)$; and linoleum over wood was associated with significantly longer durations than wood and linoleum over concrete $(\mathrm{p}<0.001)$. For both 18 " and 27 " falls with tight joint stiffness, playground foam was associated with significantly longer durations than carpet $(\mathrm{p}<0.001)$ (Table XXVII).

c. Effect of Joint Stiffness. Significantly longer impact durations were found for falls with normal joint stiffness compared to falls with tight joint stiffness for 18 " falls onto carpet and linoleum over wood $(\mathrm{p}<0.001)$ and for 27 " falls onto carpet $(\mathrm{p}=0.048)$. Conversely, significantly shorter impact durations were found for falls with normal joint 
stiffness compared to falls with tight joint stiffness for 18 " falls onto linoleum over concrete $(\mathrm{p}<0.001)$ and for 27 " falls onto playground foam $(\mathrm{p}<0.001)$ (Table XXVIII).

18" Fall with Normal Joints 0 27" Fall with Normal Joints 目 18" Fall with Tight Joints $\square 27$ " Fall with Tight Joints

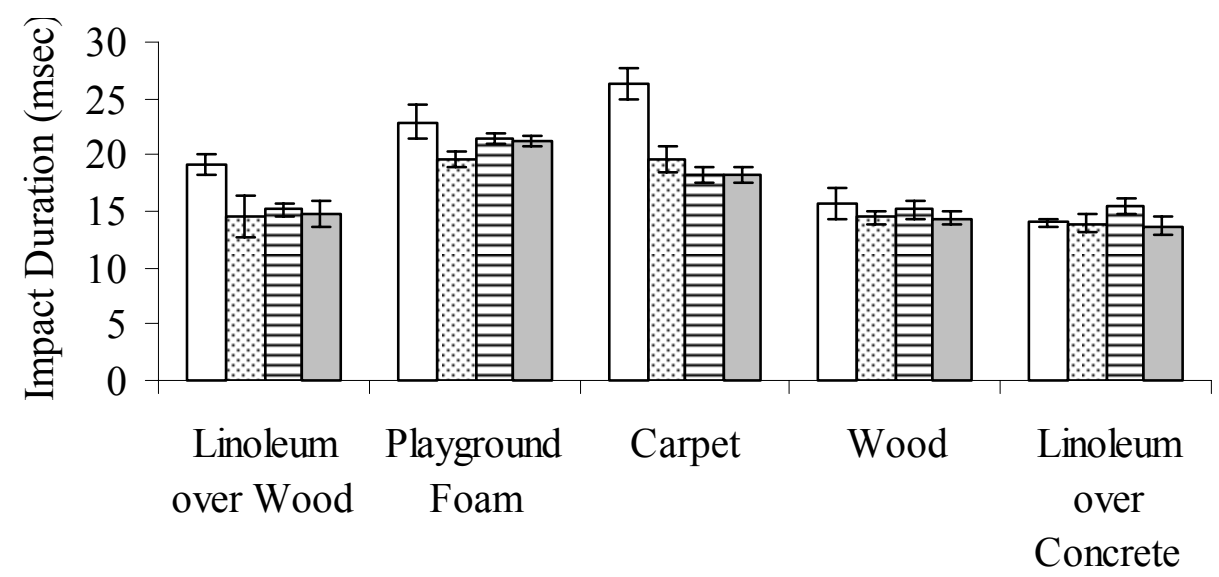

FIGURE 27 - Head Impact Durations for Falls from Standing with Various Impact Surfaces, Fall Heights, and Joint Stiffness. Error bars represent 95\% CI.

TABLE XXVI

SIGNIFICANT DIFFERENCES IN HEAD IMPACT DURATIONS FOR VARIOUS HEIGHTS IN FALLS FROM STANDING

\begin{tabular}{|c|c|c|c|c|c|}
\hline & \multicolumn{2}{|c|}{ Normal Joints } & \multicolumn{2}{|c|}{ Tightened Joints } \\
\hline & & 18 & 27 & 18 & 27 \\
\hline \multirow{2}{*}{$\begin{array}{l}\text { Linoleum } \\
\text { over Wood }\end{array}$} & 18 & & $\mathrm{X}$ & & \\
\hline & 27 & $\mathrm{X}$ & & & \\
\hline \multirow{2}{*}{$\begin{array}{l}\text { Playground } \\
\text { Foam }\end{array}$} & 18 & & $\mathrm{X}$ & & \\
\hline & 27 & $\mathrm{X}$ & & & \\
\hline \multirow{2}{*}{ Carpet } & 18 & & $\mathrm{X}$ & & \\
\hline & 27 & $\mathrm{X}$ & & & \\
\hline \multirow{2}{*}{ Wood } & 18 & & & & \\
\hline & 27 & & & & \\
\hline \multirow{2}{*}{$\begin{array}{l}\text { Linoleum } \\
\text { over Concrete }\end{array}$} & 18 & & & & $\mathrm{X}$ \\
\hline & 27 & & & $\mathrm{X}$ & \\
\hline
\end{tabular}

" $\mathrm{X}$ " indicates significant difference $(\mathrm{p}<0.05)$ 
TABLE XXVII

SIGNIFICANT DIFFERENCES IN HEAD IMPACT DURATIONS FOR VARIOUS

SURFACES IN FALLS FROM STANDING

\begin{tabular}{|c|c|c|c|c|c|c|c|}
\hline & & & $\begin{array}{c}\text { Linoleum } \\
\text { over } \\
\text { Wood }\end{array}$ & $\begin{array}{c}\text { Playground } \\
\text { Foam }\end{array}$ & Carpet & Wood & $\begin{array}{c}\text { Linoleum } \\
\text { over } \\
\text { Concrete }\end{array}$ \\
\hline \multirow{10}{*}{ 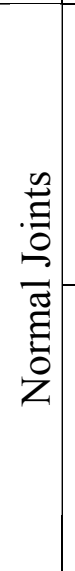 } & \multirow{5}{*}{18} & Linoleum over Wood & & $\mathrm{X}$ & $\mathrm{X}$ & $\mathrm{X}$ & $\mathrm{X}$ \\
\hline & & Playground Foam & $\mathrm{X}$ & & $\mathrm{X}$ & $\mathrm{X}$ & $\mathrm{X}$ \\
\hline & & Carpet & $\mathrm{X}$ & $\mathrm{X}$ & & $\mathrm{X}$ & \\
\hline & & Wood & $\mathrm{X}$ & $\mathrm{X}$ & $\mathrm{X}$ & & \\
\hline & & Linoleum over Concrete & $\mathrm{X}$ & $\mathrm{X}$ & $\mathrm{X}$ & & \\
\hline & \multirow{5}{*}{27} & Linoleum over Wood & & $\mathrm{X}$ & $\mathrm{X}$ & & \\
\hline & & Playground Foam & $\mathrm{X}$ & & & $\mathrm{X}$ & $\mathrm{X}$ \\
\hline & & Carpet & $\mathrm{X}$ & & & $\mathrm{X}$ & \\
\hline & & Wood & & $\mathrm{X}$ & $\mathrm{X}$ & & \\
\hline & & Linoleum over Concrete & & $\mathrm{X}$ & $\mathrm{X}$ & & \\
\hline \multirow{10}{*}{ 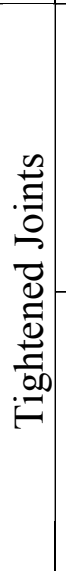 } & \multirow{5}{*}{18} & Linoleum over Wood & & $\mathrm{X}$ & $\mathrm{X}$ & & \\
\hline & & Playground Foam & $\mathrm{X}$ & & $\mathrm{X}$ & $\mathrm{X}$ & $\mathrm{X}$ \\
\hline & & Carpet & $\mathrm{X}$ & $\mathrm{X}$ & & $\mathrm{X}$ & \\
\hline & & Wood & & $\mathrm{X}$ & $\mathrm{X}$ & & \\
\hline & & Linoleum over Concrete & & $\mathrm{X}$ & $\mathrm{X}$ & & \\
\hline & \multirow{5}{*}{27} & Linoleum over Wood & & $\mathrm{X}$ & $\mathrm{X}$ & & \\
\hline & & Playground Foam & $\mathrm{X}$ & & $\mathrm{X}$ & $\mathrm{X}$ & $\mathrm{X}$ \\
\hline & & Carpet & $\mathrm{X}$ & $\mathrm{X}$ & & $\mathrm{X}$ & \\
\hline & & Wood & & $\mathrm{X}$ & $\mathrm{X}$ & & \\
\hline & & Linoleum over Concrete & & $\mathrm{X}$ & $\mathrm{X}$ & & \\
\hline
\end{tabular}

" $\mathrm{X}$ " indicates significant difference $(\mathrm{p}<0.05)$ 
TABLE XXVIII

SIGNIFICANT DIFFERENCES IN HEAD IMPACT DURATIONS FOR VARIOUS JOINT CONDITIONS IN FALLS FROM STANDING

\begin{tabular}{|c|c|c|c|c|c|}
\hline \multicolumn{2}{|c|}{} & \multicolumn{2}{c|}{18} & \multicolumn{2}{c|}{27} \\
\cline { 3 - 6 } \multicolumn{2}{|c|}{} & $\begin{array}{c}\text { Normal } \\
\text { Joints }\end{array}$ & $\begin{array}{c}\text { Tightened } \\
\text { Joints }\end{array}$ & $\begin{array}{c}\text { Normal } \\
\text { Joints }\end{array}$ & $\begin{array}{c}\text { Tightened } \\
\text { Joints }\end{array}$ \\
\hline $\begin{array}{c}\text { Linoleum } \\
\text { over Wood }\end{array}$ & Normal & & $\mathrm{X}$ & & \\
\cline { 2 - 6 } $\begin{array}{c}\text { Playground } \\
\text { Foam }\end{array}$ & Tight & $\mathrm{X}$ & & & \\
\hline \multirow{2}{*}{ Carpet } & Tight & & & $\mathrm{X}$ & $\mathrm{X}$ \\
\cline { 2 - 6 } & Normal & & $\mathrm{X}$ & & $\mathrm{X}$ \\
\hline \multirow{2}{*}{ Wood } & Normal & $\mathrm{X}$ & & $\mathrm{X}$ & \\
\cline { 2 - 6 } & Tight & & & & \\
\hline $\begin{array}{c}\text { Linoleum } \\
\text { over Concrete }\end{array}$ & Normal & & $\mathrm{X}$ & & \\
\cline { 2 - 6 } & Tight & $\mathrm{X}$ & & & \\
\hline
\end{tabular}

"X" indicates significant difference $(\mathrm{p}<0.05)$

7. Neck Injury Assessment

For each trial, neck injury measures $\left(\mathrm{N}_{\mathrm{ij}}\right.$ values) were computed for four combined loading conditions on the neck: tension-flexion $\left(\mathrm{N}_{\mathrm{TF}}\right)$, tension-extension $\left(\mathrm{N}_{\mathrm{TE}}\right)$, compression-flexion $\left(\mathrm{N}_{\mathrm{CF}}\right)$, and compression-extension $\left(\mathrm{N}_{\mathrm{CE}}\right)$. The mean peak $\mathrm{N}_{\mathrm{TF}}, \mathrm{N}_{\mathrm{TE}}$, $\mathrm{N}_{\mathrm{CF}}$, and $\mathrm{N}_{\mathrm{CE}}$ values across all trials were 0.10 (95\% CI: 0.09-0.11), 0.15 (95\% CI: 0.140.17), 0.12 (95\% CI: 0.11-0.13), and 0.13 (95\% CI: 0.12-15), respectively (Figures 28 31). The mean peak $\mathrm{N}_{\mathrm{TF}}, \mathrm{N}_{\mathrm{TE}}, \mathrm{N}_{\mathrm{CF}}$, and $\mathrm{N}_{\mathrm{CE}}$ values by fall height, joint stiffness, and surface type are shown in Table VII. The $\mathrm{N}_{\mathrm{ij}}$ values are normalized so that a value of $\mathrm{N}_{\mathrm{ij}}$ $=1$ represents a threshold for neck injury. This threshold was not exceeded in any of the falls from standing (Figure 32). 
a. Effect of Height. The effect of height in falls with normal joint stiffness was generally opposite the effect in falls with tight joint stiffness. For falls with normal joint stiffness, the 18 " fall height was associated with significantly greater $\mathrm{N}_{\mathrm{TF}}$ and $\mathrm{N}_{\mathrm{CF}}$ values than the 27 " fall height for falls onto all surfaces $\left(\mathrm{p}<0.001\right.$ for all cases except $\mathrm{N}_{\mathrm{TF}}$ with carpet where $\mathrm{p}=0.015$ and $\mathrm{N}_{\mathrm{CF}}$ with linoleum over concrete where $\mathrm{p}=0.002$ ). The 18 " fall height was also associated with significantly greater $\mathrm{N}_{\mathrm{CE}}$ values than the 27 " fall height for falls onto playground foam $(p=0.022)$, carpet $(p<0.001)$, wood $(p<0.001)$, and linoleum over concrete $(\mathrm{p}<0.001)$. However, the 27 " fall height was associated with significantly greater $\mathrm{N}_{\mathrm{TE}}$ values for falls onto wood $(\mathrm{p}<0.001)$. For falls with tight joint stiffness, the 27 " fall height was associated with significantly greater $\mathrm{N}_{\mathrm{TF}}$ values than the 18 " fall height for falls onto linoleum over wood $(\mathrm{p}=0.044)$ and linoleum over concrete $(p<0.0020)$; greater $\mathrm{N}_{\mathrm{TE}}$ values for falls onto linoleum over wood $(\mathrm{p}=0.045)$, wood $(\mathrm{p}=$ $0.003)$, and linoleum over concrete $(\mathrm{p}=0.003)$; greater $\mathrm{N}_{\mathrm{CF}}$ values for falls onto linoleum over wood $(p=0.016)$, playground foam $(p<0.001)$, and wood $(p=0.017)$; and greater $\mathrm{N}_{\mathrm{CE}}$ values for falls onto playground foam $(\mathrm{p}=0.002)$ and wood $(\mathrm{p}=0.020)$. However, the 18 " fall height was associated with significantly greater $\mathrm{N}_{\mathrm{CF}}$ values than the 27 " fall height for falls onto linoleum over concrete $(p=0.020)$ (Table XXIX).

b. Effect of Surface. For 18 " falls with normal joint stiffness, the following significant differences were found: carpet was associated with significantly lower $\mathrm{N}_{\mathrm{TF}}$ values than wood $(p=0.001)$ and linoleum over concrete $(p=0.003)$; playground foam was associated with significantly greater $\mathrm{N}_{\mathrm{CF}}$ values than wood $(\mathrm{p}=0.016)$ and linoleum over concrete $(\mathrm{p}=0.005)$; and linoleum over wood and playground foam were associated with significantly lower $\mathrm{N}_{\mathrm{CE}}$ values than all other surfaces $(\mathrm{p}<0.001)$. For 27 " falls with 
normal joint stiffness, wood was associated with significantly greater $\mathrm{N}_{\mathrm{TF}}$ values than all other surfaces $(p=0.006$ for linoleum over wood, $p=0.002$ for playground foam, $p=$ 0.001 for carpet, and $\mathrm{p}=0.003$ for linoleum over concrete), and significantly greater $\mathrm{N}_{\mathrm{TE}}$ values than playground foam $(p=0.002)$. Also, carpet was associated with significantly lower $\mathrm{N}_{\mathrm{CF}}$ values than linoleum over wood $(\mathrm{p}=0.017)$ and linoleum over concrete $(\mathrm{p}=$ 0.012). For 18 " falls with tight joint stiffness, carpet was associated with significantly greater $\mathrm{N}_{T E}$ values than all other surfaces $(\mathrm{p}=0.001$ for linoleum over wood, $\mathrm{p}=0.018$ for playground foam, $\mathrm{p}=0.001$ for wood, and $\mathrm{p}=0.008$ for linoleum over concrete). Also, wood and linoleum over concrete were associated with significantly greater $\mathrm{N}_{\mathrm{CF}}$ values than playground foam $(p=0.007$ for wood and $p=0.016$ for linoleum over concrete) and carpet $(\mathrm{p}=0.002$ for wood and $\mathrm{p}=0.005$ for linoleum over concrete). For 27 " falls with tight joint stiffness, the following significant differences were found: linoleum over wood was associated with significantly greater $\mathrm{N}_{\mathrm{TF}}$ values than carpet $(\mathrm{p}=$ 0.048); playground foam and wood were associated with significantly greater $\mathrm{N}_{\mathrm{CF}}$ values than carpet $(p=0.007$ for playground foam and $p=0.028$ for wood) and linoleum over concrete ( $p=0.002$ for playground foam and $p=0.010$ for wood); linoleum over wood was associated with significantly greater $\mathrm{N}_{\mathrm{CF}}$ values than linoleum over concrete $(\mathrm{p}=$ 0.020 ); and playground foam was associated with significantly greater $\mathrm{N}_{\mathrm{CE}}$ values than carpet $(\mathrm{p}=0.038)($ Table XXX).

c. Effect of Joint Stiffness. The effect of joint stiffness in 18" falls was generally opposite the effect in 27" falls. For 18 " falls, those with normal joint stiffness were associated with significantly greater $\mathrm{N}_{\mathrm{TF}}$ and $\mathrm{N}_{\mathrm{CF}}$ values than those with tight joint stiffness for falls onto all surfaces $\left(\mathrm{p}<0.001\right.$ for all cases except $\mathrm{N}_{\mathrm{TF}}$ with carpet where $\mathrm{p}$ 
$=0.011)$. Falls with normal joint stiffness were also associated with significantly greater $\mathrm{N}_{\mathrm{TE}}$ values than falls with tight joint stiffness for falls onto linoleum over wood $(\mathrm{p}=$ 0.002 ), and greater $\mathrm{N}_{\mathrm{CE}}$ values for falls onto carpet, wood, and linoleum over concrete ( $\mathrm{p}$ $<0.001)$. However, falls with tight joint stiffness were associated with significantly greater $\mathrm{N}_{\mathrm{TE}}$ values than falls with normal joint stiffness for falls onto carpet $(\mathrm{p}=0.019)$. For 27 " falls, those with tight joint stiffness were associated with significantly greater $\mathrm{N}_{\mathrm{CF}}$ values than those with normal joint stiffness for falls onto linoleum over wood $(\mathrm{p}=$ $0.034)$, playground foam $(\mathrm{p}<0.001)$, and wood $(\mathrm{p}<0.001)$, and significantly greater $\mathrm{N}_{\mathrm{CE}}$ values for falls onto playground foam $(p<0.001)$ and wood $(p=0.011)$. However, falls with normal joint stiffness were associated with greater $\mathrm{N}_{\mathrm{TF}}$ values than those with tight joint stiffness for falls onto wood $(\mathrm{p}=0.009)($ Table XXXI).

$\square$ 18" Fall with Normal Joints 응 27" Fall with Normal Joints 目 18" Fall with Tight Joints $\square 27$ " Fall with Tight Joints

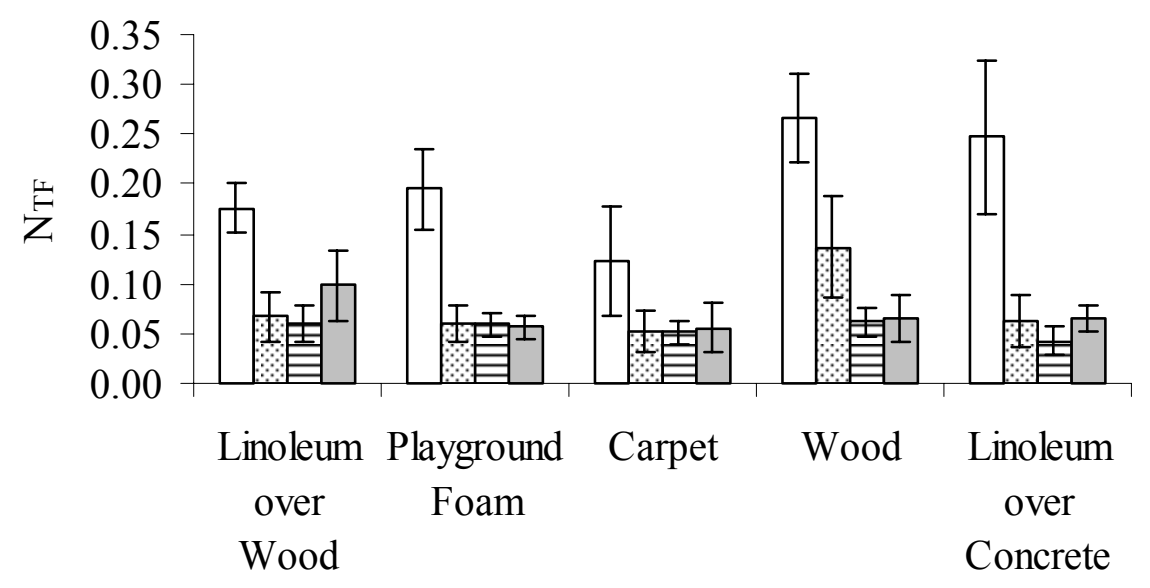

FIGURE 28 - Neck Injury Criteria for Combined Tension-Flexion Loading for Falls from Standing with Various Impact Surfaces, Fall Heights, and Joint Stiffness. Error bars represent $95 \%$ CI. 


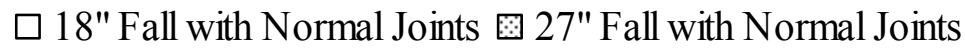

目 18" Fall with Tight Joints $\square 27$ " Fall with Tight Joints

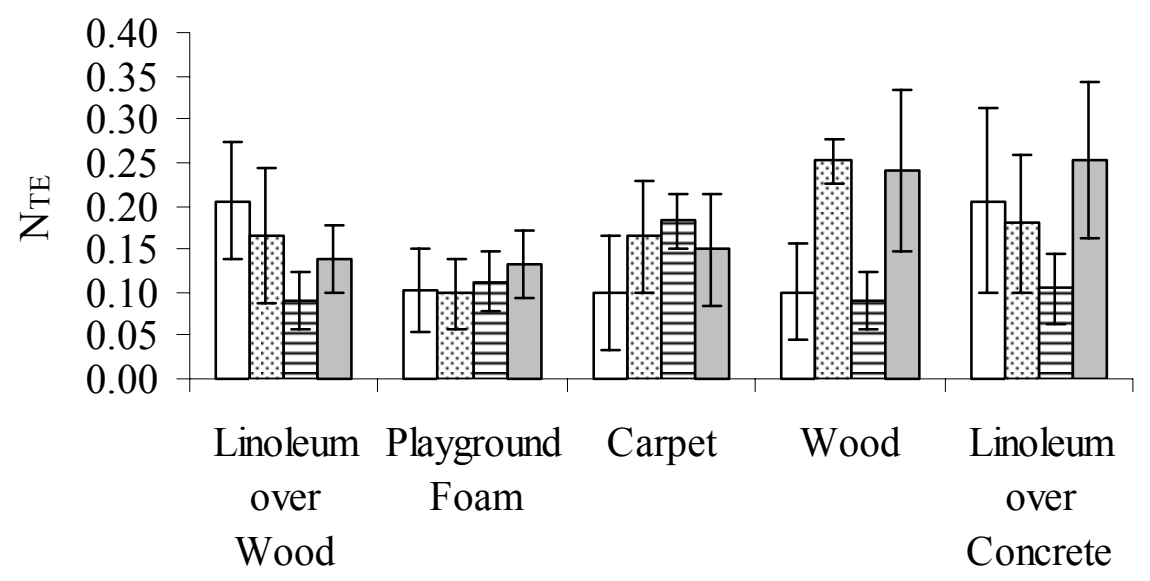

FIGURE 29 - Neck Injury Criteria for Combined Tension-Extension Loading for Falls from Standing with Various Impact Surfaces, Fall Heights, and Joint Stiffness. Error bars represent $95 \% \mathrm{CI}$.

$\square 18$ " Fall with Normal Joints : 27" Fall with Normal Joints

目 18" Fall with Tight Joints $\square 27$ " Fall with Tight Joints

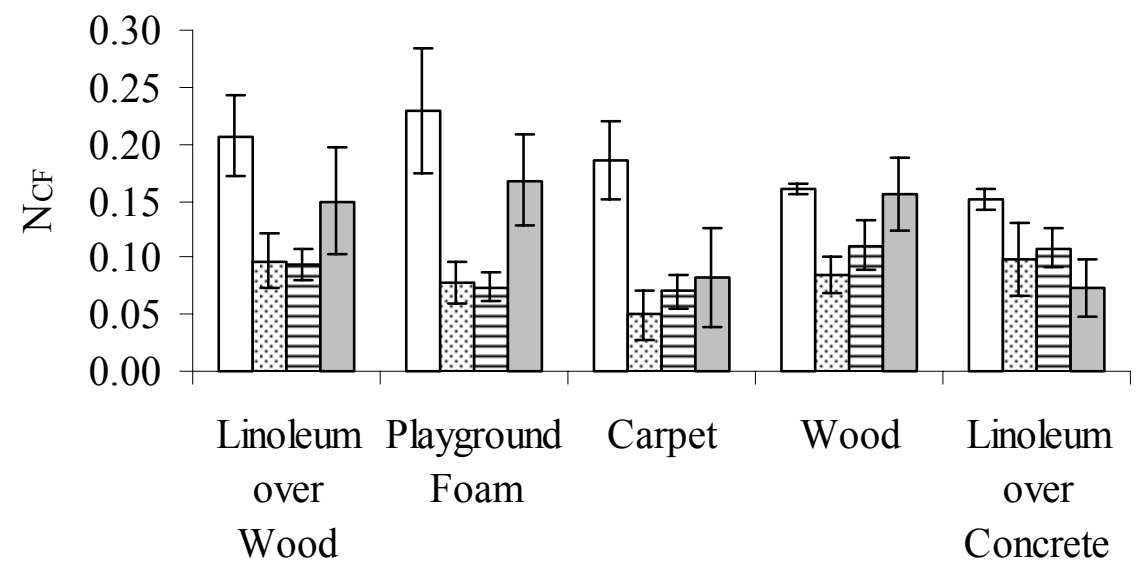

FIGURE 30 - Neck Injury Criteria for Combined Compression-Flexion Loading for Falls from Standing with Various Impact Surfaces, Fall Heights, and Joint Stiffness. Error bars represent $95 \% \mathrm{CI}$. 
$\square$ 18" Fall with Normal Joints : 27" Fall with Normal Joints

目 18" Fall with Tight Joints $\square$ 27" Fall with Tight Joints

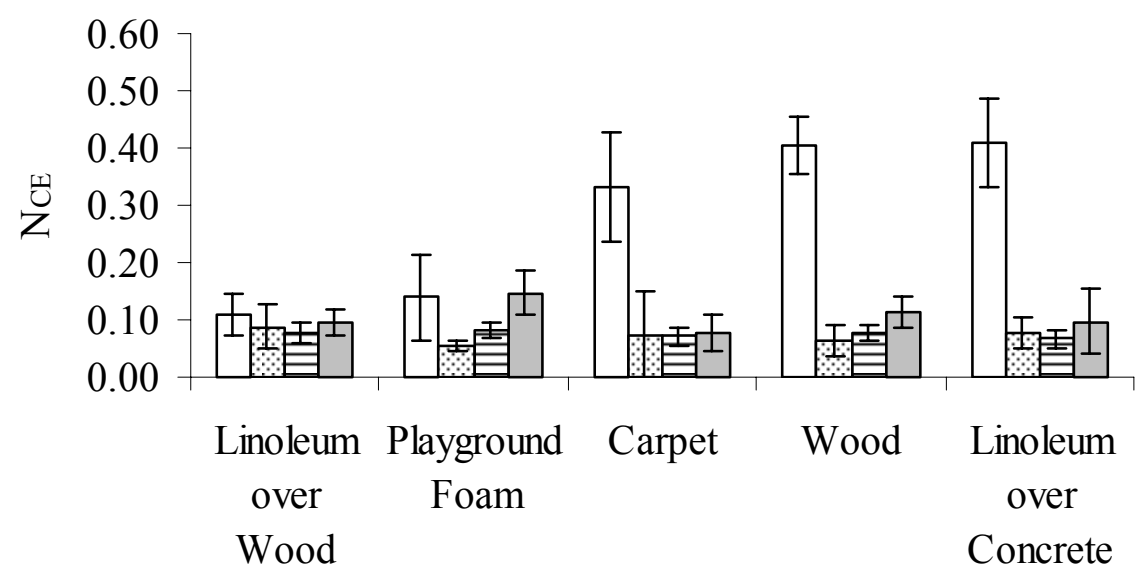

FIGURE 31 - Neck Injury Criteria for Combined Compression-Extension Loading for Falls from Standing with Various Impact Surfaces, Fall Heights, and Joint Stiffness.

Error bars represent 95\% CI.

TABLE XXIX

SIGNIFICANT DIFFERENCES IN NECK INJURY CRITERIA FOR VARIOUS

HEIGHTS IN FALLS FROM STANDING

\begin{tabular}{|c|c|c|c|c|c|}
\hline & \multicolumn{2}{|c|}{ Normal Joints } & \multicolumn{2}{|c|}{ Tightened Joints } \\
\hline & & 18 & 27 & 18 & 27 \\
\hline \multirow{2}{*}{$\begin{array}{c}\text { Linoleum over } \\
\text { Wood }\end{array}$} & 18 & & TF,CF & & TF,CF,TE \\
\hline & 27 & $\mathrm{TF}, \mathrm{CF}$ & & TF,CF,TE & \\
\hline \multirow{2}{*}{$\begin{array}{l}\text { Playground } \\
\text { Foam }\end{array}$} & 18 & & $\mathrm{TF}, \mathrm{CF}, \mathrm{CE}$ & & $\mathrm{CF}$ \\
\hline & 27 & $\mathrm{TF}, \mathrm{CF}, \mathrm{CE}$ & & $\mathrm{CF}$ & \\
\hline \multirow{2}{*}{ Carpet } & 18 & & TF,CF,CE & & \\
\hline & 27 & $\mathrm{TF}, \mathrm{CF}, \mathrm{CE}$ & & & \\
\hline \multirow{2}{*}{ Wood } & 18 & & TF,CF,TE,CE & & CF,TE \\
\hline & 27 & TF,CF,TE,CE & & CF,TE & \\
\hline \multirow{2}{*}{$\begin{array}{c}\text { Linoleum over } \\
\text { Concrete }\end{array}$} & 18 & & TF,CF,CE & & TF,CF,TE \\
\hline & 27 & TF,CF,CE & & TF,CF,TE & \\
\hline
\end{tabular}

"TF", "CF", "TE", and "CE" indicate significant differences $(p<0.05)$ in tensionflexion, compression-flexion, tension-extension, and compression-extension neck loading measures, respectively. 
TABLE XXX

SIGNIFICANT DIFFERENCES IN NECK INJURY CRITERIA FOR VARIOUS SURFACES IN FALLS FROM STANDING

\begin{tabular}{|c|c|c|c|c|c|c|c|}
\hline & & & $\begin{array}{c}\text { Linoleum } \\
\text { over } \\
\text { Wood }\end{array}$ & $\begin{array}{c}\text { Playground } \\
\text { Foam }\end{array}$ & Carpet & Wood & $\begin{array}{c}\text { Linoleum } \\
\text { over } \\
\text { Concrete }\end{array}$ \\
\hline \multirow{10}{*}{ 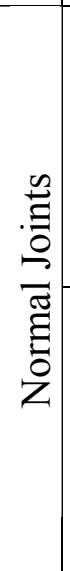 } & \multirow{5}{*}{18} & Linoleum over Wood & & & $\mathrm{CE}$ & $\mathrm{CE}$ & $\mathrm{CE}$ \\
\hline & & Playground Foam & & & $\mathrm{CE}$ & $\mathrm{CF}, \mathrm{CE}$ & $\mathrm{CF}, \mathrm{CE}$ \\
\hline & & Carpet & $\mathrm{CE}$ & $\mathrm{CE}$ & & $\mathrm{TF}$ & $\mathrm{TF}$ \\
\hline & & Wood & $\mathrm{CE}$ & $\mathrm{CF}, \mathrm{CE}$ & $\mathrm{TF}$ & & \\
\hline & & Linoleum over Concrete & $\mathrm{CE}$ & CF,CE & $\mathrm{TF}$ & & \\
\hline & \multirow{5}{*}{27} & Linoleum over Wood & & & $\mathrm{CF}$ & $\mathrm{TF}$ & \\
\hline & & Playground Foam & & & & $\mathrm{TF}, \mathrm{TE}$ & \\
\hline & & Carpet & $\mathrm{CF}$ & & & $\mathrm{TF}$ & $\mathrm{CF}$ \\
\hline & & Wood & TF & TF,TE & $\mathrm{TF}$ & & $\mathrm{TF}$ \\
\hline & & Linoleum over Concrete & & & $\mathrm{CF}$ & $\mathrm{TF}$ & \\
\hline \multirow{10}{*}{ 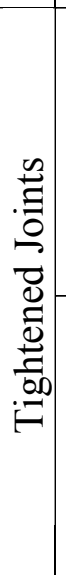 } & \multirow{5}{*}{18} & Linoleum over Wood & & & TE & & \\
\hline & & Playground Foam & & & TE & $\mathrm{CF}$ & $\mathrm{CF}$ \\
\hline & & Carpet & TE & TE & & CF,TE & CF,TE \\
\hline & & Wood & & $\mathrm{CF}$ & $\mathrm{CF}, \mathrm{TE}$ & & \\
\hline & & Linoleum over Concrete & & $\mathrm{CF}$ & CF,TE & & \\
\hline & \multirow{5}{*}{27} & Linoleum over Wood & & & $\mathrm{TF}$ & & $\mathrm{CF}$ \\
\hline & & Playground Foam & & & $\mathrm{CF}, \mathrm{CE}$ & & $\mathrm{CF}$ \\
\hline & & Carpet & TF & CF,CE & & $\mathrm{CF}$ & \\
\hline & & Wood & & & $\mathrm{CF}$ & & $\mathrm{CF}$ \\
\hline & & Linoleum over Concrete & $\mathrm{CF}$ & $\mathrm{CF}$ & & $\mathrm{CF}$ & \\
\hline
\end{tabular}

"TF", "CF", "TE", and "CE" indicate significant differences $(\mathrm{p}<0.05)$ in tensionflexion, compression-flexion, tension-extension, and compression-extension neck loading measures, respectively. 
TABLE XXXI

SIGNIFICANT DIFFERENCES IN NECK INJURY CIRTERIA FOR VARIOUS

JOINT CONDITIONS IN FALLS FROM STANDING

\begin{tabular}{|c|c|c|c|c|c|}
\hline & \multicolumn{2}{|c|}{18} & \multicolumn{2}{|c|}{27} \\
\hline & & \multirow[t]{2}{*}{ Normal Joints } & \multirow{2}{*}{$\begin{array}{c}\text { Tightened } \\
\text { Joints } \\
\text { TF,CF,TE }\end{array}$} & \multirow[t]{2}{*}{$\begin{array}{c}\text { Normal } \\
\text { Joints }\end{array}$} & \multirow{2}{*}{$\begin{array}{c}\begin{array}{c}\text { Tightened } \\
\text { Joints }\end{array} \\
\text { CF }\end{array}$} \\
\hline Linoleum & Normal & & & & \\
\hline over Wood & Tight & TF,CF,TE & & $\mathrm{CF}$ & \\
\hline \multirow{2}{*}{$\begin{array}{l}\text { Playground } \\
\text { Foam }\end{array}$} & Normal & & $\mathrm{TF}, \mathrm{CF}$ & & $\mathrm{CF}, \mathrm{CE}$ \\
\hline & Tight & $\mathrm{TF}, \mathrm{CF}$ & & $\mathrm{CF}, \mathrm{CE}$ & \\
\hline \multirow{2}{*}{ Carpet } & Normal & & TF,CF,TE,CE & & \\
\hline & Tight & TF,CF,TE,CE & & & \\
\hline \multirow{2}{*}{ Wood } & Normal & & $\mathrm{TF}, \mathrm{CF}, \mathrm{CE}$ & & TF,CF,CE \\
\hline & Tight & TF,CF,CE & & $\mathrm{TF}, \mathrm{CF}, \mathrm{CE}$ & \\
\hline \multirow{2}{*}{$\begin{array}{c}\text { Linoleum } \\
\text { over } \\
\text { Concrete }\end{array}$} & Normal & & TF,CF,CE & & \\
\hline & Tight & TF,CF,CE & & & \\
\hline
\end{tabular}

"TF", "CF", "TE", and "CE" indicate significant differences $(p<0.05)$ in tensionflexion, compression-flexion, tension-extension, and compression-extension neck loading measures, respectively.

TABLE VII

MEAN PEAK N $\mathrm{II}_{\mathrm{IJ}}$ VALUES BY FALL HEIGHT, JOINT STIFFNESS, AND IMPACT SURFACE TYPE

\begin{tabular}{|c|c|c|c|c|c|}
\hline \multicolumn{2}{|c|}{} & $\mathrm{N}_{\mathrm{TF}}$ & $\mathrm{N}_{\mathrm{TE}}$ & $\mathrm{N}_{\mathrm{CF}}$ & $\mathrm{N}_{\mathrm{CE}}$ \\
\hline Fall & $18^{\prime \prime}$ & 0.13 & 0.13 & 0.14 & 0.18 \\
\cline { 2 - 6 } Height & $27^{\prime \prime}$ & 0.07 & 0.18 & 0.10 & 0.09 \\
\hline Joint & Normal & 0.14 & 0.16 & 0.13 & 0.17 \\
\cline { 2 - 6 } Stiffness & Tight & 0.06 & 0.15 & 0.11 & 0.09 \\
\hline \multirow{4}{*}{ Surface } & Linoleum over Wood & 0.10 & 0.15 & 0.14 & 0.09 \\
\cline { 2 - 6 } & Playground Foam & 0.09 & 0.11 & 0.14 & 0.11 \\
\cline { 2 - 6 } & Carpet & 0.07 & 0.15 & 0.10 & 0.14 \\
\cline { 2 - 6 } & Wood & 0.13 & 0.17 & 0.13 & 0.16 \\
\cline { 2 - 6 } & Linoleum over Concrete & 0.10 & 0.19 & 0.11 & 0.16 \\
\hline
\end{tabular}




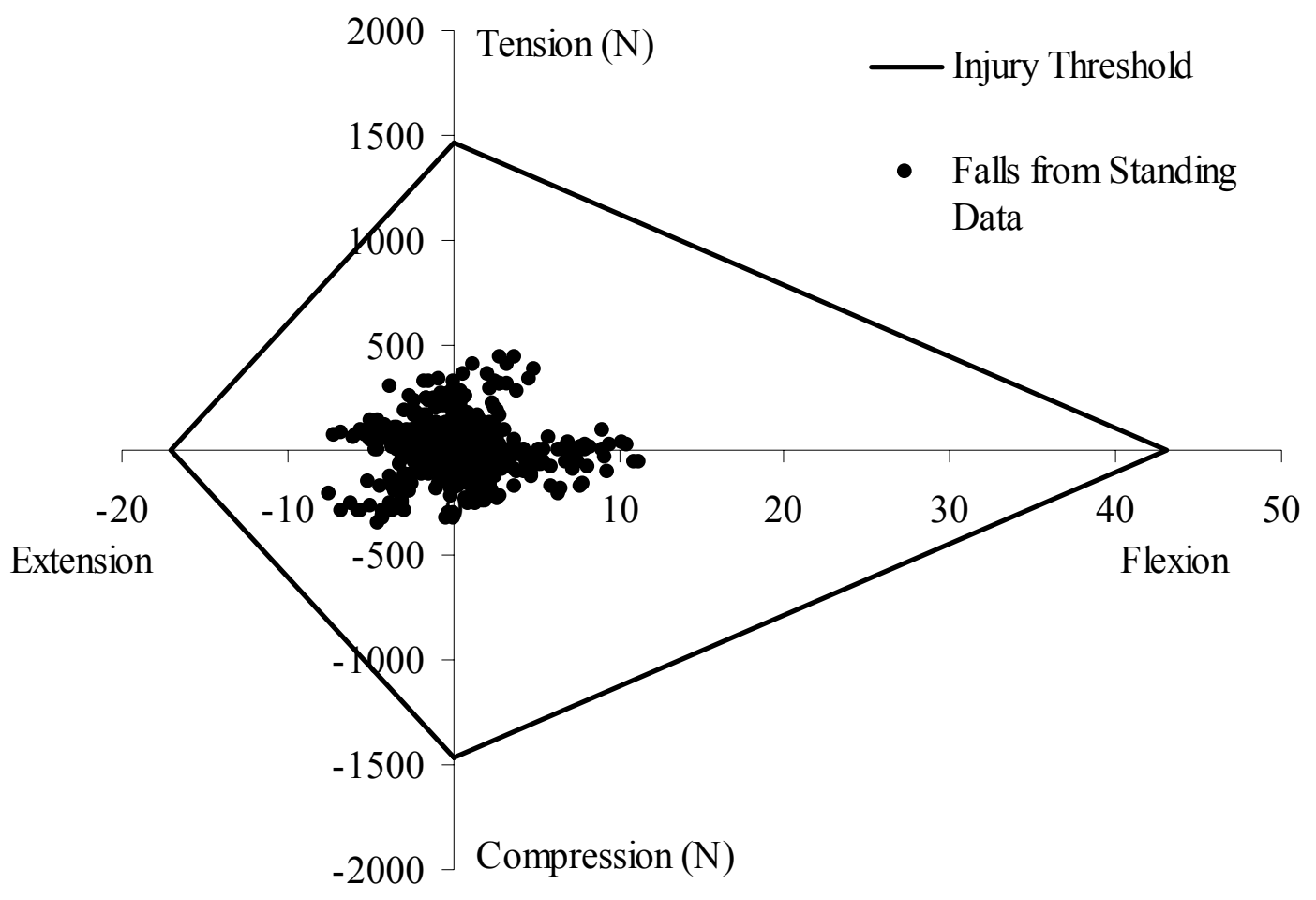

FIGURE 32 - Experimental Values of Neck Compression/Tension Forces and Flexion/Extension Moments in Falls from Standing Compared to NHTSA Neck Injury Threshold. 


\section{DISCUSSION}

\section{A. Head Injury Risk}

All of the variables tested (fall height, impact surface, joint stiffness) were found to have an effect on head injury risk. For the falls from standing, the 27 ' fall height was generally associated with greater head accelerations and smaller impact durations than the 18 " fall height. This indicates a greater head injury risk for the greater fall height which is consistent with findings from similar studies (Bertocci, 2004; Prange, 2003). However for the feet-first free falls, fall height had little effect on the risk of head injury. Furthermore, where significant differences did occur, the lowest fall height (18" from ground to center of mass of ATD) was associated with greater head accelerations and smaller impact durations than the two greater heights. This indicates a greater injury risk for the 18 " fall height, which is a ground-based fall, than for the two greater fall heights (27' and 47'). The differences can be explained by the fall dynamics and, in part, by the initial (pre-fall) position. In the 18" ground-based feet-first free falls, the ATD rotated rearward about the feet after release, and the initial impact with the ground occurred at the pelvis followed by the torso and head. In falls from the two greater heights, the feet impacted the ground first, so a large portion of the energy from the fall was absorbed in the legs with flexion of the knees and hips. Additionally, the greater head accelerations associated with the 18 " fall height, as compared to the 27 " and 47 " fall heights, occurred only with the wood and linoleum-tiled concrete surfaces. This could possibly be 
explained by differences in surface properties and their effect on fall dynamics. The wood and linoleum-tiled concrete surfaces had the lowest friction coefficients. In 27 " and 47 " falls onto these surfaces, the feet tended to slip upon impact, which did not occur to the same extent for the 18 " falls or the other surfaces (Figure 5). The initial fall dynamics were similar for all falls with the initial impact occurring at the feet followed by hip and knee flexion. For the 27 " and 47 " falls onto wood and linoleum over concrete, the feet slipped out from under the ATD causing a second impact at the buttocks. The ATD then rotated rearward pivoting about the hips. This second impact at the buttocks absorbed a portion of the energy from the fall, so there was less energy available at head impact leading to lower head accelerations in these falls. For falls in which no slipping occurred, the ATD rotated rearward about the feet, and although there was generally an impact at the buttocks before head impact, it was not as severe and the ATD maintained its momentum. This difference in fall dynamics due to foot slipping is illustrated in Figure 33. The figure plots resultant linear head acceleration versus time for three representative feet-first free falls. It can be seen that from approximately 0.3 to 0.6 seconds, the 27 " and 47 " falls had some additional peaks that did not occur in the 18 " fall. Although the magnitudes of these peaks are low, there is a reduction in the fall energy imparted to the head. 


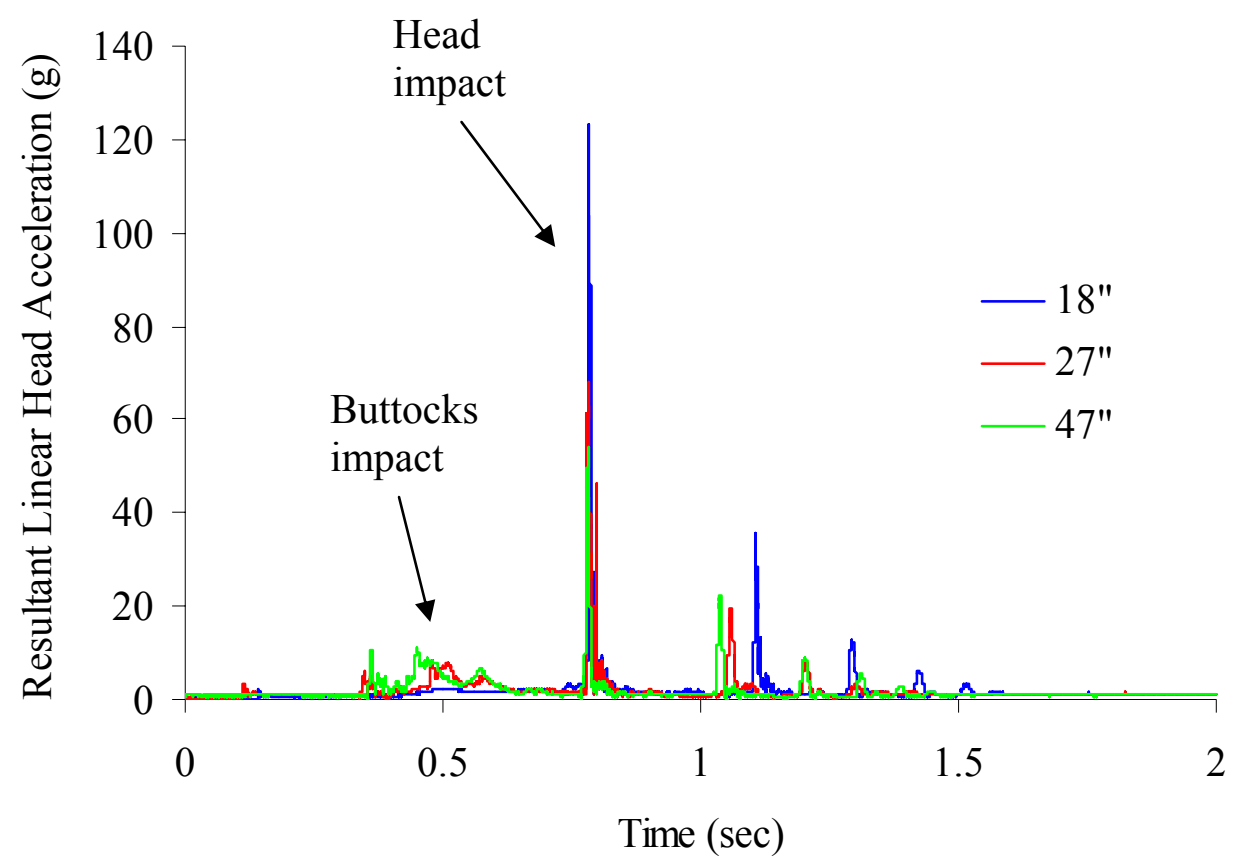

FIGURE 33 - Representative Linear Head Accelerations for 18”, 27”, and 47" Free Falls onto Linoleum over Concrete.

Generally, falls from standing were associated with greater head accelerations than feet-first free falls. This result can be explained by the different fall dynamics. Just as the 18 " free fall was associated with greater head accelerations than the 27 " and 47 " free falls, the falls from standing were associated with greater head accelerations due to a larger rotational component in which the ATD rotated rearward about the feet as compared to the feet-first free falls in which the ATD first fell to a seated position and then rotated rearward about the buttocks.

In both feet-first free falls and falls from standing, surfaces with lower coefficients of restitution were associated with shorter impact durations. The potential energy for a fall is only dependent on the mass of the object being dropped and the height of the fall. Therefore, all of the falls from the same height in these experiments had the same potential energy. The resulting accelerations however, are dependent on the 
duration of the impact. For longer durations, the impact is spread over a longer period of time, so lower accelerations result. Likewise, shorter durations result in greater accelerations. Since greater accelerations are associated with a greater injury risk, surfaces with lower coefficients of restitution (linoleum over concrete, linoleum over wood, and wood) would be associated with the greatest injury risk, and surfaces with the highest coefficients of restitution (playground foam and carpet) would be associated with the lowest injury risk, which is consistent with the results of this study. These findings are consistent with other studies that examined surface effects on injury risk (Bertocci, 2004; Cory, 2006; Prange, 2003).

ATD joint stiffness also had an effect on head injury risk. With few exceptions, falls in which the ATD's joints were tightened were associated with significantly greater head accelerations than those in which the joints were adjusted to the normal specifications. Therefore, falls in which the joints are tightened would be expected to have a greater injury risk than those in which the joints are allowed to move. These results are as expected since movement of the joints absorbs energy from the fall allowing less energy to be transferred to the head.

Head Injury Criteria (HIC) values are based on linear head acceleration and can be used to predict the probability of contact-type head injuries. The HIC was developed for use in the automotive industry to assess head injury risk in motor vehicle crash testing, but it has also been used to assess head injury risk in falls, particularly in the playground safety area (Cory, 2006; Gunatilaka, 2004). The proposed $\mathrm{HIC}_{15}$ limit for the CRABI 12-month-old ATD is 390 . For this limit, there is a 31 percent probability of skull fracture (Eppinger, 1999). All $\mathrm{HIC}_{15}$ values measured in the feet-first free fall 
experiments were less than 174 , and all those measured in the falls from standing were less than 262. Therefore, contact-type head injuries would not be expected in either of these fall scenarios.

A large range of linear head acceleration tolerance limits have been proposed. Sturz proposed tolerance limits for 6 to 7 year old children based on accident reconstructions (Sturtz, 1980). An acceleration of $60 \mathrm{~g}$ was proposed as the level at which only reversible (AIS 1) injuries could occur. A second level of $83 \mathrm{~g}$ was proposed as the level above which AIS 2+ injuries could occur. Mohan et al. reported an injury tolerance limit of 200-250 g peak acceleration for children (ages 1-10) based on a study of head-first free falls (Mohan, 1979). Cory et al. reported several tolerance limits ranging from $50-200 \mathrm{~g}$ for children (age not specified), where $50 \mathrm{~g}$ is the maximum before-injury threshold and $200 \mathrm{~g}$ is the threshold for fatal injury (Cory, 2001). Our maximum linear head acceleration across all falls was $130 \mathrm{~g}$; occurring in an 18 " fall onto the linoleum-tiled concrete surface. The results of this study were all below Mohan's proposed tolerance of $200 \mathrm{~g}$. All of the feet-first free fall scenarios except the 18 " falls onto linoleum over concrete produced mean peak linear head accelerations below Sturtz's proposed limit of $83 \mathrm{~g}$. On the other hand, all falls from standing scenarios produced mean peak linear head accelerations greater than $83 \mathrm{~g}$ except those onto playground foam and some onto carpet. If the $83 \mathrm{~g}$ threshold is applied, AIS $2+$ head injuries would seem likely in short-distance falls from standing. However, this tolerance limit was developed for children older than those used in this study.

None of the measured angular accelerations and velocities in these fall experiments exceeded thresholds for the moderate to severe DAI thresholds proposed by 
Margulies and Thibault. Ommaya et al. proposed angular head acceleration thresholds of nearly $30,000 \mathrm{rad} / \mathrm{s}^{2}$ for an infant (400 gm brain mass) and nearly $18,000 \mathrm{rad} / \mathrm{s}^{2}$ for a young child (800 gm brain mass) for mild DAI (Ommaya, 2002). The authors added that acceleration levels necessary to produce acute subdural hematoma (SDH) and deep intracerebral hemorrhage are much greater than those for mild DAI. Duhaime et al. compared accelerations from results of shaking and impact studies to thresholds of approximately $35,000 \mathrm{rad} / \mathrm{s}^{2}$ and $40,000 \mathrm{rad} / \mathrm{s}^{2}$ for SDH and DAI respectively, for an infant (500 gm brain mass) (Duhaime, 1987). The results of this study were below all of the previously mentioned injury threshold levels. Other thresholds have been reported for concussion and range from $4500 \mathrm{rad} / \mathrm{s}^{2}$ for an adult to $10,000 \mathrm{rad} / \mathrm{s}^{2}$ for an infant (Ommaya, 2002). All test scenarios except for feet-first free falls onto playground foam included trials with angular accelerations exceeding $4500 \mathrm{rad} / \mathrm{s}^{2}$, but only 1 trial produced a value exceeding $10,000 \mathrm{rad} / \mathrm{s}^{2}$ (27" fall from standing with tightened joints onto linoleum over concrete). However, it is important to note that Ommaya's proposed thresholds do not account for the impact durations. For example, falls with the same peak head acceleration, but smaller impact durations (less time of exposure to the given acceleration) would have a reduced risk of head injury. One should not assess injury risk using the impact duration or head acceleration alone, but should consider the combination of the two. For example, falls onto playground foam and carpet had the greatest impact durations, but produced lower head accelerations.

The results of this study are consistent with the findings of other studies as it relates to head injury. Severe head injuries are rare in short distance falls. Several studies have reported no fatalities in children falling three stories or less (Barlow, 1983; 
Musemeche, 1991; Snyder, 1969). Furthermore, Snyder reported no injuries for feet-first free falls from less than 25 feet, even onto a concrete surface. Chadwick reported seven fatalities from falls less than four feet, but concluded that these were likely false histories (Chadwick, 1991). Severe head injuries (including subdural hematoma) were present in all of the seven cases. Two studies of bed falls found no serious head injuries or lifethreatening injuries in a combined 512 cases (Helfer, 1977; Lyons, 1993). There were 4 skull fractures reported in these studies but all were of a non-serious nature.

A study by Prange et al. performed short distance fall experiments with an anthropomorphic surrogate of a 1.5-month-old infant (Prange, 2003). The surrogate was initially positioned horizontally with the head slightly below the body such that the head would impact the ground first. For similar heights and surfaces, the angular head accelerations measured by Prange et al. were more than 10 times those measured in our feet-first free fall experiments and more than 4 times those measured in the falls from standing. One explanation for this is the different initial positions of the surrogates. Greater head accelerations would be expected in a head-first impact than in a feet-first impact. The initial impact in falls from standing occurred at the torso, producing greater angular accelerations than those in the feet-first falls but still less than those in the headfirst falls. Another difference is the age of the surrogates used. However, the primary difference in the results of this study and those of Prange is likely due to the different fall dynamics.

A previous study by Bertocci et al. used a 3-year-old ATD in simulations of feetfirst falls (Bertocci, 2004). The authors reported linear head accelerations up to six times greater than those measured in this study for all similar heights and surfaces. Angular 
accelerations were not reported. Differences in the results as compared to this study are likely due to the differences in age representation and associated characteristics of the ATDs. The 3-year-old ATD has a larger head mass and would therefore be expected to produce greater accelerations.

Several studies have utilized animals and human cadavers to determine loads necessary to produce head injuries. Ommaya et al. describes a study by Weber in which 15 infant cadavers (average age 8.2 months) were dropped from a height of 32 in $(82 \mathrm{~cm})$ onto stone, tile, carpet, and linoleum covered surfaces (Ommaya, 2002). All of the drops were from a horizontal initial position which allowed the head to impact first and each drop produced skull fractures. Nahum and Smith simulated impacts to the frontal skull bone of 10 adult cadavers (Nahum, 1976). These impacts produced peak linear head accelerations ranging from 44-327 $\mathrm{g}\left(430-3,210 \mathrm{~m} / \mathrm{s}^{2}\right)$. Accelerations greater than $195 \mathrm{~g}$ $\left(1,910 \mathrm{~m} / \mathrm{s}^{2}\right)$ were associated with head injuries ranging from minor contusions to more severe injuries including subdural hematomas. Ommaya and Hirsch, and Gennarelli et al. studied head injuries in primates(Gennarelli, 1982; Ommaya, 1971). The former study applied rotational loads by both whiplash (indirect) and direct impact mechanisms to three primate species (squirrel monkeys, rhesus monkeys, and chimpanzees) to determine accelerations necessary to produce concussion. The authors found that smaller loads were required to produce concussion in animals with a larger brain mass. For chimpanzees (which have the largest brain mass of the three primates tested) the onset level of concussion in whiplash occurred at an angular velocity of $70 \mathrm{rad} / \mathrm{s}$. For an impact duration of $20 \mathrm{msec}$, this corresponds to an angular acceleration level of 3,500 $\mathrm{rad} / \mathrm{s}^{2}$. In the Gennarelli study, pure rotational loads, ranging from 100,000 to 200,000 
$\mathrm{rad} / \mathrm{s}^{2}$, were applied to the heads of rhesus monkeys and baboons. The resulting head injuries ranged from mild concussion to severe diffuse axonal injury. Each of the above studies attempted to determine loads necessary to produce head injuries, but it could be misleading to compare the results of these studies to those of the present study. The Ommaya and Hirsch study proved that different load levels are necessary to cause head injury in subjects of different sizes. Therefore the loads used to produce head injury in the adult cadaver and primate studies cannot be compared directly to those loads sustained by a 12-month-old child. Although the chimpanzee has the closest brain mass to that of a 12-month-old, there would be error in assuming the chimpanzee skull and brain properties and structure are similar to that of a child. The Weber study used infant cadavers in fall simulations but the initial position of the fall is very different than that used in this study. Therefore, different head acceleration and a different injury risk would be expected.

\section{B. Neck Injury Risk}

Across all the free fall experiments, including feet-first free falls and falls from standing, only one out of 300 total trials exceeded the threshold for neck injury based on the $\mathrm{N}_{\mathrm{ij}}$ values. The mean $\mathrm{N}_{\mathrm{ij}}$ values were far below the threshold indicating a low risk of neck injury in these falls.

Fall height, impact surface type, and joint stiffness were also found to have an effect on the risk of neck injury in these falls. In the feet-first free falls, the greater fall 
heights generally produced greater neck loads and thus would have a greater risk of injury. The pattern of $\mathrm{N}_{\mathrm{ij}}$ values resulting from varying impact surfaces was not as apparent as that resulting from height. In many cases for both feet-first free falls and falls from standing, no significant differences in $\mathrm{N}_{\mathrm{ij}}$ values were found. Where significant differences were found, generally wood and linoleum over concrete were associated with the greatest $\mathrm{N}_{\mathrm{ij}}$ values, and carpet was associated with the lowest values.

When examining the effects of fall height and joint stiffness in the falls from standing, it was found that the 18 " falls with normal joint stiffness produced greater $\mathrm{N}_{\mathrm{TF}}$, $\mathrm{N}_{\mathrm{CF}}$, and $\mathrm{N}_{\mathrm{CE}}$ values than the other conditions for nearly all surfaces. This result is surprising since greater fall heights and increasing joint stiffness would be expected to increase injury risk. Greater fall heights lead to a greater impact velocity which should increase neck loads. Also, with tighter joints, more energy is transferred to the head and neck since it is not absorbed by joint flexion, thus increasing neck loads. After examining the data further, it is believed that there was an error in the neck loading measurements for this particular fall scenario. In the 18 " falls with normal joint stiffness, high neck loads occurred prior to impact for all loading conditions, but this did not occur in the other falls from standing. This occurrence is illustrated in Figure 34 which shows a representative plot of $\mathrm{N}_{\mathrm{TF}}$ over time for the different fall scenarios. (In the future these falls will be repeated to see if the results are different.) Excluding the 18 " falls with normal joint stiffness, the 27 " fall height generally produced greater $\mathrm{N}_{\mathrm{ij}}$ values than the 18 " fall height and the falls with tightened joints generally produced greater $\mathrm{N}_{\mathrm{ij}}$ values than those with normal joint stiffness. 


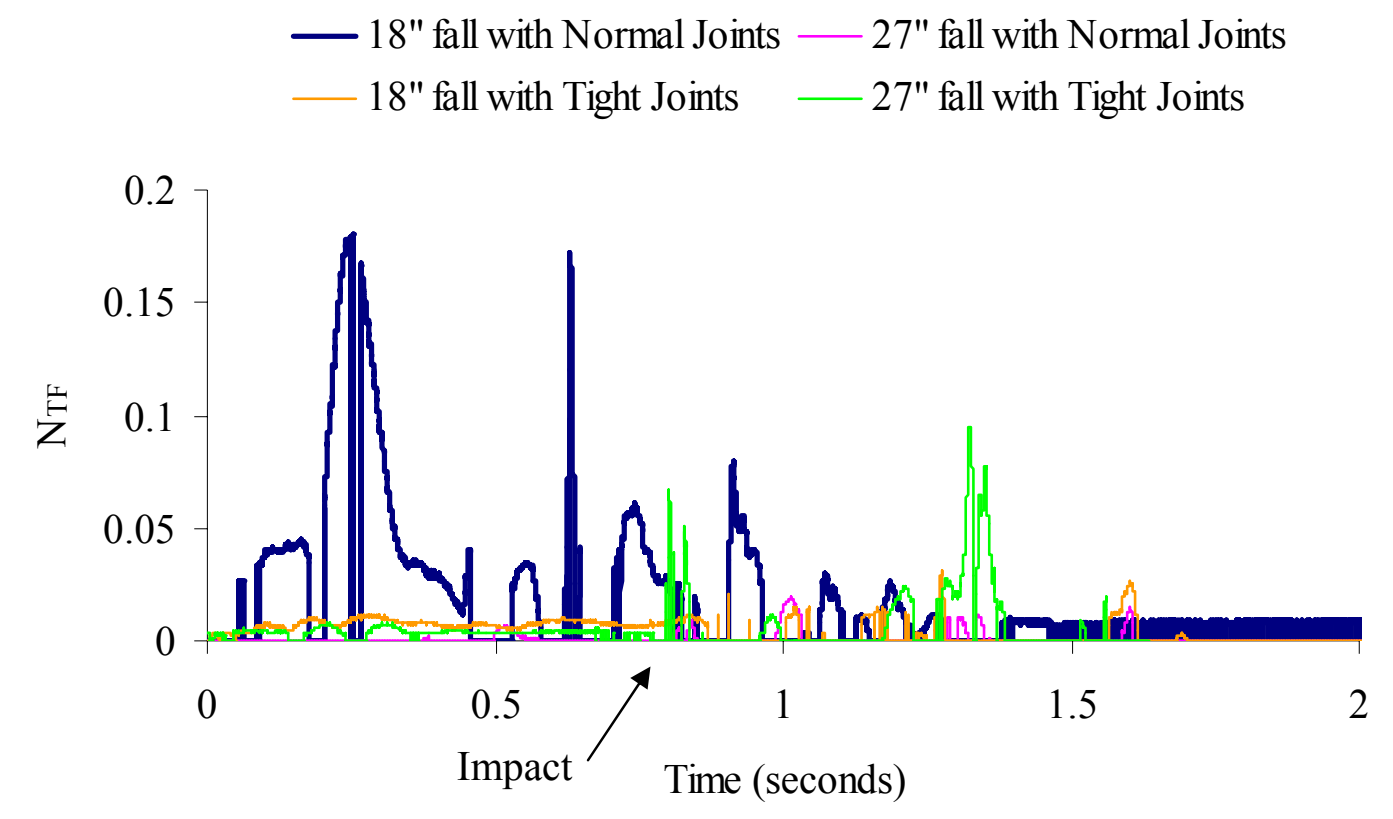

FIGURE 34 - Representative Plot of $\mathrm{N}_{\mathrm{TF}}$ Vs. Time for Falls from Standing.

To my knowledge, this is the only biomechanical study that has investigated neck injury risk or reported neck loads in pediatric falls. One study by Bandak investigated neck loads under conditions of shaken baby syndrome (Bandak, 2005). However, the results of this study were widely criticized as inaccurate (Margulies, 2006). There have been some studies documenting the occurrence of cervical spine injuries from falls (Chiaviello, 1994; Schwartz, 1997; Watson, 2005). Schwartz reviewed records from four major hospitals over an average span of 11 years and found only 41 cases of cervical spine injury. Of these only eight were caused by short distance falls. All of the children were older than two years except one nine-month old child. In the case of the nine-month old, the authors suspected the given history of a fall was false. Watson reviewed cases over a 5-year period and found only 22 cases of pediatric cervical spine injury. For children ages $0-8$ years, only three cases were due to a fall. Chiaviello studied 69 
children who fell down stairs and only one suffered a neck injury. These studies illustrate that cervical spine injuries are rare in pediatric falls. The results of our study are consistent with this finding that there is a low risk of neck injury in short distance falls.

\section{Summary and Implications of Findings to Child Abuse Diagnosis}

This study highlights the importance of fall dynamics, fall height, impact surface properties, and joint properties when evaluating head or neck injury risk for a shortdistance fall. The initial positions in the feet-first free falls and falls from standing were similar but the fall dynamics were very different for these two fall types leading to different levels of injury risk. Thus the combination of fall dynamics and initial position must be considered when assessing injury risk associated with a given fall. Fall environment factors, such as fall height and impact surface, also greatly contribute to the dynamics of the fall and thus effect the injury risk. For example, the surface friction coefficients affected the dynamics in free falls. In free falls onto surfaces with low friction coefficients, the ATD's feet slipped, and because of this, the knee and hip joints did not flex as much as in those falls onto surfaces with higher friction coefficients (where the ATD's feet did not slip). Without flexion of the joints, more energy is transferred to the head leading to a greater head injury risk. Therefore, in feet-first free falls with the ATD positioned above the floor, surfaces with lower friction coefficients were associated with a greater head injury risk than surfaces with higher friction coefficients. The surface type also had the greatest effect on the impact durations. 
Surfaces with higher coefficients of restitution (carpet and playground foam) were associated with longer impact durations. These surfaces "cushioned" the impact by spreading the fall energy out over a longer time period. This reduced the peak accelerations and thus lowered the injury risk. Greater fall heights are generally assumed to have a greater injury risk. However, this assumption could be inaccurate if the fall dynamics differ. In the feet-first free falls, the ground-based falls had a greater head injury risk than falls from greater fall heights, and this was due to different fall dynamics. In this study, ATD joint properties were also found to have a significant effect on head and neck injury risk. There was a lower injury risk in falls in which the joints were allowed to move. This is because movement of the joints absorbed some of the energy from the fall, reducing the amount of energy transferred to the head and neck, thus reducing head accelerations and neck loads.

In scenarios where clinicians must determine the compatibility between a stated cause and the presenting injury, it is clear from this study that fall dynamics and fall environment factors must be considered together to describe the complete fall event. For example, factors such as fall height and impact surface along with their combined effect on the fall dynamics need to be considered together to obtain an understanding of injury risk. It is this combined input that determines the final fall outcome.

In child abuse legal cases, matchstick falls are often presented by defense experts as a worst-case scenario in which severe injuries are possible. Matchstick falls are simply falls in which the child's joints are stiff. The results of this study confirm that falls in which the child's joints are stiff would have a greater head and neck injury risk than falls in which the child's joints bend and absorb energy. However, the results of this 
study also demonstrate that even in this worst-case scenario, for the short-distance fall types evaluated, severe head or neck injuries are unlikely.

\section{$\underline{\text { D. Limitations }}$}

There are several limitations of this study in both the experiments and the thresholds used to determine injury risk. One limitation is the biofidelity of the ATD. The CRABI ATD was designed for use in automotive crash testing and not necessarily for low energy events such as falls. In particular, the biofidelity of the neck can be questioned. The neck is much stiffer than what would be expected for a 12-month-old child. Also, the ATD was designed for frontal impact testing so there is little to no movement possible out of the sagittal plane. A more flexible neck would allow more head rotation for a given load application resulting in larger head accelerations. Therefore, the head accelerations resulting from experiments with the CRABI 12-monthold ATD may be less than those that would be experienced by a 12-month-old child. On the other hand, a more flexible neck could decrease the neck loads. This would imply that an actual 12-month-old child would have a lower neck injury risk than the CRABI ATD. A surrogate with a more biofidelic neck is needed to more accurately assess head and neck injury risk in fall scenarios. In addition to the neck, all the joints (shoulders, elbows, hips, knees) of the ATD are limited to motion in the sagittal plane. Although the falls occurred primarily in the sagittal plane, there was out of plane motion in several falls, which may lead to inaccuracies in head acceleration measures. 
An additional limitation involves the angular acceleration calculation. The pivot point, or center of rotation, was assumed to be at the base of the neck. However, the CRABI neck is a rubber structure separated into three sections with three main points of rotation. Also, there additional centers of rotation along the body of the ATD during the fall; two of these occurred at the hip and knee. There was also rotation about the ATD's feet. The base of the neck was assumed as the pivot point to determine a conservative estimate of the angular acceleration. Assuming a center of rotation further from the head would result in lower angular accelerations. Therefore, the angular accelerations reported in this study may be greater than the actual angular accelerations experienced by the head, thereby representing a conservative estimate of injury risk.

Another limitation of this study concerns the injury criteria used to predict injury risk. Little information exists on injury tolerances in children. Accordingly, proposed criteria (including those presented in this paper) have been scaled from either adult data or from primate studies. Scaling generally accounts for mass differences, but may also attempt to account for differences in geometry and material properties. The pediatric HIC thresholds are based on scaling from adult data using mass, geometry, and material properties (Eppinger, 1999). However, since there is limited information on pediatric brain tissue properties, the material properties of brain tissue were assumed to have the same age variation as calcaneal tendon (Eppinger, 1999). In addition to this assumption, the thresholds may be inadequate since they don't account for the different structure of a child's skull compared to an adult skull. A 12-month-old child's skull has several flexible fontanelles and sutures that allow for greater skull deformation than that of an adult under the same load. Because of this, a child's skull is less susceptible to fracture, 
but this also allows for more brain deformation. In a study of infant skull and suture properties investigating loading at rates similar to those that would occur in short falls, it was found that pediatric suture deforms 30 times more than pediatric cranial bone and 243 times more than adult cranial bone(Coats, 2006). Also, brain tissue properties have been found to be age-dependent (Thibault, 1998). Thibault and Margulies applied scaling based on brain tissue properties to angular acceleration thresholds for concussion, subdural hematoma, and diffuse axonal injury originally derived from brain mass scaling alone, and found that the injury thresholds were reduced. These differences between the adult and infant skull, and brain properties highlight the need for more accurate pediatric head injury criteria. The pediatric neck injury criteria presented in this paper were scaled from tolerance limits developed by paired tests using a 3-year-old ATD and a porcine animal model. Like the HIC thresholds, scaling techniques accounted for differences in geometry and material properties. Furthermore, the failure stresses of ligaments in the neck were assumed to have the same age-variation as the calcaneal tendon (Eppinger, 1999).

\section{E. Recommendations for Future Work}

This study has proven to be a significant contribution in determining objective information to aid clinicians in distinguishing between child abuse and accidental injuries. However, there are still many issues left to be addressed. First, these experiments consisted of only two simple fall types. There are many other types of 
common household falls that may have different dynamics and different levels of injury risk that need to be addressed. Bed falls and stair falls are two examples. Also, changes in initial position (for example, head-first falls rather than feet-first falls) would affect injury risk. This could be addressed by conducting more fall experiments. With so many different fall types and different parameters affecting the injury risk outcome, a more practical solution may be to create a computer simulation model in which characteristics of the fall can be easily adjusted.

Another major issue is the biofidelity of the ATD used in the fall experiments. A more biofidelic ATD is needed that more accurately represents a 12-month-old child. This issue could also be addressed using computer simulation. In a computer simulation model, properties of the ATD such as neck stiffness and joint range of motion can be easily adjusted to determine their effect on injury risk.

One last recommendation is to determine the risk for other types of injury in these falls. In particular the risk of long bone fractures should be investigated because these are common injuries associated with child abuse. 


\section{CONCLUSIONS}

This study examined the risk of severe head and neck injuries in two types of short-distance falls (feet-first free falls and falls from standing) using an ATD representing a 12 month old child. The effect of fall environment characteristics (fall height, impact surface) and ATD joint stiffness on injury risk was also assessed. The falls from standing were generally associated with a greater head injury risk than the feetfirst free falls. In the feet-first free falls, ground-based falls were associated with a greater head injury risk than the higher fall heights tested. The greater injury risk for both the falls from standing and the ground based free falls as compared to the other free falls was due to a greater rotational component in those falls. For the falls from standing, greater falls heights were associated with a greater head injury risk. Head injury risk also increased with stiffer surfaces and was greater for tightened joints than for joints adjusted to normal specifications. Neck injury risk also tended to increase with greater fall heights, stiffer surfaces, and increasing joint stiffness. However, the risk of severe head or neck injury was low for all fall scenarios evaluated using a 12-month-old ATD. The results of this study highlight the importance of initial position, fall dynamics, fall height, impact surface properties, and joint properties when evaluating head or neck injury risk for a short-distance fall. Outcomes of this study may aid clinicians in determining whether a child's injuries are consistent with the stated cause. 


\section{REFERENCES}

Bandak, Faris A. (2005). "Shaken Baby Syndrome: A Biomechanics Analysis of Injury Mechanisms." Forensic Science International 151(1): 71-79.

Barlow, Barbara, Niemirska, Maria, Gandhi, Rajinder P. and Leblanc, Wiener (1983). "Ten Years Experience with Falls from a Height in Children." Journal of Pediatric Surgery 18(4): 509-511.

Bechtel, Kirsten, Stoessel, Kathleen, Leventhal, John M., Ogle, Eileen, Teague, Barbara, Lavietes, Sylvia, Banyas, Bruna, Allen, Karin, Dziura, James and Duncan, Charles (2004). "Characteristics that Distinguish Accidental from Abusive Injury in Hospitalized Young Children with Head Trauma." Pediatrics 114(1): 165-168.

Bertocci, Gina E., Pierce, Mary Clyde, Deemer, Ernest and Aguel, Fernando (2001). "Computer Simulation of Stair Falls to Investigate Scenarios in Child Abuse." Archives of Pediatric and Adolescent Medicine 155: 1008-1014.

Bertocci, Gina E., Pierce, Mary Clyde, Deemer, Ernest, Aguel, Fernando, Janosky, Janine E. and Vogeley, Ev (2003). "Using Test Dummy Experiments to Investigate Pediatric Injury Risk in Simulated Short-Distance Falls." Archives of Pediatric and Adolescent Medicine 157: 480-486.

Bertocci, Gina E., Pierce, Mary Clyde, Deemer, Ernest, Aguel, Fernando, Janosky, Janine E. and Vogeley, Eva (2004). "Influence of Fall Height and Impact Surface on Biomechanics of Feet-First Free Falls in Children." Injury, Intl. J. of the Care of the Injured 35: 417-424.

Billmire, M. Elaine and Myers, Patricia A. (1985). "Serious Head Injury in Infants: Accident or Abuse?" Pediatrics 75(2): 340-342.

Caffey, John (1974). "The Whiplash Shaken Infant Syndrome: Manual Shaking by the Extremities with Whiplash-Induced Intracranial and Intraocular Bleedings, Linked with Residual Permanent Brain Damage and Mental Retardation." Pediatrics 54(4): 396-403.

Chadwick, David L., Chin, Steven, Salerno, Connie, Landsverk, John and Kitchen, Louann (1991). "Deaths from Falls in Children: How Far is Fatal?" The Journal of Trauma 31(10): 1353-1355.

Chiaviello, Christine T., Christoph, Richard A. and Bond, G. Randall (1994). "StairwayRelated Injuries in Children." Pediatrics 94(5): 679-681.

Child Abuse and Neglect Fatalities: Statistics and Interventions (2004). National Clearinghouse on Child Abuse and Neglect Information. 
Child Maltreatment 2003 (2005). US Department of Health and Human Services, Administration on Children, Youth and Families, US Government Printing Office.

Coats, B and Margulies, SS (2006). "Material properties of human infant skull and suture at high rates." Journal of Neurotrauma 23: 1222-1232.

Cory, C. Z. and Jones, M. D. (2006). "Development of a simulation system for performing in situ tests to assess the potential severity of head impacts from alleged childhood short falls." Forensic Science International 163(1-2): 102-114.

Cory, C. Z., Jones, M. D., James, D. S., Leadbeatter, S. and Nokes, L. D. M. (2001). "The Potential and Limitations of Utilizing Head Impact Injury Models to Assess the Likelihood of Significant Head Injury in Infants after a Fall." Forensic Science International 123: 89-106.

CRABI Twelve and Eighteen Month Infant Dummies User's Manual (1999). First Technology Safety Systems.

Deemer, Ernest, Bertocci, Gina, Pierce, Mary Clyde, Aguel, Fernando, Janosky, Janine and Vogeley, Eva (2005). "Influence of Wet Surfaces and Fall Height on Pediatric Injury Risk in Feet-First Free Falls as Predicted Using a Test Dummy." Medical Engineering and Physics 27: 31-39.

Duhaime, A. C., Alario, A. J., Lewander, W. J., Schut, L., Sutton, L. N., Seidl, T. S., Nudelman, S., Budenz, D., Hertle, R., Tsiaras, W. and Loporchio, S. (1992). "Head Injury in Very Young Children: Mechanisms, Injury Types, and Ophthalmologic Findings in 100 Hospitalized Patients Younger Than 2 Years of Age." Pediatrics 90(2): 179-185.

Duhaime, Ann-Christine, Christian, Cindy W., Rorke, Lucy Balian and Zimmerman, Robert A. (1998). "Nonaccidental Head Injury in Infants - The "Shaken-Baby Syndrome"." The New England Journal of Medicine 338(25): 1822-1829.

Duhaime, Ann-Christine, Gennarelli, Thomas A., Thibault, Lawrence E., Bruce, Derek A., Margulies, Susan S. and Wiser, Randall (1987). "The Shaken Baby Syndrome: A Clinical, Pathological, and Biomechanical Study." Journal of Neurosurgery 66: 409-415.

Eppinger, R., Sun, E., Bandak, F., Haffner, M., Khaewpong, N., Maltese, M., Kuppa, S., Nguyen, T., Takhounts, E., Tannous, R., Zhang, A. and Saul, R. (1999). Development of Improved Injury Criteria for the Assessment of Advanced Automotive Restraint Systems - II. US Department of Transportation National Highway Traffic Safety Administration. 
Geddes, J. F., Hackshaw, A. K., Vowles, G. H., Nickols, C. D. and Whitwell, H. L. (2001). "Neuropathology of Inflicted Head Injury in Children: I. Patterns of Brain Damage." Brain 124: 1290-1298.

Geddes, J. F., Vowles, G. H., Hackshaw, A. K., Nickols, C. D., Scott, I. S. and Whitwell, H. L. (2001). "Neuropathology of Inflicted Head Injury in Children: II. Microscopic Brain Injury in Infants." Brain 124: 1299-1306.

Gennarelli, TA, Thibault, LE, Adams, JH, Graham, DI, Thompson, CJ and Marcincin, RP (1982). "Diffuse axonal injury and traumatic coma in the primate." Annals of Neurology 12: 564-574.

Gennarelli, Thomas A. and Meaney, David F. (1996). Mechanisms of Primary Head Injury. Neurosurgery. Robert H. Wilkins and Setti S. Renachary. New York, McGraw Hill: 2611-2621.

Gennarelli, Thomas A. and Thibault, Lawrence E. (1982). "Biomechanics of Acute Subdural Hematoma." The Journal of Trauma 22(8): 680-685.

Ghatan, Saadi and Ellenbogen, Richard G. (2002). "Pediatric Spine and Spinal Cord Injury after Inflicted Trauma." Neurosurgery Clinics of North America 13: 227233.

Gunatilaka, AH, Sherker, S and Ozanne-Smith, J (2004). "Comparative performance of playground surfacing materials including conditions of extreme non-compliance." Injury Prevention 10: 174-179.

Hadley, Mark N., Sonntag, Volker K. H., Rekate, Harold L. and Murphy, Alan (1989). "The Infant Whiplash-Shake Injury Syndrome: A Clinical and Pathological Study." Neurosurgery 24(4): 536-540.

Hall, John R., Reyes, Hernan M., Horvat, Maria, Meller, Janet L. and Stein, Robert (1989). "The Mortality of Childhood Falls." The Journal of Trauma 29(9): 12731275 .

Helfer, Ray E., Slovis, Thomas L. and Black, Mary (1977). "Injuries Resulting when Small Children Fall Out of Bed." Pediatrics 60(4): 533-535.

Instrumentation for Impact Test Part 1 - Electronic Instrumentation (2003). SAE J211.

Irwin, Annette L. and Mertz, Harold J. (1997). "Biomechanical Bases for the CRABI and Hybrid III Child Dummies." Child Occupant Protection.

Jenny, Carol, Hymel, Kent P., Ritzen, Alene, Reinert, Steven and Hay, Thomas (1999).

"Analysis of Missed Cases of Abusive Head Trauma." JAMA 281(7): 621-626. 
Joffe, Mark and Diamond, Paul (1990). "Letter to the Editor: The Mortality of Childhood Falls." The Journal of Trauma 30(11): 1421-1422.

Lallier, M., Bouchard, S., St-Vil, D., Dupont, J. and Tucci, M. (1999). "Falls from Heights Among Children: A Retrospective Review." Journal of Pediatric Surgery 34(7): 1060-1063.

Langlois, J. A., Rutland-Brown, W. and Thomas, K. E. (2004). Traumatic Brain Injury in the United States: Emergency Departmnt Visits, Hospitalizations, and Deaths. National Center for Injury Prevention and Control Centers for Disease Control and Prevention.

Lyons, Thomas J. and Oates, R. Kim (1993). "Falling Out of Bed: A Relatively Benign Occurence." Pediatrics 92(1): 125-127.

Margulies, Susan, Prange, Michael, Myers, Barry S., Maltese, Matthew R., Ji, Songbai, Ning, Xinguo, Fisher, Jacob, Arbogast, Kristy and Christian, Cindy (2006). "Shaken Baby Syndrome: A Flawed Biomechanical Analysis." Forensic Science International 164: 278-279.

Margulies, Susan S. and Thibault, Lawrence E. (1992). "A Proposed Injury Tolerance Criterion for Diffuse Axonal Injury in Man." Journal of Biomechanics 25(8): 917923.

Mohan, D., Bowman, B. M., Snyder, R. G. and Foust, D. R. (1979). "A Biomechanical Analysis of Head Impact Injuries to Children." Journal of Biomechanical Engineering 101: 250-260.

Musemeche, Catherine A., Barthel, Martha, Cosentino, Catherine and Reynolds, Marleta (1991). "Pediatric Falls from Heights." The Journal of Trauma 31(10): 13471349.

Nahum, AM and Smith, RW (1976). "An experimental model for closed head impact injury." Proceedings of the 20th Stapp Car Crash Conference.

Ommaya, A. K., Goldsmith, W. and Thibault, L. (2002). "Biomechanics and Neuropathology of Adult and Paediatric Head Injury." British Journal of Neurosurgery 16(3): 220-242.

Ommaya, AK and Hirsch, AE (1971). "Tolerances for cerebral concussion from head impact and whiplash in primates." Journal of Biomechanics 4: 13-21.

Plunkett, John (2001). "Fatal Pediatric Head Injuries Caused by Short-Distance Falls." The American Journal of Forensic Medicine and Pathology 22(1): 1-12. 
Prange, Michael T., Coats, Brittany, Duhaime, Ann-Christine and Margulies, Susan S. (2003). "Anthropomorphic Simulations of Falls, Shakes, and Inflicted Impacts in Infants." Journal of Neurosurgery 99: 143-150.

Rooks, Veronica J., Sisler, Cheryl and Burton, Bradford (1998). "Cervical Spine Injury in Child Abuse: Report of Two Cases." Pediatric Radiology 28: 193-195.

Schwartz, Gary R, Wright, Seth W, Fein, Joel A, Sugarman, Jacqueline, Pasternack, Joel and Salhanick, Steven (1997). "Pediatric cervical spine injury sustained in falls from low heights." Annals of Emergency Medicine 30(3): 249-252.

Smith, Melvin D., Burrington, John D. and Woolf, Alan D. (1975). "Injuries in Children Sustained in Free Falls: An Analysis of 66 Cases." The Journal of Trauma 15(11): 987-991.

Snyder, R. G. (1969). Impact Injury Tolerances of Infants and Children in Free-Fall. 13th Annual Proceedings of the Association for the Advancement of Automotive Medicine.

Spivack, Betty (2001). "Letter to the Editor: Fatal Pediatric Head Injuries Caused by Short-Distance Falls." The American Journal of Forensic Medicine and Pathology 22(3): 332-334.

Sturtz, G. (1980). Biomechanical Data of Children. 24th Stapp Car Crash Conference, Warrendale, PA, SAE, Paper no. 801313.

Ten Years of Reporting Child Maltreatment (1999). US Department of Health and Human Services, Administration on Children and Families, Administration on Children, Children's Bureau, US Government Printing Office.

Thibault, Kirk L. and Margulies, Susan S. (1998). "Age-Dependent Material Properties of the Porcine Cerebrum: Effect on Pediatric Inertial Head Injury Criteria." Journal of Biomechanics 31: 1119-1126.

Watson, Gavin and Upadhyay, Vipul (2005). "Paediatric cervical spine injuries: an audit of 22 acute injuries and literature review." Injury Extra 36: 469-474.

Williams, R. A. (1991). "Injuries in Infants and Small Children Resulting from Witnessed and Corroborated Free Falls." The Journal of Trauma 31(10): 1350-1352. 
VITA

\begin{abstract}
ANGELA KNIGHT
EDUCATION

8/05 - Present University of Louisville Speed Scientific School, Louisville, KY

Mechanical Engineering, M.Eng. Expected 5/07

GPA: $4.0 / 4.0$

8/01 - 8/05 University of Louisville Speed Scientific School, Louisville, KY

Mechanical Engineering, B.S. 8/05

GPA: $4.0 / 4.0$

EXPERIENCE

5/05 - Present University of Louisville - Injury Risk Assessment and Prevention

Laboratory

Graduate Research Assistant

- Primary project: Fall experiments with pediatric test dummies to determine injury risk. Involved instrumenting test dummies, data acquisition, and statistical analysis.

- Other projects: Created lab website, wrote protocol for test dummy experiments, assisted in development of computer simulations, trained in digital motion capture (Motion Analysis)

6/04 - 4/05 University of Louisville - Bioengineering

Undergraduate research

- Primary project: Formation of stable lipid bilayers on MEMS devices. Involved microfabrication, design of test chamber and fabrication of electrodes for experimentation, measurement and analysis of electrical characteristics

- Poster Presentation at U of L Engineers Days, 2005 - "Formation of stable lipid bilayers on MEMS devices"

1/03 - 1/04 GE Consumer Products- Louisville, KY

Technology Engineer Co-op

- First rotation in Refrigeration design. Included performance testing of ice and water dispenser, assistance with design of new dispenser heater, performed consumer study, obtained feedback from customers on service call issues, and root cause analysis.

- Second rotation in Range NPI. Projects included systems level testing and analysis of 2004 Slide-in and Drop-in ranges, assistance with product design, management of cooking performance testing, contributed to a successful technical review.
\end{abstract}


- Participated in 2 Six Sigma projects. $1^{\text {st }}$ project involved testing and analysis to improve self-clean performance of GE gas ranges to increase consumer rating. Purpose of $2^{\text {nd }}$ project was to integrate DFSS Scorecard system for the Appliance and Lighting businesses of GECP. Was successful in saving the business $\$ 80,000$ a year.

\section{HONORS \& ACTIVITIES}

- Alfred T Chen Award (2005)

- Lewis Streng Award (2006)

- U of L Provost Hallmark Award (2001)

- Mechanical Engineering Academic Achievement Award (Sophomore, Junior, Senior)

- Tau Beta Pi Outstanding Freshman/Sophomore Award

- Tau Beta Pi Engineering Honor Society (2002-Present)

- Pi Tau Sigma Mechanical Engineering Honor Society - Secretary for U of L student chapter (2005-2006), President (2006-2007)

- Biomedical Engineering Society (2006-Present)

- $2^{\text {nd }}$ place in E-Expo student poster competition, March 2006

- $2^{\text {nd }}$ place in ASME SBC Student Paper Competition, MS Level design category, June 2006

\section{CONFERENCE ABSTRACTS/POSTER PRESENTATIONS}

- Knight, A, Bertocci, G, Pierce, MC, Bialczak, K. Head injury risk associated with feet-first free falls in children and influence of impact surface type. ASME Summer Bioengineering Conference, Amelia Island, FL, June 2006.

- Bialczak, K, Bertocci, G, Pierce, MC, Knight, A. Pediatric Bed Fall Computer Simulation Model Development and Validation. ASME Summer Bioengineering Conference, Amelia Island, FL, June 2006.

- Bertocci G, Pierce MC, Knight A, Bialczak K, Kaczor K, Deemer E, Head Injury Risk Associated With Free Falls From Varying Heights in Children, Pediatric Academic Society Conference, San Francisco, CA, May 2006.

- Knight, A, Bertocci, G, Pierce, MC, Bialczak, K, Deemer, E. Head injury risk associated with free falls in children. U of L Engineering Expo, March 2006.

- Knight, A, Bertocci, G, Pierce, MC, Bialczak, K, Deemer, E. Head injury risk associated with free falls in children. Research Louisville, October 2005.

- Bialczak, K, Bertocci, G, Knight, A, Deemer, E, Spivack, B. A Child Abuse Investigation: Evaluation of Exersaucer Accelerations Attained During Spinning. Research Louisville, October 2005.

- Knight, A. Formation of Stable Lipid Bilayers on MEMS Devices. University of Louisville Engineers Days, March 2005. 